Chapman University

Chapman University Digital Commons

Education (PhD) Dissertations

Dissertations and Theses

Winter 1-2021

\title{
School Psychologists as Leaders in Professional Practice: An Examination of Leadership Roles and Perceived Support
}

Jodi LaChance

Chapman University, lacha103@mail.chapman.edu

Follow this and additional works at: https://digitalcommons.chapman.edu/education_dissertations

Part of the Educational Leadership Commons, Educational Psychology Commons, Education Policy Commons, School Psychology Commons, and the Special Education Administration Commons

\section{Recommended Citation}

LaChance, J. R. (2021). School psychologists as leaders in professional practice: An examination of leadership roles and perceived support [Doctoral dissertation, Chapman University]. Chapman University Digital Commons. https://doi.org/10.36837/chapman.000210

This Dissertation is brought to you for free and open access by the Dissertations and Theses at Chapman University Digital Commons. It has been accepted for inclusion in Education (PhD) Dissertations by an authorized administrator of Chapman University Digital Commons. For more information, please contact laughtin@chapman.edu. 
School Psychologists as Leaders in Professional Practice: An Examination of Leadership

Roles and Perceived Support

A Dissertation by

Jodi Ruble LaChance

\author{
Chapman University \\ Orange, CA
}

Attallah College of Educational Studies

Submitted in partial fulfillment of the requirements for the degree of

Doctor of Philosophy in Education

January 2021

Committee in charge:

Randy Busse, Ph.D., Chair

John Brady, Ph.D.

Kris DePedro, Ph.D. 
The dissertation of Jodi Ruble LaChance is approved.

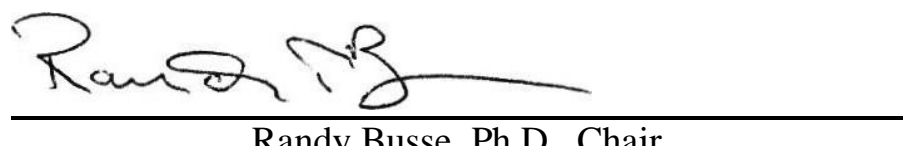

Randy Busse, Ph.D., Chair

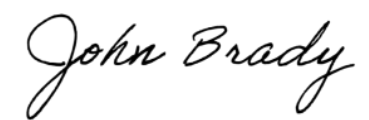

John Brady, Ph.D.

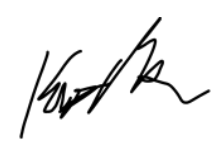

Kris DePedro, Ph.D.

August 2020 
School Psychologists as Leaders in Professional Practice: An Examination of Leadership

Roles and Perceived Support

Copyright $@ 2021$

by Jodi Ruble LaChance 


\section{ACKNOWLEDGEMENTS}

The path to this point was a challenge, and I imagine, much like running a marathon. I will forever be grateful to the many people that stood by my side, pushed me, pulled me, and carried me through this journey. To those who went before me, my grandparents, who devoted their lives to education, I thank you. To my parents, both educators, and the inspiration for my life's work, you taught me to believe in myself and in the potential of others, to have hope in adversity, to understand the power of opportunity to make a difference, to always step out in faith, and the belief that we all have talents and abilities that can impact the world for good. To my sister, you inspire me every day with your example of calm yet powerful leadership; I thank you. Your dedication to the people in your charge is a model for all educators. The students that are lucky enough to benefit from your gifts are blessed.

To my children, the loves of my life, God could not have blessed me more! I am amazed by the people you have become, the goodness you bring to the world, and your service to others. Your sense of humor, love for your family, your ambitions (I think I know where that came from), and your wisdom are gifts that I hope you recognize. You bring me joy every day, and I am so grateful for you both and the support you provided on this journey! I am so blessed to have the most incredible friends who advised and encouraged me through this process. I pray that you know I could not have done this without your love and support.

Dr. Busse, I remember my first semester at Chapman, sitting in your Quant class. It was informative and entertaining! Because of your passion, I felt encouraged. It gave me a sense of determination that maybe, with your help, I could do this! I appreciate your positive attitude, your "keep it pithy" reminders, and encouragement along the way. You learned from some of the best in the field, and in working with you, I hoped to achieve a little of the expertise you bring to 
the Chapman community. It has been an honor working with you, and I wish you the best in the years to come! Dr. Brady, you always went above and beyond to keep me on track, a recurring theme in our conversations, and not an easy job! I'm pretty sure I wouldn't be here without your guidance and patient support. Chapman students miss you! I am forever grateful and honored that you were a part of my team. I wish you the best in your retirement! To Dr. DePedro, Chapman is lucky to have you! You are a refreshing, bold, and yet respectful force in the school of education. Your guidance meant the world to me. You have a way of clarifying information and steering the ship in the right direction, even amid the chaos that was my mind at times.

To Dr. Hunter, who we so fondly call Dawn, you have provided constant encouragement on this path from the beginning of my first semester. I hold you in high esteem and believe that the work you do with students is changing lives. The best teachers care and have students' best interests at heart. I see this in you and what you do for students, and I hope you know it will not go unnoticed. A heartfelt thank you for listening, guiding, and helping me stay afloat during the challenges I faced. I'm grateful that all of you were on my team! Thank you!

To my dear family and friends, thank you for your ongoing prayers, encouragement, and support. To my professors and colleagues at Chapman, thank you for your guidance, encouragement, and seeing me through this process! 


\begin{abstract}
School Psychologists as Leaders in Professional Practice: An Examination of Leadership Roles and Perceived Support by Jodi Ruble LaChance
\end{abstract}

The professional role of a school psychologist leader is a topic of interest for those in the field. Since 1940, state or national associations have outlined recommendations and guidelines for school psychology leadership roles. School psychology leadership aligns with the NASP training and practice model and is critical in promoting best practice. However, we know very little about school psychology leadership in professional practice, and the school psychology leadership literature is relatively void of research. The purpose of this study was to investigate the current status of school psychology leadership in professional practice, identify fundamental components (NASP competencies) perceived to fall under the area of leadership, to identify barriers in providing leadership, discover how school psychologists can be empowered, supported, and engaged in organizational change through leadership, and why this is critical to the practice and profession of school psychology. A survey was developed using the NASP Practice Model to guide questions regarding leadership and systems-level services in practice. School psychologist association members from four states and two online professional networks participated in the study. The data were analyzed via descriptive statistics. Specific questions addressed: (a) whether school psychologists in practice hold leadership roles, (b) the type of leadership roles currently held and desired roles, and (c) factors influencing leadership opportunities. The results indicated that the majority of school psychologists viewed themselves as leaders and most would like to hold a leadership role in the future. Organizational principles such as supervision, climate, physical, personnel, and fiscal support, and organization and evaluation of service delivery were 
not implemented in the school setting as outlined in the NASP Practice Model. Implications of the results for current practice and future research are discussed. 


\section{TABLE OF CONTENTS}

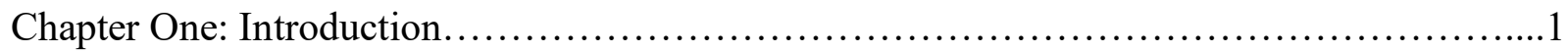

Statement of the Problem.......................................................... 2

Purpose Statement...................................................... 3

Significance of the Study ................................................ 4

Chapter Two: Literature Review.................................................. 5

History of Professional Practice, Standards, and Service Delivery .................... 6

Graduate Preparation and Credentialing................................... 7

Professional Practice Guidelines and Ethics............................... 8

Domains of Practice Past and Present....................................... 9

Practice .............................................................. 12

Current Practice Model Part II: Organizational Principles.................... 14

Organizational Principle 1: Organization and Evaluation of Service

Delivery......................................................... 15

Organizational Principle 5: Supervision, Peer Consultation, and Mentoring....17

Challenges: Lack of Resources, Burnout, and Shortages of School Psychologists......19

School Psychology Leadership...................................................23

School Psychology Leadership: Definition, Characteristics, and Theoretical Models..25

Organization and Systems Leadership...........................................36

Leadership Opportunities and Training.........................................38

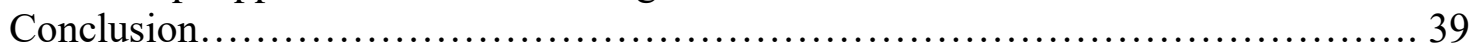

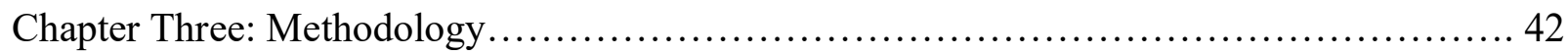

Components of a Valid Online Survey.......................................... 42

Current Survey Item Development and Content Validation.......................... 49

Item Development...................................................... 49

Content Validation..................................................... 51

Pilot Study Outcomes............................................... 52

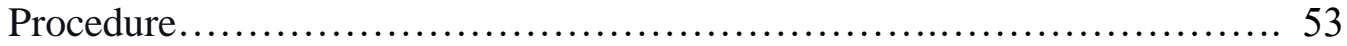

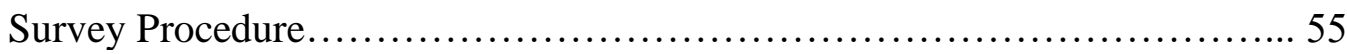

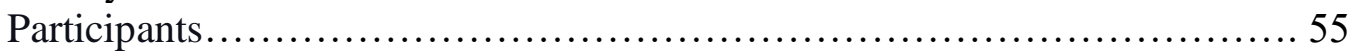

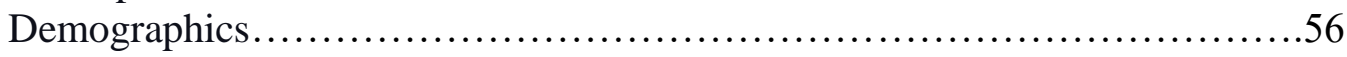

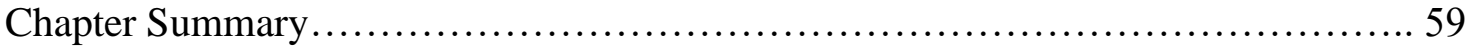

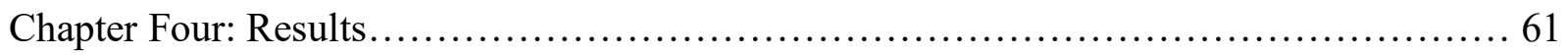

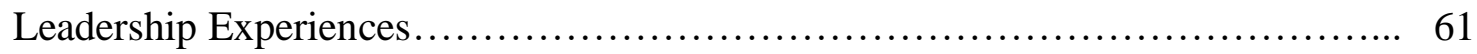

Domains of Practice.................................................. 61

Systems-Level Leadership........................................... 62

Formal Leadership Roles............................................. 64

Graduate Training in Leadership...................................... 65

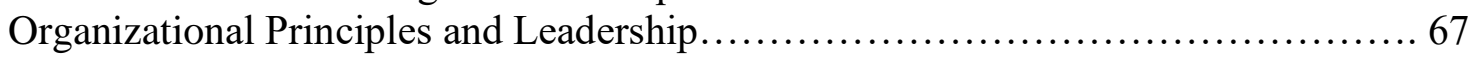

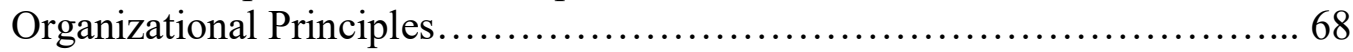

Supervision and Professional Growth.................................... 73

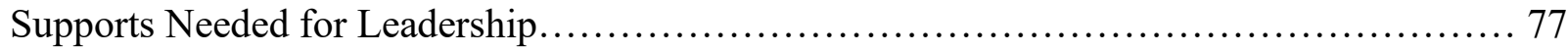




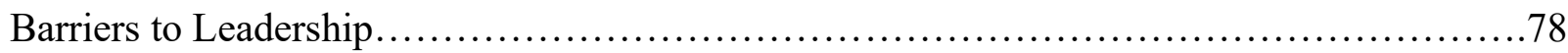

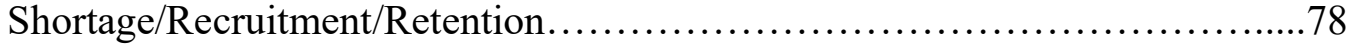

Lack of Administrator understanding and support............................79

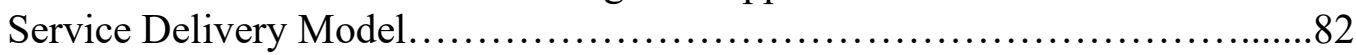

Leadership and Opportunity .......................................... 83

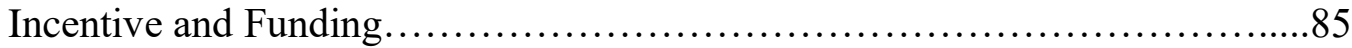

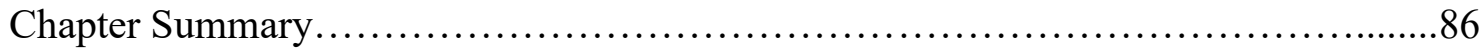

Chapter Five: Discussion................................................................. 87

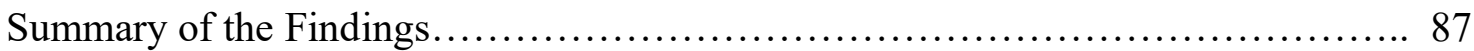

Current and Desired Leadership Roles..................................... 87

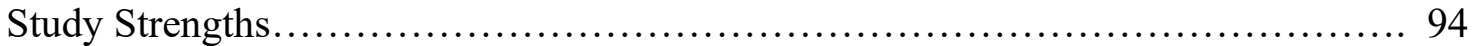

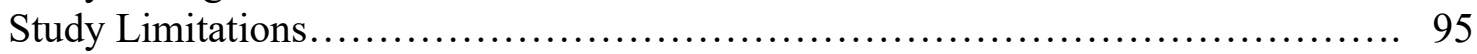

Implications for Future Research and Practice................................... 95

Implications for Practice.................................................. 97

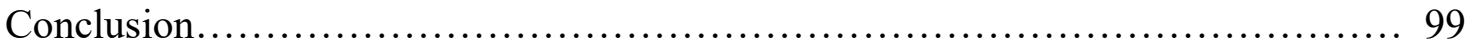

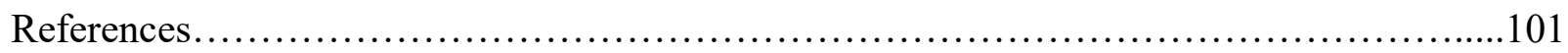

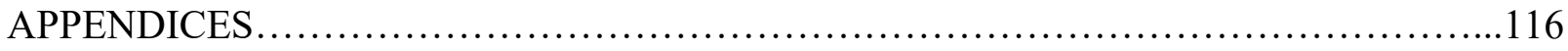




\section{LIST OF TABLES}

Table 1 Comparison of practice model domains past and present ............................ 10

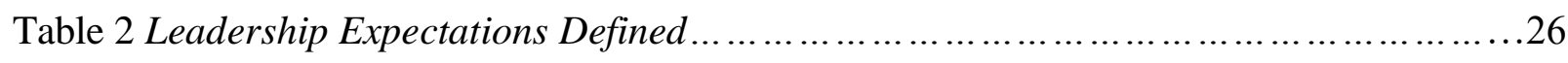

Table 3 Leadership Attributes, Qualities, and Characteristics ...............................27

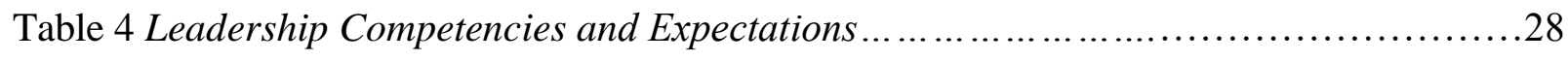

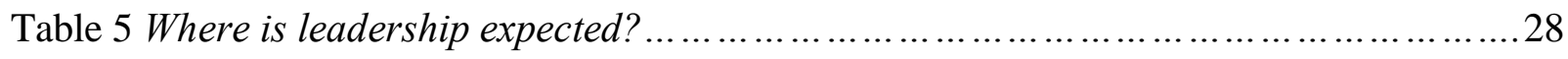

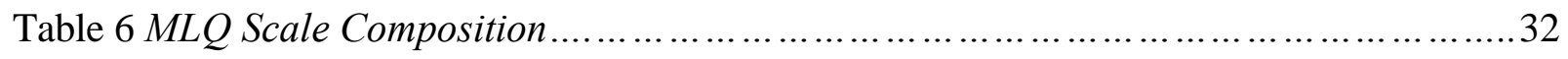

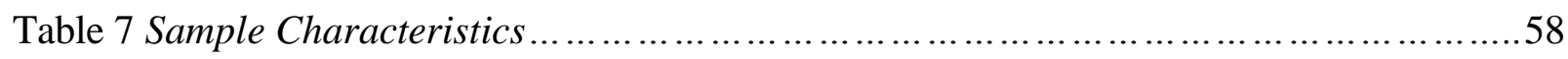

Table 8 Current and Desired Leadership Roles in Designing, Implementing, and Evaluating

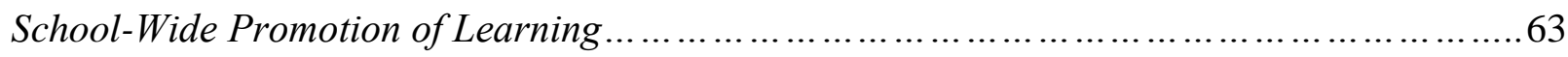

Table 9 Current and Desired Formal Leadership Roles....................................6 65

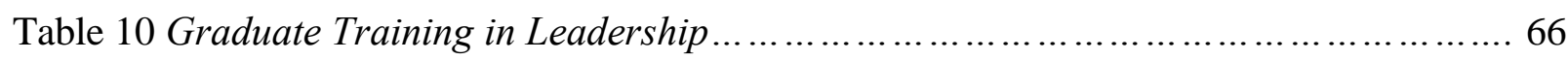

Table 11 Organization of School Psychological Services Delivery.............................67

Table 12 Organizational Principles: Organization and Evaluation of Service Delivery, Climate,

Physical, Personnel, and Fiscal Support Systems, and Professional Communication...........69

Table 13 Organizational Principles in Practice NASP Model Part II, 3.3 and 3.4............. 72

Table 14 Organizational Principles: Supervision, Peer Consultation, and Mentoring and

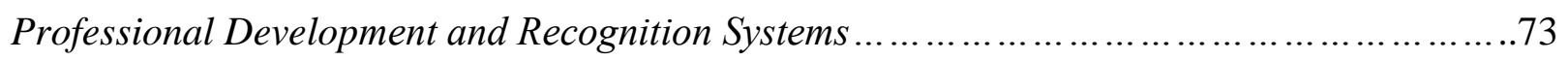

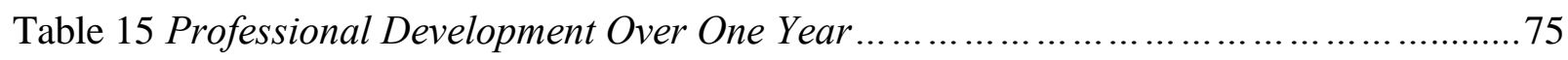

Table 16 Convention Attendance in the Past 3 Years........................................75

Table 17 Types of Recognition for Professional Growth .................................... 76

Table 18 Type of Supports Needed for School Psychologists to Lead Organizational Change

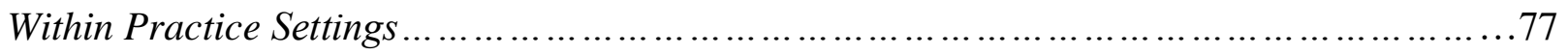




\section{Chapter One: Introduction}

School psychology leadership aligns with the National Association of School Psychologists (NASP) practice model and is critical in promoting best practices (Shapiro, 2006; Smith, 2012). School psychologists are well prepared to lead, and as leaders can better serve students and systems (Augustyniak, 2016; Shapiro, 2006; Shriberg, Satchwell, McArdle, \& James, 2010). As leaders, school psychologists engage in school improvement and change through collaboration within schools and communities, policy organizations, and parent groups to develop public policy initiatives (Ysseldyke, Burns, Dawson, Kelley, Morrison, Ortiz, Rosenfield, \& Telzrow, 2006).

Since 1940, guidelines for school psychology practice have been clearly outlined by state or national associations. The National Association of School Psychologists (NASP) Model for Comprehensive and Integrated School Psychological Services guides school psychologists, administrators of school psychologists, university training programs, and consumers of school psychological services (NASP, 2006). Irrespective of clear guidelines, a significant disconnect exists between training and practice in school settings.

As far back as 1995, Conoley and Gutkin (1995) called on national and state organizations to collaborate, bring about change in school psychology, and focus on ecological systems to realize school psychology's full potential. A study conducted by Brown, Wigart, Bolen, Hall, and Webster (1998) found no change in job role since the first national study of school psychologists by Meacham and Peckham in 1978.

With revisions to the NASP practice model, school psychologists focus on prevention and systems-level service delivery compared with a more limited role in the past (assessment for special education eligibility) (NASP, 2007). Inclusive services for general and special education 
students and the use of data-based decision making and evidence-based intervention has increased, and mental health prevention, promotion, and treatment have increasingly become integrated into the school setting (NASP, 2007).

More recently, however, the results of a NASP membership survey found that school psychologists continue to lack opportunities for a more comprehensive role due to high caseloads, a shortage of school psychologists, and a lack of resources, support, supervision, and professional development (Walcott, \& Hyson, 2018). Although leadership at the national level is committed to revisions in practice standards, standards are of little use if not implemented.

Leadership is critical for organizational change, comprehensive services, policy, planning, and training at all levels; school, district, state, and national (NASP, 2010; Riley, 1996; Schrag, 1996; Telzrow, Burns, \& Ysseldyke, 2006). School psychologists have knowledge and experience in leading systems change and are often viewed as leaders in the change process to oversee reform and coordinate comprehensive systems of care (Schrag, 1996; Shapiro, 2006).

Coordinated efforts require program planning, organization, and supervision, further substantiating a need for school psychology leadership in practice settings (Hunley, Curtis, \& Batsche, 2000). Furthermore, school psychologists are charged with a mission to create connections, collaborate, build relationships and partnerships, and take advantage of opportunities for leadership (Kelly, 2017; Shriberg, 1996).

\section{Statement of the Problem}

Leadership, a core value of the National Association of School Psychologists (NASP) (Kelly, 2018; Skalski, 2013), is an essential component of school psychology practice as outlined in the prominent publication, School Psychology: A Blueprint for Training and Practice III (Ysseldyke et al., 2006). Typically, leadership roles in public education are hierarchical and 
reserved for administrators with decision-making power such as the superintendent, principal, or special education director (Augustyniak, 2014) though a formal administrative role is not needed to be a leader (Shriberg et al., 2010).

Although school psychologists are highly educated, only 5\% of NASP's association members hold an administrative role in school systems (Walcott \& Hyson, 2018). Opportunities for leadership in school psychology practice are negligible irrespective of the assertion that school psychologists are well equipped to lead (Augustyniak, 2014; Kelly, 2017; Shapiro, 2006; Shriberg, 2007; Smith, 2017).

Despite being an essential component and an urgent need, according to Augustyniak (2014), school psychology leadership is largely neglected in the research (Hunley et al., 2002; Shriberg et al., 2010). Equally important, research on applied practice in school psychology leadership is scarce (Augustyniak et al., 2016). Systemic change is a priority for the future of school psychology practice (Shapiro, 2006). Without leadership, systems can be negatively impacted, and school psychological services may never realize their full potential (Smith, 2012).

\section{Purpose Statement}

The purpose of this study is to examine current practice in school psychology leadership and practitioners' perceptions of organizational supports for leadership. This research aims to identify whether leadership roles match the NASP model competencies, identify leadership experiences in current school psychological practice, and develop new knowledge in the field regarding current school psychology leadership practices. A survey was designed to answer the following research questions:

Research Question 1. What are the leadership experiences of school psychologists in practice? 
Research Question 1a. Which leadership opportunities are desired?

Research Question 1b. Which leadership opportunities are lacking?

Research Question 2: Which of the organizational principles from the NASP Model Part II are in place to support school psychologists?

Research Question 3: What are the barriers for school psychologists in providing leadership in school settings?

Research Question 3a: What type of support is needed for school psychologists to lead organizational change within practice settings?

\section{Significance of the Study}

This study's results may provide useful information about current practice in school psychology leadership and offer insight into school psychologists' perceptions regarding the importance of their leadership role in the school setting. Furthermore, the results may help school district leaders determine what supports are necessary for school psychology leadership. Finally, this study's results may provide a guide for action and training in response to school psychology leaders' needs. 


\section{Chapter Two: Literature Review}

School psychologists are called to lead, collaborate and build partnerships, and play a critical role in supporting school systems and communities (Kelly, 2017; Riley, 1996; Shapiro, 2006; Shriberg, 1996; Shriberg, 2007; Ysseldyke et al., 2006). School psychologists lead at the district, state, and national levels through advocacy, public policy institute, and hold positions on data teams, problem-solving teams, multidisciplinary evaluation teams, and crisis response teams (Augustyniak, 2017; Burns et al. 2017; Enz \& McCullum, 2018; Shriberg, 2007). School psychologists are called to be change agents and expand opportunities to include preventative and system-level services (e.g., Multi-tiered Systems of Support, Positive Behavior Support, and Response to Intervention) (Ysseldyke et al., 2006).

Developing leadership skills is a key initiative of NASP (McNamara, Walcott, \& Hyson, 2019). Recently initiated by NASP, the Leadership Development Committee (LDC) provides training to develop leadership in state and national associations (Malone, McCullum, \& Bhatt, 2016). Since its inception, the Leadership Development Committee (LDC) expanded its focus to include leaders with various levels of experience (e.g., early career, graduate educators, state association presidents). The LDC provides leadership training for appointed leaders, recruits leaders for upcoming association positions, and provides learning opportunities for interested leaders (Malone et al., 2016).

Whereas leadership at the state and national level is essential, equally important, and the focus of this study, is school psychology leadership in professional practice. Despite the expectation to lead, little is known about school psychology leadership in professional practice. Though sparse, extant literature in school psychology leadership begins to explore perceptions of stakeholders' views of leadership, possible relevant theoretical models, training needs, and 
school psychology leadership within organizational systems. Two primary studies of school psychology leadership will be discussed. The first study by Shriberg Satchwell, McArdle, and James (2010) surveyed school psychologists' beliefs about leadership, and the second, more recent study by Augustyniak, Kilanowski, and Privitera (2016) explored leadership in practice settings and administrators' and teachers' perceptions of school psychologists' leadership ability. Many theoretical leadership models exist; this literature review focuses on the few models that researchers have identified as aligning with school psychology professional practice.

Paramount to the practice and study of school psychology is the National Association of School Psychologists (NASP) practice guidelines. Before diving into current research, this review first examines the foundation on which training, credentialing, and professional practice in school psychology began. A previous model provides a view of past and present, similarities and differences between the two models, and the long-standing leadership expectation in practice. Next, a review of the literature, examining challenges facing school psychologists and the critical imperative for leadership in professional practice, followed by literature on leadership in school psychology, including definitions, characteristics, theory, and organizational change.

\section{History of Professional Practice, Standards, and Service Delivery}

First written in 1978, the National Association of School Psychologists (NASP) Guidelines for the Provision of School Psychological Service set out to define school psychology, create standards of practice, and lay the foundation for services (NASP, 2010). NASP developed guidelines for university training programs, state education agencies, school districts, and school psychologists. The guidelines contain four policy documents: Standards for Graduate Preparation of School Psychologists (NASP, 2010e), Standards for Credentialing of School Psychologists (NASP, 2010d), Model for Comprehensive and Integrated School 
Psychological Services (NASP, 2010a), and Principles for Professional Ethics (NASP, 2010c).

The NASP Guidelines for the Provision of School Psychological Services have undergone revisions in 1984, 1992, 1997, 2000, 2010, and again recently drafted in May of 2020. Though not mandated by law, the premise is that these guidelines will inform state and district policies for school psychological services (NASP, 2010).

\section{Graduate Preparation and Credentialing}

Two sections, the Standards for Graduate Preparation of School Psychologists and Standards for Credentialing of School Psychologists, in addition to the NASP Blueprint for Training and Practice III, established training and credentialing standards for school psychologists (NASP, 2010). University training programs approved by NASP ensure school psychologists meet specific competencies and experiences for practice. High expectations and NASP standards translate to well-educated school psychologists; 55\% hold a specialist degree; $25 \%$ a doctoral degree; and 20\% a master's degree in school psychology (Walcott \& Hyson, 2018).

Whereas state credentialing agencies are encouraged to follow NASP standards, unlike accreditation expectations for university programs, specific credentialing requirements vary from state to state (NASP, 2010). School psychologists also have an opportunity through NASP to become a Nationally Certified School Psychologist (NCSP). A recent survey of NASP members identified more than 14,500 nationally certified school psychologists (Rossen, 2017). While the NCSP certification is encouraged and demonstrates dedication to leadership and ongoing professional development, many state credentialing agencies do not recognize the NCSP. Lack of consistency across state agencies with credentialing emphasizes the need for school psychology leadership at the state level. 


\section{Professional Practice Guidelines and Ethics}

Central to the practice of school psychology is comprehensive services for all children (NASP, 2010). The NASP Model for Comprehensive and Integrated School Psychological Services Professional Practices, Part I (10 domains of practice) and Organizational Principles, Part II (6 principles) serves as a guide for school districts and administrators in the development of comprehensive service delivery, professional development, and supervision and evaluation of school psychologists (NASP, 2010). The model as a whole is a working model with interrelated parts. Furthermore, School Psychology: A Blueprint for Training and Practice, first published in 1984, was developed by a small group of prominent school psychologists to review successful practices and predict school psychologists' future needs.

The NASP Blueprint references school psychology leadership across several practice areas, including mental health, school climate, and instructional environments (Ysseldyke et al., 2006). The Blueprint outlines essential foundational competencies in school psychology, such as interpersonal and collaborative skills, diversity awareness and sensitive service delivery, technological applications, and professional, legal, ethical, and social responsibility (Ysseldyke et al., 2006). These foundational competencies overlap with individual personal characteristics; thus, school psychology training programs require a conscientious and rigorous process of admittance (Augustyniak, 2014; Ysseldyke et al., 2006).

Functional competencies in the Blueprint include data-based decision making, systems services, and enhancing the development of academic, cognitive, social, and mental health skills and competencies (Ysseldyke et al., 2006). School psychologists, as leaders in data collection, interpretation, assessment, problem-solving, research methods, and program evaluation, can evaluate outcomes and inform prevention and intervention decisions in school settings 
(Ysseldyke et al., 2006). School psychologists can engage in professional development to train teachers and paraprofessionals, design individual and system-wide interventions, facilitate problem-solving teams, and develop school policies including grading, crisis prevention, interventions, and discipline (Ysseldyke et al., 2006).

In addition to the practice model and the Blueprint, Best Practices in School Psychology IV volume 1, section 1, Professional Leadership Issues and Services includes four subsections on leadership; Professional Foundation, Professional Supervision and Leadership, System-Level Supports for Intervention-Oriented Services, and Supporting Parents, Families, and Cultural Considerations (NASP, 2002). Each subsection emphasizes important issues, guidelines, and services in leadership. Despite these guidelines, there is a dearth of information in the research regarding professional standards, systems-level services, and, in particular, leadership.

\section{Domains of Practice Past and Present}

Models for training and practice continue to evolve yet remain consistent in overarching domains; direct and indirect services, research, data-based decision making to provide effective service delivery, systems services to promote learning, and individual and systems-level consultation (See Table 1).

A select committee appointed in 1940 by the New York State Association for Applied Psychology (NYSAAP) outlined a model of practice encompassing three prominent areas: clinical, educational, and research (Goldberg, Allard, Andrus, Challman, Cornell, Gorrie, Hildreth, Rust, Thompson, Tomlinson, \& Zachry, 1943). The role included evaluation (intellectual, social, emotional, educational, vocational, and special ability), therapy to support children's emotional and social well-being, conferring with parents, teachers, and community agencies, and time for effective service delivery in the areas of clinical and educational services 
(Goldberg et al., 1943). Supervision of personnel, development of special programs, and training of teachers, administrators, and community groups were leadership opportunities (Goldberg et al., 1943).

\section{Table 1}

Comparison of practice model domains past and present

\begin{tabular}{|c|c|c|}
\hline Domains & NYSAAP (1943) & NASP (2010) \\
\hline $\begin{array}{l}\text { Research } \\
\text { Research and Program Evaluation }\end{array}$ & $\mathrm{x}$ & $\mathrm{x}$ \\
\hline \multicolumn{3}{|c|}{ Practices That Permeate All Aspects of Service Delivery } \\
\hline $\begin{array}{l}\text { Data-Based Decision- Making } \\
\text { Consultation \& Collaboration }\end{array}$ & $\begin{array}{l}\mathrm{x} \\
\mathrm{x}\end{array}$ & $\begin{array}{l}\mathrm{x} \\
\mathrm{x}\end{array}$ \\
\hline \multicolumn{3}{|c|}{ Direct and Indirect Services for Children, Families, and Schools } \\
\hline \multicolumn{3}{|l|}{ Student-Level Services } \\
\hline $\begin{array}{l}\text { Academic Interventions \& } \\
\text { Instructional support }\end{array}$ & $\mathrm{x}$ & $\mathrm{x}$ \\
\hline $\begin{array}{l}\text { Mental \& Behavioral Services and } \\
\text { Interventions }\end{array}$ & $\mathrm{x}$ & $\mathrm{x}$ \\
\hline Systems-Level Services & & \\
\hline $\begin{array}{l}\text { School-Wide Practices to Support } \\
\text { Learning }\end{array}$ & $\mathrm{x}$ & $\mathrm{x}$ \\
\hline Preventative and Responsive Services & & $\mathrm{x}$ \\
\hline Family-School Collaboration & $\mathrm{x}$ & $\mathrm{x}$ \\
\hline Curriculum Development & $\mathrm{x}$ & \\
\hline Evaluation (Individual \& Systems) & $\mathrm{x}$ & \\
\hline \multicolumn{3}{|c|}{ Foundations of School Psychologists' Service Delivery } \\
\hline $\begin{array}{l}\text { Diversity in Development and Learning } \\
\text { Legal and ethical professional practice } \\
\text { School Improvement }\end{array}$ & $\mathrm{x}$ & $\begin{array}{l}\mathrm{x} \\
\mathrm{x}\end{array}$ \\
\hline \multicolumn{3}{|l|}{ Supervision } \\
\hline Supervision and training of teachers & $\mathrm{x}$ & \\
\hline Training & $\mathrm{x}$ & \\
\hline Therapy & $\mathrm{x}$ & \\
\hline Effective service delivery (clinical) & $\mathrm{x}$ & \\
\hline
\end{tabular}


The current model of practice outlines ten domains of competence; Domain 1: DataBased Decision Making, Domain 2: Consultation and Collaboration, Domain 3: Academic Interventions and Instructional Supports, Domain 4: Mental and Behavioral Health Services and Interventions, Domain 5: School-Wide Practices to Promote Learning, Domain 6: Preventative and Responsive Services, Domain 7: Family-School Collaboration, Domain 8: Diversity in Development and Learning, Domain 9: Research and Program Evaluation, Domain 10: Legal, Ethical, and Professional Practice (NASP, 2010). In 2006, revisions to the NASP Blueprint for Training and Practice increased the emphasis on school psychologists' role as mental health specialists, putting into practice a three-tiered service delivery model (primary prevention, secondary prevention, and intensive services).

Between past and present models, similarities are explicit; for example, Practices That Permeate All Aspects of Service Delivery; Data-Based Decision Making and Consultation \& Collaboration continue to be essential services. Both past and present models included Research and Program Evaluation, Student Level Services, Systems-Level Services, and School-Wide Practices to Support Learning.

There were noticeable differences between the past and present models. The current model (NASP, 2010) includes preventative and responsive services emphasizing personal characteristics and interpersonal skills, social responsibility, diversity awareness, legal and ethical responsibility, and technology. In contrast to the current model, the NYSAAP model included additional leadership opportunities in curriculum development, school improvement, training, clinical practice, and supervision. Domains of practice have been clearly documented since 1940; however, no current studies investigate whether leadership domains (e.g., supervision, school-wide services, professional development) translate to professional practice. 


\section{Practice}

Since 1990, a NASP survey has been conducted every five years and describes demographic and professional school psychology trends. The surveys have been consistent over time to gather longitudinal data. In 2015, a random sample of 2,654 NASP members (20\%) was selected from a pool of 13,270 eligible participants and was generated based on members' state of residence to ensure balanced geographical representation. Participants met the following inclusionary criteria: active membership in NASP as a Regular or Early Career member, a valid email address, and full-time employment during 2014-2015. The full sample completing surveys included 1,247 participants (48\%). Two new questions were added to measure school psychologists' engagement in activities based on the NASP Practice Model (McNamara, Walcott, \& Hyson, 2019). This membership survey was the first to use electronic methods to distribute surveys, and the language was updated to reflect current terminology (e.g., for Gender and Race terms).

A NASP research committee, a NASP leader, and two staff liaisons reviewed the survey item by item to determine alignment with current NASP goals and organizational priorities. Survey items remained consistent with past surveys, except time spent on specific work duties, which changed from percentage of time to the degree of engagement (Likert-type scale, 0-4) in each area. The 41-item survey included questions about demographics, working conditions, and professional practices. The survey was active for two months on the NASP website in addition to notices posted in two NASP publications (Communique and NASP in Brief). Members who had not completed the survey received reminder emails, and all participants were entered into a drawing for various gift certificates $(\$ 100, \$ 50$, and $\$ 20$ for discounted NASP professional development webinars). The participants included Doctoral (24.8\%), Specialist (54.9\%), and 
Masters (20.3\%) level school psychologists. The majority of participants $(86.3 \%)$ were European American, and $84.2 \%$ were female.

Considering the changing demographics in the nation's schools, participants from the 2015 study were reportedly under-represented in race and ethnicity (Walcott \& Hyson, 2018; U.S. Department of Education, 2017). The majority of participants were from the Northeast (28.9\%) and Midwest regions (24.7\%). Members from the Southeast (19.5\%), West (17.5\%), and (1.4\%) from HI, AK, Armed Forces, Europe, and PR participated. Forty-nine percent worked in Suburban schools, $26.4 \%$ in Urban, $20.4 \%$ Rural, .4\% Frontier, and 1.8\% Other. Sixty-seven percent of the participants reported holding the NCSP credential compared to $56 \%$ during the 2010 survey time period.

The 2015 NASP survey found that school psychologists rarely participated in research or the review of research $(M=1.11)$. In addition, engagement in the following school-wide services was rare by participants; Participating in school crisis prevention and response efforts $(M=$ 1.74); Consulting and collaborating with a team regarding developing and evaluating systemlevel or school-wide programs (e.g., bullying prevention, PBIS, school violence prevention) $(M=$ 1.68); Developing and implementing school-wide strategies to promote safe and supportive learning environments and student wellness $(M=1.51)$; and Personally collecting, analyzing, and interpreting data to develop and evaluate system-level or school-wide programs (e.g., bullying prevention, PBIS, school violence prevention) $(M=1.37)$ (McNamara et al., 2019).

Not surprisingly, the highest engagement levels were in conducting evaluations and participating in IEP meetings, with $90 \%$ of school psychologists engaged in individual student assessment for special education. Survey respondents reported low engagement in school-wide programs to promote learning (PBIS, safety and wellness, and violence prevention) and 
supervision and mentorship $(M=1.26)$. Research and professional practice $(M=1.11)$ had the lowest reported engagement of all activities. A small number of participants (10\%) reported a primary leadership role other than school psychologist (i.e., state department employee, administrator) although one reason for the low number is that school psychologists in leadership roles may not be NASP members (Walcott \& Hyson, 2018).

A valuable finding from the study was the importance of appropriate caseloads. Lower ratios of school psychologists to students, below 1:1,000, were associated with increased engagement in systems services and mental health intervention, whereas higher ratios, 1,5002,000 and over, resulted in significantly greater time spent on special education evaluations $(F=$ 5.07, $p$ <.01) (McNamara et al., 2019). Participants rated their engagement in each area on a Likert-type scale (0-Not At All, 1-Rarely, 2-Somewhat, 3-Quite a Bit, 4-A Great Deal). For group comparisons, degrees of freedom reflected the smaller sample size $(n=656)$.

A NASP priority and clear need are to expand roles both at the student and system levels (Walcott \& Hyson, 2018). Considering that systems-level services have been an integral part of the service delivery model since 1940 and evidence that service delivery is restricted to a few domains, leadership in professional practice will be critical for change.

\section{Current Practice Model Part II: Organizational Principles}

Organizational Principles, Part II of the NASP practice model, is a section that is specific, thorough, and directive. The six Organizational Principles for practice, Part II of the NASP Practice Model, inform professional practice; Organization and Evaluation of Service Delivery; Climate; Physical, Personnel, and Fiscal Support Systems; Professional Communication; Supervision, Peer Consultation, and Mentoring; and Professional Development and Recognition

Systems. Research is sparse regarding leadership and part II of the Practice Model regarding the 
delivery of school psychological services and the organizational principles that support service delivery.

The structure and functioning of organizations, specifically the social environment and how people interact, affect the organization's health and the possibility of burnout (Maslach \& Leiter, 2017). Maslach and Leiter (2017) found that alignment between organizational structures and employee skills and ambitions was a determinant for employees' sense of efficacy. The type of school psychological service delivery model shapes school psychologists' experiences and the ability to lead. NASP calls on all school psychologists to advocate for organizational principles and implementation in the school setting and link NASP principles to practice.

\section{Organizational Principle 1: Organization and Evaluation of Service Delivery}

Shortly after the first NASP Model in 1978, Division 16 of the American Psychological Association (APA) and the National Association of School Psychologists (NASP) initiated The Award of Excellence to publicly recognize exemplary school psychology services units (Telzrow, 1989). From 1982 until 1990, the yearly award celebrated innovative and comprehensive psychological services units that characterized a broad range of services including research, professional development, collaborative consultation, clinical supervision, comprehensive services to all students, assessment for intervention rather than classification, and commitment to training school psychologists (Franklin \& Duley, 2002). The broad range of services reflected the importance of specific Organizational Principles outlined in the NASP Practice Model Part II (consultation, professional development, supervision, and organization of service delivery).

Development and implementation of the award demonstrated robust leadership in action through collaboration between national associations (NASP and APA Division 16: School Psychology) to advocate for Best Practices in school psychological service delivery. Most, if not 
all school districts, receiving the award had three commonalities: An autonomous department of school psychologists, provision of comprehensive services, and leadership and supervision by a licensed certificated school psychologist. Franklin and Duley (2002) reviewed six exceptional school psychology delivery programs that received The Award of Excellence: Memphis City Schools Mental Health Center, Gwinnett County School Psychological Services, Amphitheater School District School Psychology Department, Broward County Schools Psychological Services and Section 504 Support Services, Cherry Hill School District Mental health Team, and CypressFairbanks Independent School District Department of Psychological Services. In their review, Franklin and Duley (2002) identified two critical organizational considerations for delivering school psychological services - program administration and supervision.

Franklin and Duley (2002) discussed four service delivery models. The most efficacious was a separate school psychological services department in which school psychologists facilitated comprehensive service delivery with the greatest autonomy (Franklin \& Duley, 2002). Three other service delivery models were noted in the study: (a) a building-based services model in which school psychologists worked in one or more buildings supervised by the principal, (b) service delivery under the special education department, and (c) service delivery under the supervision of the student services director. All three of these models lacked necessary clinical supervision, leadership, and knowledge of professional standards, ethics, and the comprehensive nature of school psychological services (Franklin \& Duley, 2002). Furthermore, school psychologists in a building-based model reported feeling isolated from colleagues (Franklin \& Duley, 2002). 


\section{Organizational Principle 5: Supervision, Peer Consultation, and Mentoring}

School psychologist supervisors can be an integral part of a leadership team through active participation in change efforts at the individual, building, and systems levels by providing guidance and support (Hunley et al., 2002). School psychology site supervisors are called on to transcend hierarchy and create leadership opportunities inclusive of all professionals with expertise (Augustyniak, 2014); however, current practice typically does not heed this call. The results of the most recent NASP membership survey found that school psychologists not only lack leadership opportunities; they lack appropriate supervision, mentoring, and evaluation (Monahan, 2018).

Supervisors, often non-psychologists, may lack knowledge of professional standards, guidelines, ethics, and the comprehensive nature of school psychological services (Franklin \& Duley, 2002). As noted above, professional and administrative supervision and mentorship are essential factors in practice (Franklin \& Duley, 2002) and strategies for retaining school psychologists (Monahan, 2018). Competent supervision is critical not only for professional development but also for promoting quality services (Simon \& Swerdlik, 2017). Because school psychologists hold unique roles and provide a wide breadth of services, expert clinical supervision tailored to specific skills is required (Simon \& Swerdlik, 2017). Graduate education and professional development increase competencies in supervision (Simon \& Swerdlik, 2017). In Illinois, an Internship Consortium accredited by the American Psychological Association (APA) has provided doctoral-level internship supervision opportunities and professional development support for supervisors in the field (Simon \& Swerdlik, 2017).

Simon and Swerdlick (2017) discussed options the Illinois School Psychologists Association has considered to advocate for appropriate supervision such as a state-level clinical 
supervision credential to be earned through field experience and professional development workshops. A second option would be Meta-supervision groups offered statewide via electronic participation to provide consultation and problem-solving opportunities among supervisors. They also recommended creating a supervision manual in collaboration with the state board of education, universities, and the state professional association.

Administrative rather than clinical supervision is most common in school settings and creates conflict when school administrators have unrealistic expectations and lack understanding of school psychologists' roles (Boccio, Weisz, \& Lefkowitz, 2016). Hunley et al. (2002) highlighted the need for a comprehensive supervision model of school psychological services. More recently, the 2015 NASP membership survey identified needs in the area of supervision and support (Monahan, 2018). The 2015 NASP survey found that school psychologists reported a lack of professional support, $49.5 \%$ felt supported. Only $31.6 \%$ of school psychologists were evaluated by a credentialed school psychologist (Walcott \& Hyson, 2018). These results highlighted two issues, a lack of standards and guidelines informing supervision in practice settings and the direct liability assumed for supervision, navigating best practice, enforcing standards, and clarifying legal and ethical responsibilities in administrative versus clinical supervision (Monahan, 2018).

The literature is scarce on school psychology supervision (Hunley et al., 2002). Two support documents exist as guidelines for supervision, The Foundational Principles for the Supervision and Evaluation of School Psychologists, follow the NASP Practice Model (NASP, 2012). In addition, The Model for Comprehensive and Integrated School Psychological Services, Section 2: Organizational Principles, Supervision and Mentoring is a guide for leaders in the 
development of service delivery, evaluation of school psychological services, and professional development needs for school psychologists.

The principles for supervision and evaluation: Principle 1: Use the NASP Model for Comprehensive and Integrated School Psychological Services (NASP Practice Model) as the overarching framework for personnel evaluations. Principle 2: Recognize the critical importance of personnel evaluations and the essential involvement of affected professionals in creating a relevant, supportive, and instructive feedback system. Principle 3: Use measurements that are valid, reliable, and meaningful. Principle 4: Evaluation of school psychologists should be embedded within an administrative structure that ensures meaningful feedback and offers resources in support of continuous improvement (Thomas \& Grimes, 2006).

With changing roles, legal mandates, and school improvement, school psychologists' supervision must evolve and change to support the needs of practicing psychologists (Hunley, Curtis, \& Batsche, 2002). Without leadership and supervision in professional practice, challenges arise in providing comprehensive services.

\section{Challenges: Lack of Resources, Burnout, and Shortages of School Psychologists}

Challenges arise with expectations to lead and be agents of change, a high level of education and training, and limited decision-making power assigned to school psychologists. School psychologists face difficulties when working with administrators who may lack knowledge of school psychologists' expertise and the comprehensive service delivery model (Cowan, 2012). Furthermore, legal and ethical considerations arise when administrators expect school psychologists to work with outdated assessments, withhold recommendations for support, or persuade parents to agree to inappropriate services for students (Boccio, Weisz, \& Lefkowitz, 2016). 
Huebner (1993) found that school psychologists were at greater risk for burn-out than other psychological service providers and that a lack of social support, productivity, achievement, opportunities for professional advancement or development, and low self-efficacy lead to a feeling of inefficacy. Furthermore, the excessive demands of work and lack of resources lead to detachment, adverse reactions, and potential burnout. Burnout impacts a person's quality of life, resulting in physical exhaustion from excessive work demands and may lead to a change in occupation (George-Levi, Schmidt-Barad, Natan, and Margalit, 2020).

Huebner (1992) surveyed a random sample of NASP members using the Maslach Burnout Inventory (MBI), a self-report measure developed for human service professionals and widely accepted by researchers (Maslach \& Jackson, 1986). The MBI is a self-report measure that assesses three aspects of burnout: Emotional Exhaustion (EE), Depersonalization (DP), and Personal Accomplishment (PA). Maslach and Jackson's criterion for "high" scores was the upper third of the normative distribution for EE and DP scales and the lower third of the distribution for the PA scale. Several items were found to contribute to emotional exhaustion (e.g., the number of referrals, report writing, threat of due process, potential child abuse or suicide cases, uncooperative administrators, and resistant teachers or parents) (Huebner, 1992).

Out of 350 surveys mailed, a total of 187 were returned, and 139 met the criteria for the study. Participants reported a mean age of $43.4(S D=9.1)$, the majority were female $(69 \%)$, and all were working full time. The participants included Doctoral (23\%), Specialist (36\%), and Masters $(41 \%)$ with $11.2(S D=7.0)$ average years of experience. Twenty-nine percent were from rural areas, $24 \%$ urban, $41 \%$ suburban, and represented the following geographical regions: Northeast (30\%), North Central (18\%), Southeast (17\%), West Central (10\%), and West (25\%). The results indicated that school psychologists reported high levels of emotional exhaustion (EE) 
(36.2\%), depersonalization (DP) (9.8\%), and reduced feelings of personal accomplishment (PA) $(27.9 \%)$

In addition to the Maslach Burnout Inventory (MBI), participants completed the School Psychologists Stress Inventory (SPSI: Wise, 1985), which measured 35 stressful events (e.g., interpersonal conflict, time management, \& legal issues) on a scale of 1 (least stressful) to 9 (most stressful). A previous study found that working with uncooperative administrators was the 4th most stressful category out of 35 for school psychologist participants (Wise, 1985). Lack of administrator support is commonly cited as a cause of burnout in school psychology practice (Schilling, Randolph, \& Boan-Lenzo, 2018). More than 16\% of school psychologists reported interest in leaving their positions within five years due to administrative pressure to practice unethical behavior or make decisions against state or federal guidelines (NASP, 2016).

The participants also completed demographic information and a job satisfaction questionnaire created for the study, which consisted of items relating to supervision satisfaction, caseloads, job satisfaction, and intent to leave the profession (Heubner, 1993). The results were similar to a previous study by Huberty and Huebner (1988) and the normative sample $(11,067)$ in Maslach and Jackson's study (1986). The goal of the study was to examine burnout among practicing school psychologists and the relationship between job-related stressors and burnout. The Lack of Resources factor (incompetent or inflexible supervisors, lack of testing materials, inadequate secretarial help, lack of contact with colleagues, and feeling caught between children's needs and administrative constraints) was the best predictor of emotional exhaustion, accounting for about $12 \%$ of the variance.

Job satisfaction, supervision satisfaction, and a desire to leave one's job were significantly related to EE and DP. Almost $10 \%$ of respondents reported high Depersonalization, 
which was disconcerting considering the shortage of school psychologists (Huebner, 1992). This study highlighted the importance of supervisors and organizational change efforts in preventing burnout (Huebner, 1992). Due to the significant amount of variance unaccounted for in the prediction equations for burnout, further research was recommended.

A more recent study (George-Levi et al., 2020) looked at predictors of burnout and a Sense of Coherence (SOC) as a protective factor to prevent burnout. A Sense of Coherence refers to a person's response when facing a stressor. People with high SOC exhibit self-confidence and believe they have sufficient resources available to manage the stressor. High SOC indicates that an individual can adapt to challenging situations and views the world as stable, manageable, and meaningful. Educational psychologists in Israel ( 78 females and 26 males) participated in the study. Their role in public education was to provide assessment and diagnosis, prevention and intervention, consultation, and they worked with both typically developing students and students with special needs (George-Levi et al., 2020).

The study included psychologists who worked full time for one year or more and ranged between $26-59$ years of age $(M=37.4, S D=7.61)$. Eighty psychologists worked in elementary schools and 24 in middle and high schools. Participants completed the Maslach Burnout Inventory-short form, and a Cronbach Alpha of .84 was reported. The results of the study indicated that school psychologists with high levels of SOC resulted in lower levels of burnout and a sense of coherence and that close social relationships predicted positive health and reduced the risk of burnout (George-Levi et al., 2020).

Adding to the problems facing school psychologists is the shortage of school psychologists with an ever-growing need for comprehensive services in schools. With increased needs and shortages of school psychologists, the recommended ratio of students per school 
psychologist (500-700:1) will be difficult to meet (NASP, 2017). According to the 2015 NASP membership survey $(n=1,247)$, the average ratio over the previous seven years was 1,381:1. Higher caseloads due to shortages result in limited provision for capacity building such as mental health, prevention, leadership, systems-level, and comprehensive services. Though limited to NASP members, the survey provides important insight into the current status of school psychological services.

To address shortages in school psychology, NASP recommends "strategies that work," one of which is enabling school psychologists to perform their role as outlined in the NASP Practice Model (NASP, 2017). The disconnect between training and practice may be an important justification for school psychology leadership in professional practice. Ultimately, what is at stake is school psychologists' well-being and their subsequent ability to serve students.

\section{School Psychology Leadership}

Several themes emerged in the literature regarding school psychology leadership and are discussed in this section. The first theme in the literature was the exploration of existing leadership theories and similarities to school psychology. Secondly, researchers explored definitions and characteristics of leadership in school psychology. A third theme was the endorsement that school psychologists are leaders in professional practice and have broad training across domains (Augustyniak, 2017; Burns et al. 2017; Enz \& McCullum, 2018; Shriberg, 2007). Lastly, a need for organizational change to support school psychology leadership in professional practice is discussed. Contradictions exist in the literature. An example of this is the assertion that school psychologists are leaders. Yet, no clear definition of leadership in school psychology currently exists, and recent research suggests that leadership training is 
needed (Augustyniak, 2017). Without a profession-specific leadership model, researchers have studied existing leadership theories.

School psychologists are called to advocate and step into leadership roles, and school psychologists often go above and beyond what is expected of them. An example of this is a case study by Shriberg (2007) that investigated leadership in a high stakes testing environment and found that school-wide data collection, data-based decision making, and collaboration were integral in establishing leadership in practice. Shriberg followed two school psychologists in practice, one of whom wrote a position statement including recommendations for assessment and, at the state school psychology association's request, presented the recommendations to the Michigan State House of Representatives. The two school psychologists took on a transformative role by creating opportunities for themselves in school-wide assessment procedures through collaboration with internal and external leaders to benefit all students.

Shriberg (2007) made the following recommendations for leadership in practice; become a state association member, join district-wide assessment teams, and educate yourself about issues specific to your state. Although leadership is a foundational and functional competency outlined in the NASP practice model, A Blueprint for Training and Practice III (Ysseldyke et al., 2006), knowledge of leadership theories and examples of leadership in school psychology practice are limited (Shriberg, 2007; Ysseldyke et al., 2006). In a 2014 article, Augustyniak discussed the complex nature of defining a profession-specific leadership theory and attempted to find common threads between theoretical leadership models, leadership characteristics, and school psychology. Personal competencies, system factors, and the professions' values must be considered when identifying a leadership framework (Augustyniak, 2014). 


\section{School Psychology Leadership: Definition, Characteristics, and Theoretical Models}

"Effective leaders are characterized by vision, tenacity, self-evaluation and improvement, time commitment, and career dedication" (Harvey \& Struzziero, 2000, pg. 48).

Two primary studies were found in the literature. The first, a qualitative study of school psychologist association leaders' views on leadership, identified five themes for a central definition of school psychology leadership: Facilitation of change, competence, vision, team collaboration, and persuasion/influence (Shriberg, Satchwell, McArdle, \& James, 2010). The participants $(n=156)$ included Doctoral (48.3\%), Specialist (28.7\%), and Masters (23\%) level state and national association leaders (state association presidents, presidents-elect, and NASP delegates). Eighty-nine NASP leaders completed the survey (56.4\% return rate). The majority of participants (94.1\%) were European American, and 67.8\% were female. In addition to the five central themes, positive outcomes for students and systems were deemed essential in defining school psychology leadership. The School Psychology Leadership survey contained qualitative and quantitative questions.

Three research questions were analyzed, first using inductive constant comparison and Ritchie and Lewis' (2003) classical content analysis. Participants answered questions about school psychology leadership, personal characteristics, leadership skills, and what/when/where leadership was expected. The researchers identified 16 distinct categories related to a definition of leadership from several rounds of coding until reliability improved to more than $90 \%$, after which discrepancies were decided on an item-by-item basis. A list of the 16 categories important for the definition of leadership applied to school psychology is presented in Table 2 . 


\section{Table 2}

\section{Leadership Expectations Defined}

\begin{tabular}{ll}
\hline Definition of Leadership applied to the practice of school psychology & $n=51 \%$ \\
\hline Facilitates change, promotes positive outcomes/success & $52.3 \%$ \\
Competence & $27.5 \%$ \\
Vision/big picture view & $27.5 \%$ \\
Works effectively in teams/collaboration & $27.5 \%$ \\
Influences others/persuasive & $23.5 \%$ \\
Respected by others & $15.7 \%$ \\
Advocacy: puts kids first & $13.7 \%$ \\
Problem solving/school psychology skill set & $13.7 \%$ \\
Internal motivation & $11.8 \%$ \\
Goal oriented & $9.8 \%$ \\
Communication skills & $5.9 \%$ \\
Confident/assertive & $3.8 \%$ \\
Holds formal leadership position & $3.9 \%$ \\
Visibility & $2 \%$ \\
Personal character & $2 \%$ \\
Open minded & $2 \%$
\end{tabular}

In the study, association leaders endorsed one definition over all others; facilitates change and promotes positive outcomes and success (52.3\%). Three definitions were considered equally important: vision, collaboration, and persuasion and influence (27.5\%). Less important were visibility (2\%), open-minded (2\%), personal character (2\%), and holding a formal leadership position (3.9\%). The number one endorsement in defining leadership, facilitating change is evidenced in school psychology practice through data-based decision making, consultation, program evaluation, and preventative services (NASP, 2010).

Participants answered two open-ended questions: (a) What personal qualities, attributes, or characteristics (if any) do you associate with school psychologists who exhibit leadership in their work? (b) What specific skills or competencies (if any) do you associate with school psychologists who exhibit leadership in their work? Forty-one participants responded to the first question and data were coded into 19 categories. Key attributes for leaders identified in this study included competence, team skills, knowledge and expertise, personal character, and strong interpersonal skills (See Table 3). 
Sixty-five participants responded to the second question and indicated five competency areas to be important in school psychology leadership (competence/intelligence, content knowledge, team skills/collaboration, school psychology skill set, and written and oral communication skills. A listing of 21 distinct categories is found in Table 4

\section{Table 3}

Leadership Attributes, Qualities, and Characteristics

\begin{tabular}{lc}
\hline Categories & $n=41 \%$ \\
\hline Competence & $48.8 \%$ \\
Team skills & $46.3 \%$ \\
Knowledge and expertise & $41.5 \%$ \\
Personal character & $41.5 \%$ \\
Interpersonal skills & $34.1 \%$ \\
Confidence & $29.3 \%$ \\
Internal Motivation & $29.3 \%$ \\
Organization & $29.3 \%$ \\
Verbal \& Written Communication & $29.3 \%$ \\
Creativity & $26.8 \%$ \\
Advocacy & $22 \%$ \\
Respected & $19.5 \%$ \\
Flexibility & $17.1 \%$ \\
Open minded & $17.1 \%$ \\
Empathetic & $14.6 \%$ \\
Listening & $14.6 \%$ \\
Problem-solving skills & $12.2 \%$ \\
Vision & $7.3 \%$ \\
Other & $4.9 \%$
\end{tabular}




\section{Table 4}

\section{Leadership Competencies and Expectations}

\begin{tabular}{ll}
\hline Competency areas & $n=65 \%$ \\
\hline Competent/intelligent & $41.5 \%$ \\
Content Knowledge & $38.5 \%$ \\
Team skills/collaboration & $35.4 \%$ \\
School psychology skill set & $33.8 \%$ \\
Communication skills & $32.3 \%$ \\
Internal motivation & $20 \%$ \\
Confidence/assertiveness & $20 \%$ \\
Organized & $16.9 \%$ \\
Analytical thinker/creative & $16.9 \%$ \\
Interpersonal skills & $12.3 \%$ \\
Respected by others & $12.3 \%$ \\
Other & $10.8 \%$ \\
Open minded/accepts diversity & $7.7 \%$ \\
Flexibility & $7.7 \%$ \\
Aware of limitations & $6.2 \%$ \\
Listening skills & $6.2 \%$ \\
Personal characteristics & $6.2 \%$ \\
Visionary/goal oriented & $6.2 \%$ \\
Empathy & $4.6 \%$ \\
Motivates others & $3.1 \%$ \\
Advocate & $1.5 \%$
\end{tabular}

\section{Table 5}

Where is leadership expected?

\begin{tabular}{lc}
\hline Categories & $n=64 \%$ \\
\hline Classroom/academic interventions & $46.9 \%$ \\
Behavioral interventions & $37.5 \%$ \\
Crisis intervention & $37.5 \%$ \\
Special education law/processes & $31.3 \%$ \\
Assessment/evaluation & $26.6 \%$ \\
Mental health issues & $26.6 \%$ \\
Classification/eligibility & $21.9 \%$ \\
Team meeting leader & $18.8 \%$ \\
Consultation & $17.2 \%$ \\
School-wide interventions & $15.6 \%$ \\
Data analysis & $9.4 \%$ \\
Problem Solving & $9.4 \%$ \\
Advocacy & $6.3 \%$ \\
Staff Development & $6.3 \%$ \\
Current issues in education & $4.7 \%$ \\
Specific disabilities & $4.7 \%$ \\
Other & $1.6 \%$
\end{tabular}


Sixty-four participants from the total sample $(n=89)$ provided responses coded into 18 distinct categories. NASP association leaders endorsed classroom/academic interventions over other situations or topics wherein school psychologists provide leadership. Behavioral interventions, special education law/process, crisis intervention, and assessment/ evaluation followed as top areas where leadership was provided. Three primary findings emerged from the study; Leadership involves getting results that benefit children and systems, leaders are competent, knowledgeable, and possess strong interpersonal skills and character, and school psychologists feel that others expect them to lead in numerous ways, inside and outside of the classroom.

School psychology's paradigm of traditional testing for special education placement has shifted toward a more preventative approach requiring new roles in professional practice (Shriberg et al., 2010). These results mirror others' stance that school psychologists continue to be advocates for all students and are invested in building capacity of systems (Ysseldyke et al., 2006). Shriberg, Satchwell, McArdle, and James (2010) identified Servant Leadership as one leadership model congruent with identified school psychology leadership characteristics. Servant leadership, a model outlined by Greenleaf, Senge, Covey, and Spears (2002), emphasizes service to others through listening for understanding and creating opportunities. This study's authors attributed the participants' ideas to two well-known leadership models, transformational and transactional leadership. These two leadership models will be discussed in more detail in another section of this review.

NASP association leaders participating in this study endorsed somewhat traditional roles; assessment/evaluation, special education law, and two slightly more progressive roles that could be preventative or responsive, classroom academic and behavioral interventions. Overall, what 
others expect of school psychologists seems to confirm a more traditional view of professional practice. Many of the opportunities expected of school psychologists for leadership in professional practice were not endorsed by most participants, i.e., school-wide interventions, data analysis, team leader, consultation, and staff development. Although the expectation of leadership in practice remained limited in scope, NASP leaders endorsed definitions of leadership that go beyond individual intervention limited to special education (facilitates change and promotes positive outcomes and success $(52.3 \%)$ as well as vision, collaboration, and persuasion and influence). The difference between how association leaders defined leadership and what others expected of school psychologists in practice resembles the training to practice gap and provides the impetus for further research to identify a means of closing this gap.

The second study regarding school psychology leadership surveyed building administrators $(n=32)$, school psychologists $(n=31)$, and teachers $(n=122)$ using the Multifactor Leadership Questionnaire-short form (MLQ; Bass \& Avolio, 2004) and the School Psychology Perceptions Survey (SPPS; Gilman \& Medway, 2007) to determine the most prominent models of leadership and perceptions of teachers and administrators of school psychology leadership (Augustyniak, Kilanowski, \& Privitera, 2016). The sample was drawn from eight school districts in western New York, with $80.6 \%$ suburban districts and $19.4 \%$ urban districts. Most school psychologists worked in one or two schools (45.2\% and $48.4 \%$ of participants, respectively), and a smaller percentage of school psychologists served three or more schools $(6.5 \%)$.

The participants included Doctoral $(n=4)$ and Masters $(n=27)$ level school psychologists, 28 female and 3 males. Of the 122 teachers in the sample, $54.1 \%$ were general education teachers, and $45.9 \%$ were special education teachers. Surveys were distributed and 
collected in person by research assistants and given to one school psychologist, one administrator, and two teachers in each building to investigate the level of satisfaction with school psychology service delivery and leadership efficacy.

The MLQ and SPPS (section related to participants' satisfaction with school psychology service delivery) were scored according to the publishers' requirements. Independent samples $t$ tests were conducted to compare self-perception of school psychologists regarding leadership efficacy and reports of leadership efficacy by teachers and administrators. Pearson productmoment correlations were computed to assess the relationship between satisfaction scales (SPPS) and leadership profiles (MLQ) reported by administrators and teachers. In addition, independent samples $t$-tests were conducted to compare satisfaction with service delivery, MLQ leadership ratings, and the number of schools served by the school psychologist.

The MLQ assesses three leadership styles: Transformational, Transactional, and PassiveAvoidant and is intended to provide leaders with feedback on their performance from multiple perspectives within an organization. Two versions of the MLQ are available, the long-form (63 items) and the short (45 items), considered the standard version. Cronbach's alpha estimates were good and ranged from .74 to .94 on the leadership subscales, and validity was adequately supported through confirmatory factor analysis in the MLQ manual (Bass \& Avolio, 2004). The outcomes scale measures the evaluee's perceptions of themselves, or the level of satisfaction that other raters have with the evaluee's leadership methods and has nine subscales and three subscales (Table 6). 


\section{Table 6}

\section{MLQ Scale Composition}

\begin{tabular}{|c|c|c|c|}
\hline $\begin{array}{l}\text { Transformational } \\
\text { Leadership Scale }\end{array}$ & $\begin{array}{l}\text { Transactional } \\
\text { Leadership Scale }\end{array}$ & $\begin{array}{l}\text { Passive-Avoidant } \\
\text { Leadership Scale }\end{array}$ & $\begin{array}{l}\text { Outcomes of } \\
\text { Leadership Scale }\end{array}$ \\
\hline $\begin{array}{l}\text { Idealized Attributes } \\
\text { Idealized Behaviors } \\
\text { Inspirational Motivation } \\
\text { Intellectual Stimulation } \\
\text { Individual Consideration }\end{array}$ & $\begin{array}{l}\text { Contingent Reward } \\
\text { Management-by } \\
\text { Exception: Action }\end{array}$ & $\begin{array}{l}\text { Management-by } \\
\text { Exception: Passive } \\
\text { Laissez-Faire }\end{array}$ & $\begin{array}{l}\text { Extra Effort } \\
\text { Effectiveness } \\
\text { Satisfaction With } \\
\text { Leadership }\end{array}$ \\
\hline
\end{tabular}

Brief descriptions of the subscales were discussed. Transformational Leadership consisted of 5 facets of leadership. The first, Idealized Attributes and Idealized Behaviors, described as admirable characteristics of the leader that entice followers to identify with them. Second, Individual Consideration, described as the level of support and mentoring provided for followers. Third, Inspirational Motivation, the leader's ability to articulate an appealing vision that inspires followers, and lastly, Intellectual Stimulation, how leaders encourage others' ideas, provides new insight and teaches new skills.

A second leadership model described in the study, Transactional Leadership, is based on two types of leadership behavior: (a) Contingent Reward and (b) Management-by Exception. Contingent Reward reinforces followers' appropriate behavior with some kind of reward and Management-by Exception means tending to situations that fall outside of the established standard. There are two types of Management-by Exception. The first type, Active, monitors the follower's behavior, anticipates problems, and takes action, whereas a Passive style waits for problems to occur before taking action.

Transformational leadership embodies a commitment of shared responsibility and goals directed toward working collaboratively toward meaningful outcomes (Shriberg, 2007). School psychology practice aligns with transformational leadership of shared commitment and values, 
empowerment, high ethical and moral standards, organizational goals, and vision (Shriberg, 2007). A Transformational theoretical approach based on social justice is inclusive of community members, focused on positive social change, and is purposed with addressing marginal groups and the impact of power on social communities (Mertens, 2015). School psychologists advocate for inclusive practices and social justice for all students and work with students, staff, and the community collaboratively to educate and bring about necessary change. Transformational leaders support individuals in pursuing their potential while working toward group goals. In Transformational leadership, high moral and ethical standards are at the forefront of goal-directed activities and often use empowerment and inspirational motivation to engage in change collectively (Augustyniak et al., 2016).

Transactional and Transformational leadership developed by Bass (1985) are two leadership styles often used by leaders, whether in a formal or informal leadership role (Augustyniak et al., 2016). Transactional leadership is associated with set standards and guidelines agreed upon between leaders and followers for achieving goals with the understanding of a reward for goal completion (Augustyniak et al., 2016). Transformational leadership is sometimes referred to as a values-based type of leadership, whereas Transactional is more of a rewards-based type of leadership (Augustyniak et al., 2016).

The results from the study indicated that teachers' ratings of school psychologists were significantly higher than national norms in the areas of Extra Effort $(M=2.94, S D=1.76)$, Effectiveness $(M=3.29, S D=.857)$, and Satisfaction $(M=3.43, S D=.817)$. School psychologists identified most strongly with Transformational leadership $(M=12.62, S D=2.24)$ which was found to be significantly higher than Transactional $(M=3.6, S D=1.05, t(24)=$ 
20.02, $\mathrm{p}<.001)$, or Passive-Avoidant leadership type $(M=1.40, S D=84, t(24)=24.97, p<$ $.001)$.

Administrator satisfaction with school psychology services most strongly correlated with Transactional leadership style $(r=.72, p<.01)$ and negatively correlated with the Passive leadership style $(r=.688, p<.01)$ as measured by the SPPS. Teacher satisfaction of school psychology services however was most strongly correlated with Transformational leadership style $(r=.412, p<.05)$ and also negatively correlated with the Passive leadership style $(r=.389$, $p<.05)$. Administrator ratings indicated that Transformational leadership was significantly higher for SP's serving multiple schools $(M=13.90, S D=1.81)$ than SP's serving one school $(M=9.67, S D=4.82, t(14)=9.02, p<.01)$. Passive-Avoidant leadership style was significantly higher for SP's serving one school $(M=2.12, S D=1.58)$ than multiple schools $(M=.87, S D=$ $.67, t(15)=-7.45, p<.01)$. On teacher MLQ ratings, Transformational leadership was significantly higher for SP's serving multiple schools $(M=13.10, S D=3.14)$ than those serving one school $(M=12.05, S D=3.36, t(66)=2.73, p<.01)$.

This was the first study to document school psychologists' self-perceptions of leadership style and ability and established precedence for empirical investigation of school psychology and specific leadership models in practice. The results indicated school psychologists viewed themselves as active leaders in their professional practice and placed a high value on ethical standards, encouraging growth, and empowering those around them (Augustyniak et al., 2016). School psychologists rated themselves higher than the MLQ national normative sample on two subscales, Satisfaction and Effectiveness, indicating that they perceived themselves to be more effective than others in advocating and meeting the needs of others, meeting organizational requirements, and believed others feel satisfied working with them (Augustyniak et al., 2016). 
Administrators and teachers rated school psychologists lower than themselves on Individual Consideration, indicating that school psychologists saw themselves as more sensitive to individual differences and abilities than their coworkers perceive. The researchers suggested that this may be an area to improve leadership skills. School psychologists were rated higher by teachers on Laissez-Faire or non-leadership behavior than administrators. They were more likely to view school psychologists as avoidant or non-responsive to their requests. Administrators' satisfaction with school psychologists was associated with Transactional leadership, and the authors surmised that this finding could be due to administrators' narrow view of the school psychologist's role and potential.

Post-hoc investigations of years of experience, gender differences, or education level ruled out any effect these had on leadership type (Administrators endorsed Transformational for SP's with multiple schools and Transactional or Passive-Avoidant for SP's with one school). A Kruskal-Wallis test for independent samples found years of experience was evenly distributed across the number of schools and not a reason for the differences in leadership type.

Although the MLQ has been validated on a vast and diverse population, it has not been utilized for school psychology practice prior to this study, and the small sample size limits generalizability of the results (Augustyniak et al., 2016). Future studies need a representative sample from all geographical areas of the country. The study by Augustyniak et al. (2016) provided a validation that school psychologists view themselves as leaders that align with the Transformational leadership style, which is consistent with the views of school psychology professional practice (Augustyniak et al., 2016). Research, specific to school psychology leadership, resources, and development of a conceptual model of leadership is a need evidenced by this study. The researchers called for discipline-specific leadership competencies to be 
identified and integrated into professional preparation programs, as well as attention to systemic factors that foster school psychology leadership (Augustyniak et al., 2016). In school psychology, current leaders and trainers can promote and encourage leadership capacity in professional practice through modeling, training, supervision, and professional development.

\section{Organization and Systems Leadership}

"School psychologists are uniquely qualified to advance school systems toward empirically-supported, problem-solving models of service delivery and to address other complex human and situational factors to facilitate school improvement" (Augustyniak et al., 2016, pg 371-372).

School psychologists can be leaders in building organizational capacity and systems services that foster competencies in all areas of student learning (Armistead \& Smallwood, 2010). Distal attributes specific to school psychology leadership include cognitive capacity, adaptability, ethical imperatives, openness, continuous learning, and risk tolerance, whereas proximal attributes such as technical skills, social aptitude, and knowledge are shaped through interaction with the environment (Augustyniak, 2014). Particularly fitting with NASP's Blueprint and the reauthorization of ESEA/NCLB is a contemporary view of leadership embracing collaboration, diverse expertise, and shared power (Augustyniak, 2014). Distributed leadership strives for collective and shared responsibility in an environment of expected educational accountability and school improvement. School psychologists, given the specialization and training in problem-solving models of service delivery, collaboration, and systems change, can be involved as distributed leaders in schools (Augustyniak, 2014). Although disagreement exists around the construct of distributed leadership, there is evidence of distributed leadership in schools (Augustyniak, 2014). The potential of co-leadership roles in education to promote collaboration within organizations has gained little attention and is an area for future research (Augustyniak et al., 2016). 
School psychologists' knowledge of program evaluation, problem-solving processes, mental health, and learning has influenced school reform by disseminating information to parents and professionals (Dwyer \& Gorin, 1996). Richard Riley, Secretary of Education under President Clinton, worked to redesign federal programs under the Goals 2000: Educate America Act by providing a framework for communities to develop a vision of schools for children. Riley called on school psychologists to be involved at classroom, school, community, and system levels by using their knowledge of psychology and education (Riley, 1996). Building capacity within and across educational, family, and community systems is a call to action (NASP, 2006). To achieve that goal, we need system change from within and radical changes in policy (Robinson, 2015).

School psychologists are educated to understand systems-level change principles and are key stakeholders in educational systems (Curtis \& Stollar, 1996). School psychologists can play an integral role in promoting public policy and professional practice through engagement and leadership (Skalski, 2013). Leadership is viewed as critical (NASP, 2010) for organizational change, systems-level, and comprehensive services, and policy, planning, and training at all levels (school, district, state, and national). Changing systems with poor leadership is extremely difficult (Smith, 2008).

When administrators make decisions without the involvement of key stakeholders, it can negatively impact organizational change (Curtis \& Stollar, 1996). Local capacity is vital to long term change efforts and why we need leaders in schools rather than relying on outside agencies. School psychologists in local education settings have the experience and knowledge to lead systems change efforts and need to be at the forefront (Shapiro, 2006). Leaders participating in decision making, program evaluation, problem-solving, and training from within the education 
system have been shown to establish a system of ongoing evaluation and continuous

improvement (Dwyer \& Gorin 1996; Shapiro, 2006).

\section{Leadership Opportunities and Training}

Contrary to the belief that school psychologists are prepared to lead and the expectation for school psychologists to be change agents, the profession is limited by a lack of systematic leadership development (Augustyniak, 2014). Although leadership is expected in practice, leadership development, field-based experiences in leadership, and partnership models between higher education institutions and local education agencies are lacking (Augustyniak, 2014; Shapiro, 2006).

University faculty and site supervisors share responsibility in creating opportunities, mentoring, and modeling to provide appropriate placements that offer training that encompasses all domains of practice (Augustyniak, 2014). Needs include mentoring and professional development, targeted outreach and recruitment of school psychologists, and partnerships between universities, SEA's, LEA's and state professional organizations to support leadership in practice (Monahan, 2018). Leadership development and implementation of the NASP Practice Model at the state and local education agencies are two of NASP's strategic goals for 2022 (McNamara et al., 2019).

The following are recommendations from NASP (2016) to improve the retention of school psychologists: professional supervision, professional development relevant to practice, and positive work environments. To achieve those goals, a collaborative network of local, state, and national policy leaders working for ecological and systemic change to determine future plans must be a priority (Conoley \& Gutkin, 1995). Furthermore, enabling school psychologists to 
perform their role as articulated in the NASP Practice Model may be critical for addressing shortages in the profession (NASP, 2017).

Priorities in the development of training programs might include leadership theory, conceptual models of school psychology leadership, and specific program expectations around engaging in leadership activities and course development in leadership areas of teamwork, communication, conflict resolution, and motivational strategies (Augustyniak, 2014). Field-based experiences are critical to leadership development and should provide opportunities to engage in inquiry, collaboration, use data-based decision making, and lead systems for improvement (Augustyniak, 2104).

Faculty of higher education have an opportunity to work collaboratively, engaging as a team to build leadership within school settings, and educate future leaders through graduate education programs (Augustyniak, 2014). University faculty and site supervisors share responsibility in creating opportunities, mentoring, modeling, and providing appropriate placements that offer training that encompasses all domains of practice (Augustyniak, 2014). A collaborative network of local, state, and national policy leaders working for ecological and systemic change to determine future plans must be a priority.

\section{Conclusion}

There is strong evidence to suggest that further research in school psychology leadership is needed. Due to school psychologists' needs, leadership will be critical to the well-being of individuals working in the field and the health of the profession (and subsequent ability to better serve children). Consequences of a field deprived of leadership show up in shortages, burn out, and people leaving practice to pursue leadership at the association or administrative levels. A process for change that empowers school psychologists in practice, implementation of a school 
psychology services delivery model, and leadership specific to school psychology from a systems perspective have yet to be identified. As new research materializes, school psychology leadership will emerge as consequential for unambiguous practice guidelines in the future.

Researchers have created a foundation and a starting point to build and problem solve. The current literature has taken a holistic approach outlining broad challenges in leadership to identify future research. Problematic is the dissonance or lack of clarity regarding school psychology leadership throughout school psychology's evolution as a profession. Leadership is a broad construct often found in the school psychology literature as well as the practice model and is loosely applied to the school psychologist's role. There is an apparent disconnect between what designates a leader in school psychology and the proclamation that school psychologists are leaders.

Beyond a missing definition, one problem is the lack of knowledge about what school psychology leadership looks like in practice. Currently, school psychologists are expected to go above and beyond their role, advocate, and participate on teams to assume leadership. School psychology education and training, expectations to lead and be agents of change, and the limited decision-making power assigned to school psychologists in school settings create challenges for school psychologists.

One purpose of the NASP Model for comprehensive service delivery was to guide administrators in developing service delivery, evaluation of school psychological services, and professional development needs for school psychologists (NASP, 2010). With clearly outlined expectations in the NASP practice model, there appears to be a gap in research on school psychology leadership and, more importantly, what is needed to close the gap from training to practice. This might be one of the most important arguments for school psychology leadership in 
practice and also speaks to the service delivery model and the need for school psychology service units, separate from special education.

Additionally, though the practice model is specific and clear, what is unclear is the status of graduate training programs coursework in leadership. Without a specific training model or coursework specific to school psychology leadership, are school psychologists, in fact, leaders? Augustyniak (2014) called for a model or framework to specifically identify a structure, definition, guidelines, and leadership path.

In contrast to the call for graduate training in leadership, is it possible that training programs following NASP standards and certification expectations are currently preparing leaders, however leadership roles in practice do not exist due to school structure, certification requirements, role definition, or other variables? Does the public education model of traditional administrative hierarchy perpetuate inequality and oppression of school psychological services and leadership in practice?

It might be pertinent to identify possible leadership outcomes in current training programs. Graduate training programs accredited by NASP follow the Model for Comprehensive and Integrated School Psychological Services, Principles for Professional Ethics, and Standards for Credentialing of School Psychologists. NASP, along with accredited graduate training programs are expected and equipped to prepare school psychologists for practice. The profession must address the gap from higher education to practice in schools, lack of understanding of leadership roles, and the development of a process to bring school psychology organizational guidelines and leadership into practice settings. In the next chapter, a survey method is presented that was designed to garner school psychologists' perceptions of their current and desired leadership roles and perceived support toward assuming leadership roles. 


\section{Chapter Three: Methodology}

This quantitative study aims to examine the current state of school psychology leadership and identify barriers to leadership in practice. A survey was developed based on the NASP Practice Model domains to gather information about organizational leadership experiences that would have validity in school psychology. School psychologists are knowledgeable about databased decision making, and leaders within organizations are responsible for using data to evaluate school psychological service delivery (Reschly, 1995). This chapter provides an overview of online survey development and describes the method and procedure used in this study.

\section{Components of a Valid Online Survey}

Surveys are widely used, relatively low cost, and designed to describe the status of a construct, compare groups, or show change (Fink \& Kosecoff, 1998; Strickland, 2017). Survey methodology components include survey design, sampling plan, survey construction, question development, and data analysis (Mertens, 2015; Rossi, Wright, \& Anderson, 1983). Technology paved the way for collecting data through online Web-based surveys, which are financially feasible and provide quick, accurate reporting and analysis. Flexible design and creativity in using graphics, color, icons, and video create user-friendly aesthetic surveys. Online surveys often offer prompts, pop up instructions, drop-down boxes for ease of use, and a variety of question types including click-box (yes/no), ranking, multiple-choice, open-ended response, and adaptations for people with disabilities (Mertens, 2015). Additional benefits of online surveys include anonymity, automated data collection, quick access for technological fixes, and easy access to results (Mertens, 2015). 
Survey design describes the type of survey (descriptive, cross-sectional, or longitudinal) and environmentally controlled variables (frequency of administration, individual or number of groups participating in the study, and when the survey is administered) (Fink \& Kosecoff, 1998; Mertens, 2015). Although survey methodology has many benefits, survey methods commonly used in educational and psychological research pose challenges and have design issues (Alwin, 1977; Mertens, 2015). For example, there is minimal experimental control; therefore, the fidelity of online survey design is critical (Strickland, 2017). Responding from any place at any time is convenient for respondents, though it could increase errors if people reply to items too quickly (Mertens, 2015).

Mertens (2015) outlined three survey types; descriptive, cross-sectional, and longitudinal. Both simple descriptive (one group) and cross-sectional (several groups) designs collect data at one point in time (Fink \& Kosecoff, 1998; Mertens, 2015). The advantages of cross-sectional designs include ease of design, gathering descriptive data, determination of differences between and within subgroups, and a frequency count of certain behaviors, attitudes, or beliefs (Fink \& Kosecoff, 1998).

The goals in developing an online survey are to determine the research questions, clear objectives, target audience, type of information needed, and the mode of data collection (Mertens, 2015). The quality and analysis of data are critical in reducing errors and are dependent on the method of sampling, question formulation, and theoretical formulation of the problem (Alwin, 1978). Factors in determining statistical procedures include; type of group (independent, dependent, repeated measures, matched groups), the number of variables, the scale 
of measurement (nominal, ordinal, interval, ratio), and whether assumptions of parametric statistics can be met (Mertens, 2015).

The Code of Federal Regulations outlines confidentiality guidelines for safeguarding survey information (Fink \& Kosecoff, 1998). The process includes a request for permission letter to obtain access to the target audience's members and then informed consent at the beginning of the survey (consent to participate in the study). It is essential to provide the title of the study, procedures and duration, potential risks and benefits (development of new knowledge and information to inform programs and policies), and potential compensation. Confidentiality, contact information for any questions, participation, and assurance of voluntary withdrawal from the study are vital (Fink \& Kosecoff, 1998).

Other considerations are sample size and response rate (Fink \& Kosecoff, 1998). The sample frame (target sample) is participants that have a chance to be selected for the study (Fowler, 1993). Adequate sample size is dependent on the sampling procedure and the estimated standard error (Fink \& Kosecoff, 1998; Fowler, 1993). The sample size influences statistical significance and effect size (Mertens, 2015). In contrast to the sample frame, the survey population includes actual data received from the target sample (Rossi et al., 1983).

Two main categories of sample design, the specific procedure used to select participants, are probability and nonprobability (Fink \& Kosecoff, 1998; Mertens, 2015; Rossi et al., 1983). Probability sampling assures statistical inference in predicting that the results will generalize to the larger population (Rossi et al., 1983). Examples of probability techniques are simple random sampling, stratified random sampling, systematic random sampling, and cluster sampling (Fink \& Kosecoff, 1989; Mertens, 2015; Rossi et al., 1983). 
Contrary to probability sampling, nonprobability (non-random) sampling may be used in the case of time or cost restraints and does not include all the population surveyed. There are several examples of nonprobability samples; systematic (every $n$th person or group), quota sampling (subgroups of a specific proportion), and convenience sampling (willing and available participants) (Fink \& Kosecoff, 1998; Mertens, 2015).

To determine adequate sample size, one estimates the response rate expected and the minimum sample size needed for the subgroup (based on a \#\% rate, $n \#$ participants are necessary to disaggregate the data) (Fowler, 1993). Larger sample sizes will decrease sampling error, and the participant response rate will determine the need to further validate the survey through follow-up interviews (Fowler, 1993).

Regarding content, an online survey must be easy to navigate, load quickly, be compatible with mobile devices, and should begin with a brief welcome, introduction, and description of the purpose of the survey. A welcome screen should provide specific instructions, use a simple font, clear, consistent layout throughout the survey, and simple graphics designed not to distract. To improve data collection, it is important to verify understanding through short questions, use clear scale anchors, and repeat instructions on each page (Strickland, 2017). The survey should have a title, headings for logical flow, clear questions organized by similar types, examples when needed, and a clean visual layout (Mertens, 2015).

Although shorter surveys may have a better response rate, ethical and scientific implications arise when brief surveys are designed to increase participation (DeVellis, 2012). When respondent fatigue occurs, participants become bored or tired of answering questions, and data are affected. The recommended length is fifteen to twenty minutes or 25-35 questions 
(Lavrakas, 2008). The items to include in the opening section of a survey might include demographic information (e.g., age, gender, race/ethnicity), education level, income, role, and type of school (e.g., elementary, middle, high school, rural, suburban).

More than one type of response format can be included; the length of the survey, participants, the information you hope to gather, and the question you are trying to answer determines which response format to choose (Thomas, 2004). Two common types of responses, open or fixed response, provide unique information. Open response requires the respondent to create an answer. It provides more detailed information, offering a range of answers, though it often requires additional analysis and may be perceived as extra work for the participant. Guidelines for open response questions include avoiding leading questions, words that imply approval or disapproval, social desirability, and avoiding items that suggest a specific response.

Response formats may include an adjective checklist that provides an equal number of positive and negative responses to report feelings or reactions. Limitations to using a checklist might include an incomplete list or a limited degree of feelings (Thomas, 2004). A ranking format requires respondents to identify interests and preferences in order of importance. Fixed sum items identify the significance of activities or time allocation by assigning a percentage or sum to 100 . The benefit of fixed sum items is that data obtained provide a ranking or relative position. An example of this would include the percentage of time school psychologists spend on various work tasks (report writing, meetings, testing, consultation, etc.).

Rating scales provide intensity, duration, frequency, and degree of agreement or interest, whereas ranking format gives a relative standing (Thomas, 2004). Rating scales have two parts, the stem (question or statement) and response (rating) or scale anchors (a point on a scale), i.e., a 
Likert-type scale. Likert scales typically use five anchors, e.g., strongly agree, agree, undecided or neutral, disagree, and strongly disagree. Likert scales, however, have several limitations; indepth knowledge of the topic is needed, the time it takes to write clear questions and attaining the number of items to obtain a reliable and meaningful score (Thomas, 2004). The following are considerations for writing a stem (Thomas, 2004):

- One concept or point /only ask one question for each item

- Short, concise statements

- Consider the reading level of the respondent

- Specificity, not ambiguity (define and clarify)

- Avoid stereotyping (e.g., the use of 'he' for a Principal)

- Avoid leading questions/bias

- Best to avoid using acronyms

- No double negatives

- Likert rating- reverse wording on $1 / 3$ to $1 / 2$ (positive to negative word stems)

- Level of detail respondent has to remember

- Use a full range of response choices but don't overdo (not recommended to use always or never rather almost always or almost never)

- Response scales should be comprehensive

- The anchors must match the information you need (very important to not important or agree/disagree)

- Order of scale anchors makes a difference (agree-disagree in that order--positive anchors first 
- Numeric - higher numbers mean more satisfaction/agreement

- Use logical order with answer choices

- Likert scales - assign the anchors points

Critical to the development of reliable and valid surveys is understanding the theoretical construct, quantitative tools, the relationship between hypothetical constructs, and the phenomena being studied (DeVellis, 2012). A reliable measure is consistent over time, produces an accurate estimate of the construct being measured, and minimizes error (Fink \& Kosecoff, 1998; Mertens, 2015).

In a post-positivist theoretical paradigm, validity, reliability, and objectivity are three standards that determine the quality of quantitative measurement (Mertens, 2015). In terms of the reliability of a measurement tool, repeated measures (test-retest or parallel forms) and internal consistency (Kuder-Richardson or coefficient alpha) are two approaches (Mertens, 2015). When a measure has various scales or measures attitudes, characteristics, and qualities, internal consistency (Cronbach's alpha) becomes a factor (Fink \& Kosecoff, 1989).

Validity is an essential aspect of scale development and refers to the extent to which the scale measures what it intends to measure. There are several measures of validity; predictive, concurrent, content, and construct validity. Predictive validity predicts that an individual will perform a certain way, for example, a high positive or negative correlation between attitude and performance (grade). Concurrent validity compares the measure to expert opinions or another measurement tool for the level of correlation. Content validity refers to items that accurately represent the attitudes and traits they are intended to measure or relevance to content (Mertens, 2015). 
For surveys such as the one used in this study, establishing content validity is of primary importance. Items are evaluated by an expert panel and then further evaluated using a pilot study to assess content validity. The pilot study allows testing of the survey's logistics and provides information about ease of responding, standardized procedures, redundant or misleading questions, affirms the items are appropriate to the subgroup surveyed, and if the survey provides the needed information (Fink \& Kosecoff, 1998). The pilot sample should be similar to the survey group (Mertens, 2015).

\section{Current Survey Item Development and Content Validation}

\section{Item Development}

Without a clear definition of school psychology leadership in the literature, it was essential to operationalize leadership in school psychology practice to develop the survey. The NASP Practice Model and extant literature guided the development of school psychology leadership as a construct for the survey. Leadership opportunities were divided into formal and informal leadership roles to include both current and desired leadership opportunities.

Questions regarding a formal leadership role defined as a supervisor, mentor, or lead school psychologist asked about participants' graduate education experiences in supervision and leadership, the desire to supervise others, and available supervision opportunities in practice. The second category of questions, systems-level leadership (informal role), referred to practice domains such as leading crisis intervention teams, universal screening, and program evaluation. The last category of leadership questions investigated school psychologists' leadership through organizational principles of service delivery (organization of services, collaboration, communication, and climate) and professional growth (professional development, appropriate 
supervision, recognition, and promotion). The overall survey consisted of six sections, including a demographic section. Demographic information regarding age, gender, race/ethnicity, education level, years of practice, income, and school setting (elementary, middle, high school, rural, suburban) were included in the survey.

The item pool was developed using the NASP domains of practice and organizational principles as a guide. Questions were in a fixed response format, except one open-ended question about barriers to school psychology leadership in practice. A fixed response option is clear cut, offers a series of choices for the respondent, and is formatted as a checklist (reactions, feelings, or behaviors), ranking, or rating scale (Thomas, 2004). For validity, random guessing was reduced by providing a response choice such as, "I don't know" or "Not Applicable" (Strickland, 2017). The question format included checklists and response matrices. The majority included Likert-type rating scales. The researcher reviewed the following considerations for writing the stem: one question for each item, concise statements, specificity, and avoid leading questions/bias (Thomas, 2004).

The first section of the survey (Part 1 of the NASP practice model) asked respondents to report their current position and whether they currently have or would like to have a leadership role in the future. Participants were asked to choose the domains of practice (multiple choice answer) that described their current position to identify whether they are engaged in all ten domains of practice. Next, the questions consisted of a matrix format to report on their current leadership roles, desired leadership roles, or none in terms of systems-based services. The respondents were asked to use a 5-point Likert as well as multiple-choice questions to report on 
their formal leadership roles (supervision, lead school psychologist, mentoring) and previous graduate education in leadership.

The last four sections asked respondents about organizational principles (Part II of the NASP Model) using a 5-point Likert scale with anchors of 1 (strongly agree) and 5 (strongly disagree). One additional multiple-choice question asked about the types of support available in the workplace (clerical, furniture, software, etc.). Information was gathered about their supervisor's education and experience, title (principal, special education director, educational coordinator, school psychologist), and knowledge of school psychology services.

\section{Content Validation}

For the survey, content validity consisted of an expert panel of four university trainers with expertise in survey construction and school psychology, and a pilot study with practicing school psychologists. The validation consisted of qualitative feedback regarding the content and response format.

Expert panel outcomes. The expert panel recommended changes to improve the organization for survey content and flow, including a narrative to introduce each section and provide context and specificity about the questions. One reviewer suggested ordering NASP domain questions in the order they appear in the NASP Practice Model. Several items were determined to be irrelevant to the questions of this study and deleted from the survey. Examples of items deleted from the survey included additional questions about supervision evaluation process and tools; Which of the following is used for the evaluation of school psychologists in your district? (teacher or administrator evaluation form, informal evaluation tool, other), I am involved in developing and implementing a coordinated plan for the accountability and 
evaluation of school psychological services (Likert rating) and whether school psychologists' evaluations are based on measurable outcomes of skills and services. One question regarding district policies on the storage and maintenance of school psychological records was deleted. Questions about type of contract (administrator, teacher, pupil personnel, other) and caseload were omitted, and a question about credentials was added. Two questions about the importance of school psychologists' contributions and beliefs regarding policy development and a lack of leadership and the impact on comprehensive service delivery were rewritten and included in other questions. Furthermore, two questions, Who provides mental health services in your district? School psychologists are recognized as qualified providers of mental health (Likert rating) were not considered necessary for answering this study's questions.

Lastly, several revisions were made to the questions using a matrix format for ease of responding. Initially, the matrix questions were organized as individual questions using a Likert scale. As feedback was received and the survey evolved, specific leadership categories were clearly delineated, which influenced the writing of the matrix questions. The layout of the matrix questions provided an important visual representation of the types of contributions school psychologists made in practice settings (leader, team member, none) and framed the services in terms of leadership or other (not leadership). Furthermore, the matrix questions allowed for three types of responses (leadership, team, other) as well as defining formal (supervision, mentor, lead) and informal leadership opportunities (systems-level leadership).

\section{Pilot Study Outcomes}

A link to the survey prototype was emailed to 10 school psychologists in California and Nebraska to test the logistics of the questionnaire. A brief analysis was conducted to identify the 
clarity of questions, the inclusion of all relevant topics, and gain information about the survey's general format using Qualtrics. The pilot group was asked to provide information about ease of responding, redundant or misleading questions, inclusion of all appropriate questions, the consistency of the information, and whether the survey provided the needed information (Fink \& Kosecoff, 1998). Five follow-up interviews were conducted, and qualitative feedback from the respondents was utilized to validate the survey content. The reviewers suggested changes for clarification and formatting of questions, consistent ordering of responses from positive to negative, shortening questions (only one question per item), and adding an open-ended question. One reviewer noted that the headings were not displayed on the survey and suggested adding page numbers. Instead, a progress bar was added at the bottom of each page. Also, clarification regarding the terms leadership and facilitator was discussed though no changes were made to the survey. Suggestions were made to separate two of the questions into four items for clarity.

The items in the survey followed the NASP model guidelines, which are familiar to most school psychologists. One recommendation was to include a link to the NASP Practice Model with the survey for school psychologists who may not be familiar with the Model. Because the information is easily accessible on the association web page, it was not included with the survey.

\section{Procedure}

Completing the survey required access to and approval from the Institutional Review Board and other entities involved. The survey and procedure were approved by the Institutional Review Board (IRB) at Chapman University (see Appendix A). The process for soliciting participants included an email and cover letter explaining the research to request permission and obtain access to members of the target audience. Three states were chosen based on the 
researchers' affiliation and work experience (California, Missouri, and Nebraska), and two states, Louisiana and Colorado, were chosen randomly. The California Association of School Psychologists (CASP), Nebraska School Psychologists Association (NSPA), Missouri Association of School Psychologists (MASP), Louisiana School Psychologists Association (LSPA), and the Colorado Society of School Psychologists (CSSP) were contacted via email. Two online professional organizations, Evidence-Based School Psychologists and Said No School Psychologist Ever, were also contacted.

A letter requesting permission and the IRB approval was sent via email to directors of CASP, NSPA, MASP, LSPA, CSSP (Colorado Society of School Psychologists), and site managers for the online professional networks. One state association, the Colorado Society of School Psychologists (CSSP), required membership in their association; therefore, it was not included. A second organization, MASP, needed the researcher to be a member of MASP or the researchers' home state association. The researcher confirmed membership status in CASP and was approved to invite MASP member participants. Two state associations (LSPA and NSPA) did not require association membership to participate. The online professional networks did not require group membership, although the researcher was a member of both groups.

Once permission was received from state association directors, a cover letter and link to the survey was emailed to all four directors and online site administrators. The cover letter included the title of the study, purpose, duration, potential risks and benefits (development of new knowledge and information to inform programs and policies), confidentiality, participation and assurance of withdrawal if desired, and contact information for any questions the respondent might have. 


\section{Survey Procedure}

The online survey was easy to access via a link provided to the participants, loaded quickly, and was available for mobile devices in addition to computer use. The questionnaire started with a welcome screen introducing the researcher, explaining the study's purpose, the researcher's contact information, and thanking them for their time. An explanation that the survey was confidential, voluntary, had no known risks, and there would be no compensation was provided. A simple font, consistent layout with clear section headings, and the opportunity to go back to previous questions were used throughout the survey. The questionnaire had a title, logical flow with questions organized by similar types, and examples. A progress bar at the bottom of each page informed participants of their progress. A thank you was included at the end of the survey. The survey took approximately 15-20 minutes to complete and was within the recommended length (20-25 minutes).

\section{Participants}

Potential participants or the sample frame in this study were school psychologists as of spring 2020. As noted above, members of the two online professional networks and five state associations were invited to participate; the California Association of School Psychologists (CASP), the largest state association in the nation, as well as the Missouri Association of School Psychologists (MASP), the Nebraska School Psychologists Association (NSPA), CSSP (Colorado Society of School Psychologists), and the Louisiana School Psychologists Association (LSPA).

Nonprobability convenience sampling was used due to time restraints, the convenience of survey completion, and access to the participants. More than 1900 CASP individual members 
work in school districts and private practice. There are currently about 140 members of MASP, just under 300 members of NSPA, and 242 members of LSPA. The two online professional networks had 2500 total members. Demographic information, years of practice, and level of education were obtained. Table 1 below presents the demographic characteristics of the survey participants.

The cover letter and anonymous link to the survey were posted on the CASP, LSPA, and MASP association websites in the spring of 2020. Additionally, the cover letter and survey link were included in the CASP and NSPA newsletter in the spring of 2020. The survey link took participants to the survey. The finalized survey consisted of 52 items (63 with demographics). An individual-based online method was used to collect the data via the online program Qualtrics between May 11th and July 19th, 2020.

\section{Demographics}

A total sample of 97 school psychologists completed the survey (see Table 1). Of the 97 participants, $91.8 \%(n=89)$ identified as female, $5.2 \%(n=5)$ identified as male, and $3.1 \%(n=$ 3) identified as other. The majority of participants, $83.5 \%(n=81)$ identified as White/European American, 13.4\% $(n=13)$ Hispanic/Latinx, 2.1\% $(n=2)$ Black/African American, and other, $1.0 \%(n=1)$. The majority of participants worked in a suburban setting, $54.6 \%(n=53), 25.8 \%$ $(n=25)$ worked in a rural setting, $25.8 \%(n=25)$ worked in an urban setting, and 4.1\% $(n=4)$ worked in a county program.

Most of the participants were from California ( $n=35)$, The percentage of participants who earned a Master's degree was 23.7\% $(n=23)$, Educational Specialist degree 58.8\% $(n=$ 57), and those who had completed a Doctorate comprised $17.51 \%(n=17)$ of the sample. The 
majority of the participants had between 11 and 15 years of experience at $21.6 \%(n=21), 19.6 \%$ $(n=19)$ had $16-20$ years of experience, $20.6 \%(n=20)$ had $0-5$ years of experience, and $19.6 \%$ $(n=19)$ had 6-10 years of experience. Participants with $21-30$ years of experience, $13.4 \%(n=$ 13) and $5.2 \%(n=5)$ had $31+$ years of experience.

The percentage of state credentialed school psychologists was $91.8 \%(n=89)$, nationally certified school psychologists (NCSP) was 48.5\% $(n=47)$, licensed educational psychologists was $14.4 \%(n=14)$, and administrator credential $10.3 \%(n=10)$. The percentage of participants with their BCBA was $1 \%(n=1)$ and one special education director $(1 \%)$. Participants listed the following credentials in addition to those already mentioned; LCPC, private practice, National HSP, licensed clinical psychologist, LPES, ABSNP, LPCC, LSSP, LPA, LPC, LMFT, and LSSP (Licensed Specialist in School Psychology).

Most participants' income was between 51,000 and 75,000, 40.2\% ( $n=39)$, income between $76,000-100,000$ was $30.9 \%(n=30)$, income greater than 100,000 was $17.5 \%(n=17)$, and income between $36,000-50,000$ was $11.3 \%(n=11)$. Sixty seven percent $(n=65)$ were members of their state associations, 58.8\% $(n=57)$ were members of the National Association of School Psychologists, and 23.7\% $(n=23)$ were members of other organizations.

The majority of participants in this study worked at the elementary school level, comprising $80.4 \%(n=78)$ of the sample, $53.6 \%(n=52)$ worked at a middle school, and $44.3 \%$ $(n=43)$ worked in a high school. Fewer participants worked at the preschool level $49.5 \%(n=$ 48), $15.5 \%(n=15)$ worked with birth to preschool age, $16.5 \%(n=16)$ worked in the adult program (18-21), and 5.2\% $(n=5)$ worked with students with significant disabilities, students in 
juvenile detention, alternative middle and high school, prison schools, and one participant was a chief school psychologist.

\section{Table 7}

\section{Sample Characteristics}

\begin{tabular}{lrr}
\hline Characteristic & $\boldsymbol{n}$ & $\boldsymbol{\%}$ \\
\hline Gender & & \\
& 89 & 91.8 \\
Female & 5 & 5.2 \\
Male & 3 & 3.1 \\
Other & & \\
& & \\
Race/Ethnicity & 81 & 83.5 \\
White/European American & 13 & 13.4 \\
Hispanic/Latinx & 2 & 2.1 \\
Black/African American & - & - \\
American Indian or Native American & - & - \\
Asian American & - & - \\
Pacific Islander & 1 & 1.0 \\
Other & &
\end{tabular}

Highest Level of Education

Master's Degree

Educational Specialist

Doctorate

Experience

$0-5$ years

6-10 years

$11-15$ years

16-20 years

21-30 years

$31+$

Income

$$
\begin{aligned}
& <35,000 \\
& 36,000-50,000 \\
& 51,000-75,000 \\
& 76,000-100,00 \\
& >100,000
\end{aligned}
$$

23.7

58.8

17.5

Current Assignment

20.6

19.6

21.6

19.6

13.4

5.2

$\begin{array}{rr}13 & 5.2\end{array}$


$\begin{array}{lll}\text { Birth- Preschool } & 15 & 15.5\end{array}$

$\begin{array}{lll}\text { Preschool } & 48 & 49.5\end{array}$

$\begin{array}{llr}\text { Elementary } & 78 & 80.4\end{array}$

Middle School $\quad 52 \quad 53.6$

High School $\quad 43 \quad 44.3$

Adult Program (18-21) $16 \quad 16.5$

Other $\quad 5 \quad 1.95$

Geographic Area

$\begin{array}{lrr}\text { Rural } & 25 & 25.8 \\ \text { Urban } & 25 & 25.8 \\ \text { Suburban } & 53 & 54.6 \\ \text { County Program } & 4 & 4.1\end{array}$

Location

$\begin{array}{lll}\text { California } & 36 & 37.1\end{array}$

Louisiana $\quad 9 \quad 9.2$

$\begin{array}{lll}\text { Nebraska } & 12 & 12.3\end{array}$

Missouri $\quad 2 \quad 2$

$\begin{array}{lll}* \text { Other } & 38 & 39.1\end{array}$

Credential

$\begin{array}{lll}\text { State Credentialed School Psychologist } & 89 & 91.8\end{array}$

$\begin{array}{lll}\text { Nationally Credentialed School } & 47 & 48.5\end{array}$

Licensed Educational Psychologist $\quad 14 \quad 14.4$

$\begin{array}{lll}\text { Administrator } & 10 & 10.3\end{array}$

Special Education Director $\quad 1 \quad 1$

Other $\quad 16$

*Other states represented: Texas, Florida, Pennsylvania, Kansas, South Carolina, Washington, Iowa, Illinois, Maine, New York, New Jersey, Georgia, Maryland, Ohio, Wisconsin, Massachusetts, New Mexico, \& Tennessee.

\section{Chapter Summary}

This chapter reviewed important components in survey development, outlined the survey methodology for this study, and presented demographic information from the survey. The survey was first reviewed by a small group of university faculty to evaluate the content validity of the survey and was administered as a pilot to 10 school psychologists. Follow up interviews were conducted to gather more specific recommendations to improve the survey presentation, flow, clarity, and organization. Participants provided positive feedback and no problems with the 
survey link that was reported. The final survey was administered online via Qualtrics by sending the link to members of four state associations and two online professional groups.

Demographic information included gender, race/ethnicity, years of experience, level of education, income, credentials, geographic setting, and current educational setting. Overall, 97 school psychologists participated in the survey. The majority of participants identified as female, White/European American, had 11-15 years of experience, worked in suburban areas, and 59.38\% held an Educational Specialist degree. Participants listed several credentials in addition to state and national credentialing. The next chapter presents descriptive results from the survey. 


\section{Chapter Four: Results}

The following research questions guided this study: (1) What are the leadership experiences of school psychologists in practice? (1a) Which leadership opportunities are desired? (1b) Which leadership opportunities are lacking? (2) Which of the organizational principles from the NASP Model part II are in place to support school psychologists? (3) What are the barriers for school psychologists in providing leadership in school settings? (3a) What type of support is needed for school psychologists to lead organizational change within practice settings?

Descriptive statistics were used to analyze the results of the survey.

Respondents were asked to identify the following leadership roles; current practice, roles they see for themselves in the future, and roles lacking in practice. Three types of leadership roles were investigated; the first was a formal role (mentor, lead school psychologist, supervisor), second, a leadership role in two of the three overarching domains from the NASP Practice Model (systems-level services and foundations in service delivery), and thirdly, leadership of school psychologists (supervision and organizational principles). Ninety-nine percent of participants reported either strongly agree or somewhat agree that leadership is important for maintaining the integrity of the profession (75.53\% and $23.40 \%$ respectively). Few participants $(1.06 \%)$ chose the response of neither agree nor disagree.

\section{Leadership Experiences}

\section{Domains of Practice}

Participants were asked about their current practice in each of the ten domains (NASP Practice Model Part I) to determine whether their role is comprehensive or limited to specific domains. The domains with the highest engagement included data-based decision making (87.5\%), consultation and collaboration (99\%), legal and ethical practice (83.3\%), interventions 
and mental health services (76.0\%), family-school collaboration (66.7\%), and preventative and responsive services $(61.5 \%)$. Domains with lower rates of engagement in current practice consisted of interventions and instructional support to develop academic skills (46.9\%), diversity in development and learning (44.8\%), school-wide practices to promote learning (40.6\%), and research and program evaluation (20.6\%).

Most participants somewhat agree $(41 \%)$ that their training and expertise in all school psychology areas were utilized currently; 27\% strongly agree, $1 \%$ neither agree nor disagree, $18.6 \%$ somewhat disagree, and $12.4 \%$ strongly disagree $(M=2.48, S D=1.38)$. Foundational and systems-level domains provide opportunities for school psychologists as leaders to design, implement, and evaluate systems-level services. Two foundational domains, Diversity in Development and Learning (44.8\%) and Research and Program Evaluation (20.8\%) and one systems-level domain, school-wide practices to promote learning (40.6\%), had low to very low engagement rates.

\section{Systems-Level Leadership}

Four matrix questions were developed to identify current leadership practices in systemslevel services (see survey in the Appendix) offering three response choices (Leadership Role/Facilitator, Team Member, None): (a) What best describes your current role in planning and implementing preventative and responsive services (Universal Screening, School-Wide Service Delivery, School-Wide Positive Behavior Support, and Multi-Tiered Systems of Support)? (b) What best describes your interest in planning and implementing preventative and responsive services, if you were given time (Universal Screening, School-Wide Service Delivery, School-Wide Positive Behavior Support, and Multi-Tiered Systems of Support)? (c) What best describes your current role in designing, implementing, and evaluating school-wide 
promotion of learning (Crisis Preparation, Response, and Recovery, Mental Health Services, School Improvement Activities, Development of District Policies and Procedures, Safe and Violence-Free Schools, School-Wide Data Collection and Analysis, and Program Evaluation)?

(d) What best describes your interest in designing, implementing, and evaluating school-wide promotion of learning, if you were given time (Crisis Preparation, Response, and Recovery, Mental Health Services, School Improvement Activities, Development of District Policies and Procedures, Safe and Violence-Free Schools, School-Wide Data Collection and Analysis, Program Evaluation, and Professional Development/Training Staff)? (See Table 8)

\section{Table 8}

Current and Desired Leadership Roles in Designing, Implementing, and Evaluating SchoolWide Promotion of Learning

\begin{tabular}{|c|c|c|c|c|c|c|}
\hline \multirow[b]{2}{*}{ Leadership Service } & \multicolumn{2}{|c|}{ Current } & \multicolumn{2}{|c|}{ Desired } & \multicolumn{2}{|c|}{ No Interest } \\
\hline & $\%$ & $n$ & $\%$ & $n$ & $\%$ & $n$ \\
\hline Universal Screening & 13.68 & 13 & 35.00 & 35 & 8.00 & 8 \\
\hline School-Wide Service Delivery & 10.42 & 10 & 24.75 & 25 & 6.93 & 7 \\
\hline School-Wide Positive Behavior & 16.67 & 16 & 33.01 & 34 & 3.88 & 4 \\
\hline Multi-Tiered Systems of Support & 22.92 & 22 & 43.00 & 43 & 3.00 & 3 \\
\hline $\begin{array}{l}\text { Crisis Preparation, Response, } \\
\text { and Recovery }\end{array}$ & 21.88 & 21 & 31.00 & 31 & 5.00 & 5 \\
\hline Mental Health Services & 32.29 & 31 & 49.00 & 49 & 3.00 & 3 \\
\hline School Improvement Activities & 4.26 & 4 & 13.13 & 13 & 15.15 & 15 \\
\hline $\begin{array}{l}\text { Development of District Policies and } \\
\text { Procedures }\end{array}$ & 8.33 & 8 & 28.57 & 28 & 15.31 & 15 \\
\hline Safe and Violence Free Schools & 4.17 & 4 & 13.40 & 13 & $11 / 34$ & 11 \\
\hline $\begin{array}{l}\text { School-Wide Data Collection } \\
\text { and Analysis }\end{array}$ & 13.68 & 13 & 32.32 & 32 & 14.14 & 14 \\
\hline Program Evaluation & 11.70 & 11 & 24.74 & 24 & 20.62 & 20 \\
\hline $\begin{array}{l}\text { Professional Development/Training } \\
\text { Staff }\end{array}$ & --- & & 42.86 & 42 & 5.10 & 5 \\
\hline
\end{tabular}


More than twice as many school psychologists responded they would like to lead than are currently leading in the four broad areas of systems-level services. Many more school psychologists saw themselves in a future leadership role regarding specific services within systems than have opportunities currently. The two highest interest areas were Professional Development/Training and Mental Health Services. Crisis Preparation, Response, and Recovery, School-Wide Data Collection and Analysis, Universal Screening, School-Wide Positive Behavior, and Multi-Tiered Systems of Support were also high-interest areas. Safe and Violence Free Schools and School Improvement were the two least desired areas for leadership engagement.

\section{Formal Leadership Roles}

Formal leadership roles were identified through two multiple answer checklist questions: (1) In my current role, I hold a formal leadership role in the following areas: mentor first-year school psychologists, supervise interns, lead school psychologist, supervisor of school psychologists, other, or none (2) In which of the following formal leadership roles do you see yourself in the future? (mentor first-year school psychologists, supervise interns, lead school psychologist, supervisor of school psychologists, other, none).

Many participants did not currently hold a formal leadership role $(n=42)$, and some held multiple roles. Of those in formal leadership roles, 23 mentored 1st-year school psychologists, 32 supervised interns, 21 were lead school psychologists, and six held a supervisor role. Additional (other) opportunities for leadership were reported by 11 participants; supervision of practicum students and coordinator (PBIS, 504, Early Childhood, MTSS) (See Table 3). Two participants reported that they were the only school psychologist in the district and one school psychologist covered two districts. 


\section{Table 9}

\section{Current and Desired Formal Leadership Roles}

\begin{tabular}{|c|c|c|c|c|}
\hline \multirow[b]{2}{*}{ Leadership Service } & \multicolumn{2}{|c|}{ Current } & \multicolumn{2}{|c|}{ Desired } \\
\hline & $\%$ & $n$ & $\%$ & $n$ \\
\hline Supervisor & $6.2 \%$ & 6 & $29 \%$ & 28 \\
\hline Supervise Intern & $33 \%$ & 32 & $64 \%$ & 62 \\
\hline Mentor & $23.7 \%$ & 23 & $66 \%$ & 64 \\
\hline Lead School Psychologist & $21.6 \%$ & 21 & $43 \%$ & 42 \\
\hline
\end{tabular}

The response was overwhelmingly positive regarding school psychologists viewing themselves as future leaders in a formal role (mentor, lead school psychologist, supervisor). Over half reported they would like to mentor 1st-year school psychologists $(66 \%)$ and supervise interns (64\%) in the future. Many saw themselves as a lead school psychologist (43\%) and fewer as a supervisor of school psychologists (29\%). Participants (11\%) reported other formal leadership opportunities they desired in the future: Administrator, director of student services, special education director, program specialist, practicum supervisor, school psychological services director, early childhood special education coordinator, and autism coordinator. Very few respondents $(10.4 \%, n=10)$ did not see themselves in a future leadership role.

\section{Graduate Training in Leadership}

Participants answered questions about graduate education in leadership to identify whether a gap exists between training and current practice (See Table 10). 


\section{Table 10}

\section{Graduate Training in Leadership}

\begin{tabular}{|c|c|c|}
\hline Leadership Service & $\%$ & $N$ \\
\hline School-Wide Practices to Promote Learning (system-level services ) & 70.8 & 68 \\
\hline Providing Professional Development/Training Staff. & 81.3 & 78 \\
\hline Program Evaluation & 50.0 & 48 \\
\hline School-Wide Data Collection and Analysis & 72.9 & 70 \\
\hline Mentor First Year School Psychologists & 43.8 & 42 \\
\hline Supervise Interns & 46.9 & 45 \\
\hline Lead School Psychologist & 33.3 & 32 \\
\hline Supervisor of School Psychologists & 20.8 & 20 \\
\hline Other & 4.2 & 4 \\
\hline None & 3.1 & 3 \\
\hline
\end{tabular}

Participants identified formal leadership roles (mentor, lead, supervisor) as areas where they received the least training. School-wide data collection, school wide practices to promote learning, and providing professional development were areas in which most school psychologists received training. Only $3.1 \%(n=3)$ of participants reported that they received no graduate training in the areas of leadership. Additional (other) areas of graduate training reported by participants $(4.2 \%, n=4)$ included mental health program implementation, consultation and collaboration with school leaders and administration, referral team leader, behavioral support, crisis, and curriculum development and alignment. 


\section{Organizational Principles and Leadership}

Participants were asked which service delivery model best described the organization of school psychological services in their current practice (building based, within special education, within student services, separate school psychology department, other) (Table 11).

\section{Table 11}

\section{Organization of School Psychological Services Delivery}

\begin{tabular}{|l|c|c|}
\hline Model of Service Delivery & $\%$ & $N$ \\
\hline $\begin{array}{l}\text { Building Based: school psychologist is based at one or more buildings reporting to the } \\
\text { principal (s) }\end{array}$ & $18.09 \%$ & 17 \\
\hline Within the Special Education Department & $46.81 \%$ & 44 \\
\hline Within the Student Services Department & $18.09 \%$ & 17 \\
\hline Separate School Psychology Department & $4.26 \%$ & 4 \\
\hline Other & $12.77 \%$ & 12 \\
\hline Total & $100 \%$ & 94 \\
\hline
\end{tabular}

The largest number of participants worked within the Special Education department. The least number of participants $(n=4)$ worked in a school psychology department, and an equal number of participants $(n=17)$ were building-based or within the student services department. The most efficacious model, a separate school psychology department (Franklin \& Duley, 2002), was the least common model reported by participants.

Twelve participants chose other and reported variations on the options listed in the survey: within Pupil Appraisal; under supervision of Special Education; under Student Services; within Special Education under the director but assigned to a school and report to that Principal 
for school-based matters; within Pupil Appraisal under Special Education; School Psychology is a separate department of the overall Special Education department; housed at two schools but considered administration and partner to Principal; Special Education Department though, my city is an all charter district. Not all charters choose to hire or contract with a school psychologist, I report to the Principal and Special Education Coordinator; we report to both the building administrator and the Student Services Director (can be confusing); both within the Special Education and Student Services Department (one department in our district) and building based; School Psychology Department within Special Ed Department; Supervised by Director of Special Education but also building based.

\section{Organizational Principles}

To answer question two of the study, respondents were asked which of the organizational principles from the NASP Model part II were in place to support school psychologists. Items referring to the NASP Organizational Principles, Part II of the Model, were presented in a Likert scale response format (strongly agree, somewhat agree, neither agree or disagree, somewhat disagree, strongly disagree) to determine the types of support school psychologists received in practice. There are six principles with several subcategories under each principal. Not all subcategories were included in the survey. Table 12 presents principles one through four and the respondents' results. 


\section{Table 12}

Organizational Principles: Organization and Evaluation of Service Delivery, Climate, Physical, Personnel, and Fiscal Support Systems, and Professional Communication

\section{How Strongly Do You Agree With the Following Statements?}

\section{Organizational Principle 1: Organization and Evaluation of Service Delivery}

School psychological services in my district are planned and delivered on the basis of a systematic assessment of the educational and psychological needs of the students and families in the local community. (NASP Model Part II, 1.1)

\begin{tabular}{|l|c|c|c|c|c|}
\hline & $\begin{array}{c}\text { Strongly } \\
\text { Agree }\end{array}$ & $\begin{array}{c}\text { Somewhat } \\
\text { Agree }\end{array}$ & $\begin{array}{c}\text { Neither Agree or } \\
\text { Disagree }\end{array}$ & $\begin{array}{c}\text { Somewhat } \\
\text { Disagree }\end{array}$ & $\begin{array}{c}\text { Strongly } \\
\text { Disagree }\end{array}$ \\
\hline$n(\%)$ & $26(26.80)$ & $34(35.05)$ & $9(9.28)$ & $17(17.53)$ & $11(11.34)$ \\
\hline \multicolumn{2}{|l}{$M=2.52 S D=1.35$}
\end{tabular}

School psychological services in my district are available to all students (general and special education) on an equal basis and are not determined by a specific funding source or based on eligibility. (NASP Model Part II, 1.2)

\begin{tabular}{|l|l|l|l|l|l|}
\hline$n(\%)$ & $26(26.80)$ & $16(16.49)$ & $25(25.77)$ & $24(24.74)$ & $6(6.19)$ \\
\hline
\end{tabular}

$M=3.22 S D=1.48$

School psychological services in my district are integrated with other school and community services. School psychological and mental health services are provided through a "seamless" system of care. (NASP Model Part II, 1.3)

\begin{tabular}{|l|c|c|c|c|c|}
\hline$n(\%)$ & $4(4.12)$ & $32(32.99)$ & $11(11.34)$ & $31(12.69)$ & $19(19.59)$ \\
\hline$M=3.30 S D=1.23$ & $3(3.09)$ & $25(25.77)$ & $13(13.40)$ \\
\hline $\begin{array}{l}\text { School psychologists in my school district provide a range of services, to include direct and indirect services to } \\
\text { meet the academic and mental health needs of students. (NASP Model Part II, 1.6) }\end{array}$ \\
\hline$n(\%)$ & $22(22.68)$ & $34(35.05)$ & 3.41 & \\
\hline
\end{tabular}


Organizational Principle 2: Climate

My school district promotes cooperative and collaborative relationships and conflicts are resolved in a constructive and professional manner. (NASP Model Part II, 2.1)

\begin{tabular}{|l|c|c|c|c|c|}
\hline$n(\%)$ & $26(26.80)$ & $35(36.08)$ & $16(16.49)$ & $15(15.46)$ & $5(5.15)$ \\
\hline
\end{tabular}

My school district provides an organizational climate in which school psychologists may advocate in a professional manner for the most appropriate services for students and families, without the fear of reprisal from supervisors or administrators. (NASP Model Part II, 2.2)

\begin{tabular}{|l|c|c|c|c|c|}
\hline$n(\%)$ & $29(29.90)$ & $34(35.05)$ & $11(11.34)$ & $15(15.46)$ & $8(8.25)$ \\
\hline
\end{tabular}

My school district promotes a work environment that maximizes job satisfaction and measures of work climate are included in organizational self-evaluation. (NASP Model Part II, 2.3)

\begin{tabular}{|l|c|c|c|c|c|}
\hline$n(\%)$ & $13(13.40)$ & $33(34.02)$ & $15(15.46)$ & $18(18.56)$ & $18(18.56)$ \\
\hline
\end{tabular}

My school district promotes and advocates for balance between my professional and personal life. (NASP Model Part II, 2.4)

\begin{tabular}{|l|c|c|c|c|c|}
\hline$n(\%)$ & $21(21.65)$ & $31(31.96)$ & $17(17.53)$ & $14(14.43)$ & $14(14.43)$ \\
\hline
\end{tabular}

Organizational Principle 3: Physical, Personnel, and Fiscal Support Systems

My school district supports recruitment and retention of qualified school psychologists by advocating for appropriate ratios of school psychologists to students (The current recommended ratio is 1:750). (NASP Model Part II, 3.2)

\begin{tabular}{|l|c|c|c|c|c|}
\hline$n(\%)$ & $19(19.59)$ & $24(24.74)$ & $9(9.28)$ & $22(22.68)$ & $23(23.71)$ \\
\hline$M=3.06 S D=1.48$ \\
\hline
\end{tabular}


Organizational Principle 4: Professional Communication

My school district provides opportunities for school psychologists to communicate with each other about issues of mutual professional interest on a regular basis. For example, organized monthly school psychologist meetings.

(NASP Model Part II, 4.1)

\begin{tabular}{|l|r|r|r|r|c|}
\hline$n(\%)$ & $43(44.33)$ & $34(35.05)$ & $6(6.19)$ & $9(9.28)$ & $5(5.15)$ \\
\hline
\end{tabular}

My district supports collaborative problem-solving approaches with other departments and outside agencies in the planning and delivery of school psychological services. (NASP Model Part II, 4.2)

\begin{tabular}{|l|c|c|c|c|c|}
\hline$n(\%)$ & $24(24.74)$ & $37(38.14)$ & $14(14.43)$ & $13(13.40)$ & $9(9.28)$ \\
\hline
\end{tabular}

My school district ensures that I have access to technology and the training necessary to perform my job adequately and to maintain appropriate and confidential communication with students, families, and service providers within and outside the system. (NASP Model Part II, 4.3)

\begin{tabular}{|l|c|c|c|c|c|}
\hline$n(\%)$ & $41(42.27)$ & $34(36.05)$ & $9(9.28)$ & $10(10.31)$ & $3(3.09)$ \\
\hline
\end{tabular}

Less than half of the respondents reported that school psychological services are integrated with other school and community services and available to all students. Recruitment and retention of qualified school psychologists to maintain an appropriate ratio of student to school psychologist was evenly divided between agree and disagree ( $n=43$ and $n=45)$ with nine responses neither agree nor disagree. Opportunities for professional collaboration and access to technology and training were reported by most school psychologists as strongly agree and agree. 
To determine specific physical, personnel, and fiscal support systems in current practice (organizational principle 3), respondents were provided with a checklist of resources (Table 13).

\section{Table 13}

\section{Organizational Principles in Practice NASP Model Part II, 3.3 and 3.4}

Resources $n(\%)$

Laptop Computer and/or IPAD

$93(95.9)$

Current scoring software

$92(94.8)$

A variety of current and appropriate assessments sensitive to

$90(92.8)$

to the individual needs of students you evaluate (test kits and protocols)

$\begin{array}{ll}\text { Accessible Printer/Fax/Scanner } & 90 \text { (92.8) }\end{array}$

$\begin{array}{ll}\text { Desk } & 89 \text { (91.8) }\end{array}$

Office supplies (paper, stapler, ink, pens, highlighters) 79 (81.4)

$\begin{array}{ll}\text { Bookshelf } & 75 \text { (77.3) }\end{array}$

$\begin{array}{ll}\text { Access to private telephone and office } & 75 \text { (77.3) }\end{array}$

$\begin{array}{ll}\text { Video Conferencing } & 72 \text { (74.2) }\end{array}$

$\begin{array}{ll}\text { Quiet place to assess students with a table and chairs } & 71 \text { (73.2) }\end{array}$

$\begin{array}{ll}\text { Professional Interpreter and Translation services } & 69(71.1)\end{array}$

$\begin{array}{ll}\text { Locking file cabinet } & 62 \text { (63.9) }\end{array}$

Access to virtual evaluation platforms (assessments, rating scales) 61 (62.9)

Advanced technological resources in communication systems $49(50.5)$

and data management systems

Intervention materials 43 (44.3)

Social Emotional, Behavioral, and/or Academic 33 (34)

Tier 2 and Tier 3 evidence-based curriculum materials

Personnel support for documentation of professional development activities 27 (27.8)

$\begin{array}{ll}\text { Access to professional literature } & 22(22.7)\end{array}$

Clerical services (scheduling, proof-reading, preparing materials, etc.) 13 (13.4)

$\begin{array}{ll}\text { Report Writing software } & 12(12.4)\end{array}$

The most commonly referenced resources included a laptop computer and/or IPAD, current scoring software, a variety of current and appropriate assessments, an accessible printer/fax/scanner, and a desk. The least referenced resources included report writing software, 
clerical services, access to professional literature, support for professional development documentation, and evidence-based curriculum materials.

\section{Supervision and Professional Growth}

Participants were supervised by the director of special education $(n=54)$, student services director $(n=20)$, the principal $(n=16)$, the superintendent $(n=6)$, educational coordinator $(n=3)$, and other (program manager, pupil appraisal coordinator, student services lead, special education coordinator, no supervisor, and assistant superintendent). One participant, an owner of a company, contracted with charter schools for school psychology services and was not supervised by anyone in the district. Another participant was the supervisor for the psychology department and supervised by the superintendent. Twenty-three participants were supervised by a current or previous school psychologist who was currently in an administrator position.

The results for Organizational Principle 5, Supervision, and Organizational Principle 6, Professional Development and Recognition Systems, are presented in Table 14.

\section{Table 14}

Organizational Principles: Supervision, Peer Consultation, and Mentoring and Professional Development and Recognition Systems

\section{How Strongly Do You Agree With the Following Statements?}

Organizational Principle 5: Supervision Peer Consultation, and Mentoring

Supervision methods of school psychologists in my district match the developmental level of the school psychologist. For example, experienced school psychologists may meet as a group or utilize peer mentoring whereas first-year school psychologists might meet weekly. (NASP Model Part II, 5.2)

\begin{tabular}{|l|l|l|l|c|c|}
\hline & $\begin{array}{l}\text { Strongly } \\
\text { Agree }\end{array}$ & $\begin{array}{l}\text { Somewhat } \\
\text { Agree }\end{array}$ & $\begin{array}{l}\text { Neither Agree or } \\
\text { Disagree }\end{array}$ & $\begin{array}{l}\text { Somewhat } \\
\text { Disagree }\end{array}$ & $\begin{array}{l}\text { Strongly } \\
\text { Disagree }\end{array}$ \\
\hline$n(\%)$ & $12(12.37)$ & $24(24.74)$ & $17(17.53)$ & $19(19.59)$ & $25(25.77)$ \\
\hline$M=3.22 S D=1.39$
\end{tabular}


My school district allows time for school psychologists to participate in supervision and mentoring. When a supervising school psychologist is not available, the school system ensures that school psychologists are given opportunities and provided funding to seek peer support and supervision through regional, state, or national school psychologist organizations. (NASP Model Part II, 5.3)

\begin{tabular}{|l|l|l|l|c|c|}
\hline & $\begin{array}{l}\text { Strongly } \\
\text { Agree }\end{array}$ & $\begin{array}{l}\text { Somewhat } \\
\text { Agree }\end{array}$ & $\begin{array}{l}\text { Neither Agree or } \\
\text { Disagree }\end{array}$ & $\begin{array}{l}\text { Somewhat } \\
\text { Disagree }\end{array}$ & $\begin{array}{l}\text { Strongly } \\
\text { Disagree }\end{array}$ \\
\hline$n(\%)$ & $17(17.53)$ & $26(26.80)$ & $14(14.43)$ & $22(22.68)$ & $18(18.56)$ \\
\hline
\end{tabular}

$M=2.98 S D=1.39$

My school district has a coordinated plan for the accountability and evaluation of school psychological services. (NASP Model Part II, 5.4)

\begin{tabular}{|l|l|l|l|l|c|}
\hline & $\begin{array}{l}\text { Strongly } \\
\text { Agree }\end{array}$ & $\begin{array}{l}\text { Somewhat } \\
\text { Agree }\end{array}$ & $\begin{array}{l}\text { Neither Agree or } \\
\text { Disagree }\end{array}$ & $\begin{array}{l}\text { Somewhat } \\
\text { Disagree }\end{array}$ & $\begin{array}{l}\text { Strongly } \\
\text { Disagree }\end{array}$ \\
\hline$n(\%)$ & $12(12.37)$ & $27(27.84)$ & $17(17.53)$ & $19(19.59)$ & $22(22.68)$ \\
\hline
\end{tabular}

$M=3.12 S D=1.36$

My supervisor provides professional leadership through participation in school psychology professional organizations and is active in local, state, and federal public policy development. (NASP Model Part II, 5.6)

\begin{tabular}{|l|l|l|l|c|c|}
\hline & $\begin{array}{l}\text { Strongly } \\
\text { Agree }\end{array}$ & $\begin{array}{l}\text { Somewhat } \\
\text { Agree }\end{array}$ & $\begin{array}{l}\text { Neither Agree or } \\
\text { Disagree }\end{array}$ & $\begin{array}{l}\text { Somewhat } \\
\text { Disagree }\end{array}$ & $\begin{array}{l}\text { Strongly } \\
\text { Disagree }\end{array}$ \\
\hline$n(\%)$ & $15(15.46)$ & $21(21.65)$ & $11(11.34)$ & $21(21.65)$ & $29(29.90)$ \\
\hline
\end{tabular}

$M=3.29 S D=1.47$

\section{Organizational Principle 6: Professional Development and Recognition Systems}

My school district provides support (e.g., funding, time, supervision) to ensure that school psychologists have access to continuing professional development at a level necessary to remain current regarding professional practices. (NASP Model Part II, 6.1)

\begin{tabular}{|l|l|l|l|c|c|}
\hline & $\begin{array}{l}\text { Strongly } \\
\text { Agree }\end{array}$ & $\begin{array}{l}\text { Somewhat } \\
\text { Agree }\end{array}$ & $\begin{array}{l}\text { Neither Agree or } \\
\text { Disagree }\end{array}$ & $\begin{array}{l}\text { Somewhat } \\
\text { Disagree }\end{array}$ & $\begin{array}{l}\text { Strongly } \\
\text { Disagree }\end{array}$ \\
\hline$n(\%)$ & $31(31.96)$ & $37(38.14)$ & $10(10.31)$ & $15(15.46)$ & $4(4.12)$ \\
\hline $\mathrm{M}=2 . .22 S D=1.17$
\end{tabular}

About half of the participants reported they somewhat disagree or strongly disagree in the area of supervision as far as their experiences with time for supervision and mentoring, evaluation of school psychologists, and supervision matched with the developmental level of the 
school psychologist. On the other hand, most reported that their school district provided support for continuing professional development and most school psychologists had attended at least 1 to 2 times per year and about half of the participants attended 3 to 5 professional development opportunities over the course of one year (See Table 15). Participants reported attending professional development activities specific to school psychology over the past year $(M=2.07$ $S D=.84)$. Table 16 outlines specific conventions, state and national, that participants attended over the past three years.

\section{Table 15}

Professional Development Over One Year

\begin{tabular}{|l|l|l|}
\hline Frequency & $\boldsymbol{\eta}$ & $\boldsymbol{n}$ \\
\hline $1-2$ times & $26.80 \%$ & 26 \\
\hline $3-5$ times & $44.33 \%$ & 43 \\
\hline More than 5 times & $23.71 \%$ & 23 \\
\hline Never & $5.15 \%$ & 5 \\
\hline Total & $100 \%$ & 97 \\
\hline
\end{tabular}

\section{Table 16}

\section{Convention Attendance in the Past 3 Years}

\begin{tabular}{|l|c|}
\hline Convention & $\boldsymbol{n}$ \\
\hline National Association of School Psychologists (NASP) Convention & 59 \\
\hline State Association Workshops/Convention & 89 \\
\hline American Psychology Association (APA) Convention & 44 \\
\hline
\end{tabular}


Participants reported high attendance at the state conventions and workshops over the past three years. School psychologists appear to be dedicated to professional growth however, what type of recognition do they receive? To determine whether districts provide recognition for professional growth and the types of recognition, a checklist was provided (Table 17).

\section{Table 17}

\section{Types of Recognition for Professional Growth}

\begin{tabular}{|l|c|c|}
\hline Type & $\%$ & $\boldsymbol{n}$ \\
\hline Stipend & $21.9 \%$ & 21 \\
\hline Opportunity to use new skills & $41.7 \%$ & 40 \\
\hline Training others & $45.8 \%$ & 44 \\
\hline Promotion in role & $5.2 \%$ & 19 \\
\hline Move on the pay scale & $19.8 \%$ & 22 \\
\hline Salary & $22.9 \%$ & 3 \\
\hline Other & $2.1 \%$ & 24 \\
\hline None & $25.0 \%$ & \\
\hline
\end{tabular}

The types of recognition most endorsed by participants were the opportunity to use new skills and training others. Promotion in role was the least identified type of recognition (5.2\%). Paid promotion or advancement opportunities were provided in current practice; a Lead School Psychologist position (20.8\%), Supervisor of an Intern (22.9\%), School Psychologist Supervisor (6.3\%), District Level School Psychologist Consultant (3.1\%), and Other, Practicum Supervisor 
and student service leads (4.2\%). Fifty percent of respondents worked for an employer that did not provide paid promotion or advancement opportunities.

Stipends were provided for holding a Doctorate in current practice (29.2\%), Nationally Certified School Psychologist credential (NCSP) (20.8\%), Licensed Educational Psychologist (LEP) license (3.1\%), State and/or National School Psychology association memberships (5.2\%), and $31.3 \%$ for professional development opportunities (conferences, workshops, travel). Thirtyfive participants reported none (36.5\%). The category of Other $(7.33 \%)$, included Clinical License, Lead School Psychologist; Supervisor of Intern, Bilingual certification, BCBA Supervisor, and Licensed Psychologist.

\section{Supports Needed for Leadership}

Participants were given a checklist and asked what type of support they believed to be necessary for leadership in practice. The results are presented in Table 18.

\section{Table 18}

Type of Supports Needed for School Psychologists to Lead Organizational Change Within Practice Settings

\begin{tabular}{|l|c|c|}
\hline Supports & $\%$ & $n$ \\
\hline $\begin{array}{l}\text { Continuing training opportunities specific to leadership (NASP workshops, } \\
\text { Webinars, University workshop, etc.) }\end{array}$ & $81.4 \%$ & 79 \\
\hline $\begin{array}{l}\text { A consortium model for professional collaboration (district, university, } \\
\text { community professionals working together) }\end{array}$ & $55.7 \%$ & 54 \\
\hline A Leadership Institute (Short 2-3 day training opportunity) & $55.7 \%$ & 54 \\
\hline Graduate training specific to leadership (supervision, systems services, etc.) & $44.3 \%$ & 43 \\
\hline Specific School Psychology Leadership Credential & $42.3 \%$ & 41 \\
\hline Leadership Model/Framework & $40.2 \%$ & 39 \\
\hline Other & $8.2 \%$ & 8 \\
\hline
\end{tabular}


The results show the need for ongoing professional development in leadership of different types. The researcher created types of support based on a review of the literature and the important themes of collaboration, cohesiveness, policy, and a theoretical model to guide practice in school psychology leadership.

\section{Barriers to Leadership}

Participants' open-ended comments in response to the question "What are the barriers for school psychologists in providing leadership in school settings?" fell into five main categories: Shortage/Recruitment/Retention, Lack of Administrator Understanding and Support, Model of Service Delivery, Leadership and Opportunity, and Incentive and Funding. Examples of comments are presented below. (Note: The categories were derived by the researcher as general descriptions on a rational/descriptive basis. No specific qualitative theme analysis was conducted.)

\section{Shortage/Recruitment/Retention}

- Large caseloads, a large district and not enough school psychologists and educational diagnosticians.

- No school psychologist wants to be an administrator in our district, they all quit, high turnover in staff

- Difficulty finding school psychology interns

- An overall lack of school psychologists in the field to fulfill leadership roles, I am the only LSSP in a rural district with 6 campuses. We had a part time LSSP for awhile but have not found a replacement though I have expressed willingness to supervise an intern 
- Difficulties in recruitment of certified school psychologists (Prior to me being hired my district used an agency that supplied them with clinical psychologists, so both staff and my supervisor do not understand the training of certified school psychologists)

- We are understaffed so it is hard to find much time to engage in leadership opportunities The biggest barrier for me is my ratio. My site is 1.4 school psychs to 2500 students; I'm there full time. It's hard to manage the counseling and assessment caseload and be able to take a leadership role

- (TIME) My job role has narrowed since I began three years ago. I do not have time to seek out professional activities for professional growth due to case loads

- There are barely enough school psychs to cover the testing needed for students in our large urban district, let alone enough to allow for many leadership opportunities

- Time constraints related to high caseloads. It is difficult to participate in leadership activities when we are unable to meet our legal requirements (i.e. testing, DIS counseling, IEPs, etc.) on a daily basis.

- Time - all of my roles compete with one another for time

- Minimal boundaries to maintain a healthy workload when given additional leadership tasks, on top of current caseload

- Time. I would be hesitant to take in a leadership role unless I was going to have other responsibilities reduced

- Case load, primary duty is assessment and there is little time to do other things

\section{Lack of Administrator understanding and support}

- The director of schools is not interested in the SP being a member of system-wide program planning or service delivery. She acts as though my only role is only to be an evaluator. 
- Lack of understanding regarding role

- Poor school climate that seems-emphases School mental health

- Principals not understanding the role of a school psychologist and not being open to listen mostly impact my ability to be more involved and in taking a lead approach

- Poor understanding of my training and role from my supervisor,

- No one truly understands what we do

- Lack of administrator training and experience

- Our district sees us as test only psychs

- Teachers are not always receptive.

- Attempts to change it are met with animosity and reprisal through less desirable schools.

- Leadership still doesn't understand what we and how our job descriptions

- At my last district it was hard to bring in new ideas and lead when the administrators were not on board and refused to change their ways

- Psychologists are hired by individual charters. Their duties are sometimes limited to test/evaluate/write reports. Other charters employ school psychologists as special education administrators/coordinators. Charter schools generally have very limited knowledge about scope and practice of school psychology

- The Director of Special Ed does not understand the role or value of school psychologists. Limits scope to testing only.

- The politics of the school district

- Administration understanding of our roles and what we can offer not only individually, but on a school-wide/district-wide level. 
- Administrators and colleagues seem to think that all we do is test and place, and we are underutilized in many domains of professional practice. In turn, we are over utilized and pigeonholed into being testing machines. Perpetuated by some training programs, some individuals' misconceptions etc.

- Lack of support from our administrator

- At a site-based level, it will depend on the school principal. Some show respect and support school psychs as experts. While others are less receptive to psychs having a leadership role.

- Lack of knowledge or awareness of school psychological services on the part of educational administrators.

- Micromanaged by excessive layers of administrators who do not have any training in mental health School psychologists are required to attend large amount of meetings but are expected to be fairly quiet and offer few suggestions (oppression)

- Our administrators have no clue what school psychologists do.

- Often requested to "fix" or "put out fires" Teachers are burnt out

- Demands of buildings, lack of release time.... (desire to take another time on)..

- Lack of prioritization of SpEd

- Terrible administration and poor communication across the district. Lack of knowledge about school psychologist skill set (aside from testing). Poor prevention and intervention.

- District has an abundance of administrators who usually make the decisions without input from school psychologists.

- There is a lack of support from district leadership, and after endless self-promotion and positive emails sent by supervisors about the accomplishments or helpful/competent 
things we have done for the district, that leadership still doesn't understand what we and how our job descriptions should reflect from our training.

\section{Service Delivery Model}

- Our district doesn't have systems in place and school psychologist administrators bash their head into a wall trying to make it happen (it never does).

- We are not considered administrators and therefore are not promoted as leaders over other school psychologists. We are not truly a part of management

- Lack of unified approach across school, each school within the district does many things their own way. For Psychs that work at multiple sites, there are different methods of organization, which puts the psychs on different levels and different responsibilities at each site.

- Not part of my districts model

- We are viewed as special education evaluators first and other responsibilities are treated as additional activities. I think this model is outdated. Assessment is an important piece but is far from the only option of service provision.

- The role is testing first, consultation second.

- We're Undervalued. No one understands our training, what we actually do, or what we are capable of doing. I have only had a school psychologist as a supervisor briefly (maybe a total of 5 years) over 26 years. There is a bias that only teachers can supervise other teachers. All PD and recognition programs are designed for teachers. A resource officer or counselor will be given a private, large enough office before a psychologist! We're just testers!! 
- My district is large (approximately 45 psychologists). Many of us don't know all of the psychologists.

- Lack of multi-tiered supports

- The gap between Iowa AEA's and districts. School Psychologists are hired by the AEA's and then assigned to districts. We may have the skills for leadership roles within districts and can often serve on teams, but it's complex because of the relationship between Iowa AEA's and school districts.

- Lack of district understanding and desire to understand the role. Reduced interest and value placed on special education as a whole as well as within the larger educational system. Lack of clear leadership for education as a whole. No policies or procedures in place or desired by admin. (and leadership category)

- Lack of appropriate service delivery in schools, always grouped with sped. No prevention or systems wide services. Always responsive and looking at deficits

- My organization is very compartmentalized. This makes it difficult to access individuals and programs that may be relevant to current needs that I have or see that the children I work with might benefit from. Additionally, making contact with individuals in other divisions is actively discouraged

- Support to try something different than the "standard way" thought to be done in education

- Level of support needs intensive

\section{Leadership and Opportunity}

- No framework or training provided for advancement in leadership positions, or incentives to take on new responsibilities in leadership roles

- Training for the role 
- No formal training

- Many leadership roles have "teaching requirements" Interest of others to learn and grow can be minimal

- Leadership is not well versed in SPED regulations

- 5 positions supervising a group of 180 Psychologists

- No current position

- To be an experienced \& knowledgeable school psychologist does not require a PhD.

Many times in schools, however, they want "leaders" to have that credential. It's not fair that we get overlooked for simply not having a PhD. I feel that sometimes real, practical experience trains you better than additional degrees. And if there is no incentive within the district to pursue an additional degree (i.e., chance of promotion, additional stipend, etc.), it's not always worth the time you would put into going back to school.

- Leadership usually are not school psychs. Our director is an ex-school counselor and our coordinators were SPED teachers.

- Our district has a policy that administrators must have at least two years of teaching experience.

- No district supports in place (no leadership options such as lead psychologist, mentor or supervisor roles), no stipend for anything

- Those is leadership positions do not provide a platform

- As an executive board member and committee chair for our state SP association, I have created amazing leadership opportunities. My district has also been supportive of this work.

- Consistent leadership goals and interests within school psych team 
- Lack leadership opportunities provided and interest in areas of expertise shared by school psychologist by district and school site level administrators

- In my district, those positions are kind of clique-y and that doesn't fit with my personality or professional style so I choose to avoid them

- Depends on time in a building and climate if someone is willing to let you lead

- Lack of confidence Lack of opportunity to break into already established hierarchies

- No opportunity for advancement or administrative/leadership roles.

- Opportunities are available but have to be initiated by the school psychologist

- Small single-school school district with 6 administrators (superintendent, director student services, director C\&I, (2) co-principals). I am the only school psychologist in the school/district on a Child Study Team with a Social Worker and Learning Consultant. My team consults and works directly with administration on specific problems/projects, but there are few opportunities or need for overarching leadership in a top-heavy district. I am completing my doctorate in Educational Leadership and have included myself in various meetings under the role of "administrator intern".

- I attend SPED team meetings and participate in those, but I'm rarely involved in the school-wide supports/announcements from admin \& counselors.

- Leadership opportunities tend to be offered to the same school psychologist each year without any discussion of opportunities for others to have that role

\section{Incentive and Funding}

- Not given extra time or pay

- There is no funding despite advocacy efforts.

- Very limited funds available for professional development 
- Most significant training is paid for by personal funds

- All PD comes out of our pockets and is self-directed. The district does not invest in school psychologists. Our NCSP stipend is a fraction of what teachers get for their National Boards Certification.

- Not getting paid for mentoring is a deterrent. Being a good mentor is time intensive and we get no compensation, nor do we have a lighter caseload.

\section{Chapter Summary}

The results outlined in this chapter provided information regarding the current and desired formal and informal leadership experiences of school psychologists. The Organizational Principles from the NASP model create the foundation and environment that either supports or diminishes school psychologist leader practitioners and the services they provide. Service delivery models create the structure within which school psychologists' function, and supervision from within the system of service delivery was found to be a factor for school psychologists in practice. School psychologists in this study appear to be dedicated to professional growth and development. In addition, participants in this study hope to be leaders in the future; however, many lack opportunities and do not feel supported.

Opportunities identified to support leadership included professional development, leadership institute, consortium and collaboration, graduate training, and credential development in leadership. Barriers to leadership included a lack of opportunities, misunderstanding of role and expertise, lack of service delivery model and leadership in schools, shortage of school psychologists, and a lack of time and incentive for taking on a leadership role. The next chapter will discuss the results, strengths and limitations of the study, and implications for practice and future research. 


\section{Chapter Five: Discussion}

\section{Summary of the Findings}

To more fully understand leadership in school psychology practice, this study explored the various components that potentially work together to promote or inhibit leadership in professional practice. The extant literature specific to school psychology leadership is limited to exploring existing theoretical perspectives and identifying characteristics of leadership. The foundation of this study, the NASP Practice Model, provided an existing framework to explore the questions of this study.

The study focused on three components; the ten domains of practice (Part I of the Model) and whether school psychologists were engaged in leadership through systems-level and foundational domains or formal roles; Second, an examination of whether Organizational Principles (Part II of the NASP Model) were present in practice to support school psychologists; And finally, any barriers that inhibit leadership in practice. A survey was created based on the NASP Practice Model Part I and Part II, and data were collected from 97 participants via an anonymous online survey. Descriptive statistics were used to analyze the data. This chapter is a discussion of the results, strengths and limitations of the study, and future directions.

\section{Current and Desired Leadership Roles}

\section{Research Question 1: What are the leadership experiences of school psychologists in practice? Research Question 1a: Which leadership opportunities are desired?}

The results from this study indicated that the majority of school psychologists viewed themselves as leaders, which is consistent with the assertion that school psychologists are leaders in practice (Augustyniak, 2017, Shapiro, 2006, Ysseldyke et al., 2006). One of the most interesting findings indicated that $90 \%$ of participants saw themselves holding some type of 
formal leadership role in the future. In a comparison of participants' current leadership roles (formal or informal) and their desired leadership roles in the future, increases were seen across all areas revealing that school psychologists would like to be more involved in leadership.

In contrast to the number of school psychologists who hold a formal role as a mentor, intern supervisor, or lead school psychologist ( $n=23, n=32, n=21$ respectively), more than half of respondents saw themselves as a mentor or supervising interns in the future ( $n=64$ and $n$ $=62$ respectively), and twice as many $(n=42)$ stated they would like to hold a lead school psychologist position. The greatest difference between current and desired practice was the position of supervisor of school psychologists. Only six participants held a supervision position, yet 28 school psychologists saw themselves as a supervisor in the future.

Participants reported they practice in a variety of domains in their current role. Data based decision making (87.5\%), consultation and collaboration (99\%), legal and ethical practice (83.3\%), interventions and mental health services (76\%), preventative and responsive services (61.5\%), family-school collaboration (67\%), and instructional support to develop academic skills $(46.9 \%)$ were identified as the most engaged roles in practice.

\section{Research Question 1b: Which leadership opportunities are lacking?}

Considered informal leadership opportunities for the purpose of this study, two of three foundational domains (Research and Program Evaluation and Diversity in Development and Learning) and one of three systems-level domains (school-wide practices to promote learning) were low on engagement in practice. The least endorsed domain, research and program evaluation, was endorsed by less than $21 \%$ of participants. Furthermore, leadership was lacking in other areas of systems-level services, including crisis preparation and response, school 
improvement, development of district policies and procedures, safe and violence-free schools, school-wide data collection and analysis, and program evaluation.

The results of this study confirmed that school psychologists' role is somewhat limited to a few specific domains; data-based decision making (to include testing), consultation and collaboration, and legal and ethical practice. Participants somewhat agree (40.38\%) and strongly agree (26.92\%) that their training and expertise in all areas of school psychology were utilized in their current position. The results indicated that four of the ten domains were endorsed by approximately $50 \%$ or fewer participants, evidence that school psychologists are limited in practice. Informal leadership opportunities in systems-level and foundational domains were three of the lowest engagement rates indicating a lack of leadership opportunities in practice.

Respondents appeared to be qualified to fulfill their job role. More than $77 \%$ of school psychologists who responded to the survey earned advanced degrees beyond a Masters, more than $70 \%$ reported they received graduate training in systems-level domains with the exception of program evaluation (50\%), and $92 \%$ were credentialed by their state department of education. Almost half of school psychologist participants completed the optional requirements for the national certification (NCSP), and between 10 and $20 \%$ held additional certification or license. Sixty-seven percent were members of their state school psychological association, and 59\% were members of the national association (NASP). Only $3 \%$ reported no graduate training in the leadership roles outlined in this study. 


\section{Research Question 2: Which of the Organizational Principles from the NASP Model}

\section{Part II are in place to support school psychologists?}

The results of this study indicated that most school psychological service delivery was conducted through a special education department (46.81\%), and only 4 participants worked within a separate school psychology department, which has shown efficacy in service delivery. Organizational Principles that were endorsed by school psychologists included professional communication $(n=43)$ and access to technology $(n=41)$. Few school psychologists received financial recognition for professional growth, and $45.8 \%$ provided training to others as a form of recognition. School psychologists $(44.33 \%)$ attend professional development 3-5 times per year, indicating their dedication to professional growth.

Results indicated several Organizational Principles were not present for school psychologists in professional practice such as supervision, physical, personnel, and fiscal support, climate, and organization and evaluation of service delivery. Very few school psychologists received appropriate supervision. Supervision to match the developmental level of the school psychologist ( $n=12$ strongly agree), time for supervision and mentoring $(n=17$ strongly agree), and professional leadership of supervisor ( $n=15$ strongly agree). School psychological services integrated with other school and community services $(n=4$ strongly agree), a work environment that maximizes job satisfaction and measures work climate $(n=13$ strongly agree), and retention and recruitment of qualified school psychologists $(n=19$ strongly agree) did not appear to be representative supports in practice.

School psychologists reported that organizational principles are not implemented in the school setting, as outlined in the NASP Practice Model, which most likely impacts their ability to provide services. 


\section{Research Question 3: What are the barriers for school psychologists in providing}

\section{leadership in school settings?}

Barriers reported by participants were grouped into five categories; (a) shortage,

recruitment, \& retention, (b) leadership opportunities, (c) model of service delivery, (d) lack of understanding and support, and (e) incentive and funding. All five of these themes fall under Organizational Principles outlined by NASP to support school psychological service delivery. Organizational Principles appeared to have an impact on the participants' level of job satisfaction, domains of practice, caseloads, and opportunities for professional growth and leadership.

The results of this study revealed that only four school psychologists worked within a school psychology department, which is problematic considering it was the model in the extant literature that best supports service delivery. The majority of participants worked within a special education department. Considering the broad scope of training, including the ten domains of practice, working in a specialized department such as Special Education could inhibit the provision of comprehensive and preventative services. Bound by a special education department and budget restraints, school psychologists could be confined to assessment and compliance for special education rather than services for all students, limiting informal systems-level leadership opportunities such as universal screening and prevention.

Apart from service delivery, supervision was the organizational principle that stood out. The study outlined four guidelines for supervision from the NASP Practice Model. According to NASP, supervisors should be a school psychologist with a minimum of 3 years of experience. The results of this study indicated that only 23 of those in current practice were supervised by a 
school psychologist, and the majority of participants were supervised by the director of special education $(n=54)$. Additionally, principals, coordinators, student services directors, superintendents, and program managers provided supervision to school psychologists. No supervision was also reported.

Furthermore, almost half of the participants responded that supervision was not matched to their developmental level $(n=44)$ or that supervisors had a coordinated plan for the evaluation of school psychologists $(n=41)$. Approximately half of the participants $(n=50)$ reported that their supervisor did not provide professional leadership through participation in professional organizations or active local, state, or federal policy development. The fourth supervision guideline recommends that school psychologists are provided time to participate in supervision. The results indicated that not all participants received time for supervision (strongly disagree, $n$ $=18$ and somewhat disagree, $n=22$ ).

The responses regarding Organizational Principle 3: Physical, Personnel, and Fiscal Support Systems presented an interesting finding. The results were evenly divided pertaining to the recruitment and retention of qualified school psychologists and appropriate ratios of school psychologists to students (1:750). Forty-three respondents agree (strongly and somewhat), whereas 45 disagree (strongly and somewhat) that the school district advocated for appropriate ratios of school psychologists to students. This would appear to be an area of needed regulation and policy development as there may be an unnecessary and problematic variance from location to location. Without school psychology leaders to oversee the recruitment and retention of qualified professionals, those in practice could bear a heavier load, potentially leading to burnout. Furthermore, it seems indisputable that all school psychologists should have adequate 
resources to perform their job, though many reported a need for basic amenities such as a bookshelf, private office and phone, locking file cabinet to secure confidential student files, and translation services. Few of the participants had access to clerical services $(n=13)$.

Lastly, there was little incentive for school psychologists to advocate for their role and take on more responsibility in practice. Twenty-five percent of the participants did not receive any type of recognition for professional growth activities (stipend, promotion, salary, opportunities to train others), only $5 \%$ of the participants received a promotion for professional growth, and less than half of the participants reported opportunities to train others. Without the implementation of organizational principles in schools, opportunities for leadership in the

provision of services could be impacted. School psychologists in practice appear to be invisible regarding opportunities for leadership and recognition offered to other professionals.

\section{Research Question 3: What type of support is needed for school psychologists to}

\section{lead organizational change within practice settings?}

School psychologists working in systems without the NASP Practice Model organizational principles in place face significant challenges. There is a need for appropriate supervision, service delivery options, recruitment and retention of school psychologists, recognition, and professional growth opportunities in leadership. When comparing graduate training in leadership to current practice, $20 \%$ of respondents reported that they received graduate training in supervision though only $6 \%$ held a supervisor role, and 33\% received training as a lead school psychologist compared to $22 \%$ who held a lead school psychologist position. Considering future training, out of six leadership educational opportunities presented, most of the participants $(81 \%)$ reported they would participate in continuing training 
opportunities specific to leadership (e.g., NASP workshops, Webinars, University workshops). Approximately half of the participants reported they would participate in a leadership institute

(56\%), graduate training (44\%), and a consortium for professional collaboration (56\%). Fortytwo percent reported interest in a leadership credential specific to school psychology, and $40 \%$ saw a need for a leadership model or framework.

\section{Study Strengths}

This study was unique in terms of how leadership in practice was framed. Rather than attempting to match school psychology with existing leadership theories or identifying important leadership characteristics, the researcher identified strengths and barriers in current practice utilizing the existing NASP Practice Model with the assumption that school psychologists are leaders. The inclusion of various components of practice, such as organizational support and supervision, was another strength of the study and provided a framework for thinking about school psychology leadership in practice, not only the influence of leadership on systems but the impact of systems and service delivery on leadership.

Furthermore, the researcher attempted to define two types of leadership roles (formal and informal leadership) based on the NASP Practice Model. Role clarification was important to recognize different types and opportunities for leadership in practice. A formal role or typical leadership role (administrator, coordinator) is common in education, whereas collaborative leadership opportunities, working with teams to problem solve, implement, and evaluate also require leadership. Informal roles such as school psychology leadership in systems-level services may not be well understood in education. Thus, this was the first study to directly examine 
school psychologists' leadership roles and perceived barriers to undertaking leadership roles in the school setting.

\section{Study Limitations}

There are several limitations regarding sample selection and the use of an online format. The sample was restricted to four state associations, leaving out school psychologists who were not members of their state associations other than those participating through online professional communities (Evidence-Based School Psychology and Said No School Psychologist Ever). State associations chosen for the study were limited to the Midwest, south, and western United States, excluding school psychologists in northern and eastern states.

The online format may not have been available to all participants depending on their ability to access technology. Also, online formats often show only one part of the survey at a time, and without access to the whole survey, participants may judge the survey as not being beneficial for them based on the first few questions. Additionally, the survey neglected to ask about work status (full-time, part-time), which may have had a bearing on the results.

\section{Implications for Future Research and Practice}

Leadership as a specific topic in the school psychology literature is scarce, and there is a pressing need for further research. This study was an effort to identify leadership opportunities and Organizational Principles (NASP Practice Model) that support school psychological comprehensive service delivery in practice. This study identified several areas of future research. First, a more representative sample would provide additional information about the status of leadership in practice. An investigation of administrators' knowledge of school psychology leadership in practice, whether collaborative leadership practices exist in schools, and if so, the 
model of implementation that supports collaborative practices should be explored. Others' perceptions and understanding of school psychologists' training, experience, and model of service delivery could provide insight into the promotion or lack of school psychology leadership in practice.

Additionally, more information is needed regarding graduate training in leadership and which specific areas of leadership are needed or desired (e.g., formal and informal roles, program evaluation, systems change). Few school psychologists reported having training in formal leadership roles (supervisor, mentor, lead school psychologist, supervise intern). To provide the type of supervision recommended by NASP, it would be pertinent to learn more about supervision in practice and the impact it has on leadership opportunities.

Expanding on this study, researchers could identify whether the NASP Model is relevant to leadership or if a separate or integrated leadership model is needed. There were several options for training presented in this study. Further research could provide information about the type of professional development that would increase leadership opportunities in practice settings (e.g., graduate training, leadership institute, consortium, collaboration, credential, or leadership model).

The difference between leadership in practice compared to leadership at the state and national levels (differences, similarities, hierarchical or collaborative) and how or if they complement each other could inform leadership in practice. In addition, a question for future research is whether school psychologists are represented in leadership within state departments of education and how leadership at the state level impacts the role and service delivery of school psychologists in professional practice. 
Policy is another area of future research and important for credentialing at the state and national levels, as well as determining specific roles and responsibilities of school psychologists as leaders in practice. What role does credentialing play for leadership opportunities in practice? The national certificate in school psychology (NCSP) is an additional certification requiring additional professional development, an exam, and a fee. It may be worth investigating whether the NCSP credential represents leadership or promotes school psychology leadership roles in practice. Furthermore, credentialing bodies, typically state departments of education, might examine whether school psychologists are involved in policy regarding credentialing, recognizing the NCSP, and leadership in credentialing of school psychologists. The inclusion of the NCSP for the credentialing process could potentially lead states to accept the national credential as a stand-alone credential that encompasses all domains of practice, including leadership capabilities of school psychologists, and ultimately could impact the way services are provided, not to mention the ease of credentialing for school psychologists who move to other states.

Professionals in the field have long been advocating for change, and the lack of leadership in the implementation of school psychological service delivery may be the most pressing issue. Research in organizational change, systems leadership, and collaborative leadership models to increase school psychologists' ability to participate fully in their role is needed.

\section{Implications for Practice}

There are several models of leadership put forward in the literature, including Transformational and Transactional leadership (Bass, 1985), Servant leadership (Greenleaf, Senge, Covey, \& Spears, 2002), and Distributed leadership. Servant leadership focuses on 
creating opportunities and serving others, whereas Transformational leadership focuses on shared values, high ethical standards, and empowerment of others. Distributed leadership or coleadership is viewed as a collective responsibility, and Transactional leadership aligns with the administration of services, specific directives, and rewards for completing the expected directives.

The results of this study support the Transformational leadership model. School psychologists are called to advocate and empower others, have high ethical standards, and collaborate with others in the school and community settings to bring about change and positive school environments. School psychologists' graduate-level education and ongoing professional development support their expertise in problem-solving and systems-level service delivery. Ongoing professional development, policy change, and implementing organizational principles in school settings require school psychologists' leadership for appropriate school psychological service delivery.

School psychologists in practice benefit from collaborative and cohesive practice (Organizational Principle 4: Professional Communication). Opportunities to communicate with other school psychologists on a regular basis through monthly meetings and collaboration between departments and outside organizations or agencies was the area in which the majority of participants felt supported. The supports endorsed by respondents were creating a balance between personal and professional life (Organizational Principle 2: Climate), promoting cooperative and collaborative relationships, and a positive organizational climate in which school psychologists can advocate for appropriate services for students. Building relationships with supervisors and other leaders in practice is important and can be challenging depending on the other professionals' level of education and understanding of school psychologists' roles. 
At the time of this writing, COVID 19 was rampant globally, and school personnel at district, state, and national levels were scrambling to discover new options for education. Possibly more than ever before, the need for effective leadership is incontrovertible. Without direction or guidance, chaos could easily transpire. The fast spread of the virus brought extreme measures such as closing schools and transitioning to online learning. As problem solvers, school psychologists have the skills needed to research, plan, implement, and evaluate new learning opportunities for students. School psychologists could lead the charge with mental health support, a critical need. Communication is key, and school psychologists have expertise in collaboration and consultation with school and community leaders. School psychologists need to be at the decision-making table, though rather often, they are left waiting in the wings.

\section{Conclusion}

School psychology leadership is a dichotomy. Some say school psychologists are leaders and well prepared to lead (Augustyniak, 2017; NASP, 2010; Riley, 1996; Shapiro, 2007; Shriberg et al., 2006; Smith, 2012), while others see the need for a leadership model and training (Augustyniak, 2017). In addition, some view leadership as a formal role reserved for those in an administrative position or outside of practice settings. An example of this would be NASP's leadership development committee; it would appear that the committee's scope is limited to state and national association leadership development and does not include school psychologists in professional practice (Malone, McCullum, \& Bhatt, 2016).

Not only is the concept of leadership inconsistent in the field, but extant literature also establishes that school psychologists lack opportunities to engage in the basic domains of practice in which they are trained. As an expectation to more fully engage in their intended role, school psychologists are called to advocate. School psychologists without a formal leadership 
role often lack decision-making power, which could create challenges when expected to advocate for themselves. School psychologists have the expertise, and schools need leadership in data-based decision-making, systems-level change, program evaluation, and preventative services for students. When school psychologists are not able to provide comprehensive services, then it follows that students are not receiving the benefits of those services and, equally important, organizations are not learning from their hired employee's expertise. Besides the investment of time and financial resources for graduate training, school psychologists could be placing themselves in a position of oppression when working for organizations that do not recognize, appreciate, or utilize their education and expertise.

The results from this study indicated that most school psychologists aspire to leadership roles and appear committed to professional growth, as evidenced by their ongoing commitment to professional development, level of education, and credentials. The lack of opportunities to advance in the profession is a glaring need. A model for service delivery in schools with embedded leadership opportunities and recognition that matches the level of education, dedication, and contribution to practice will be important for practicing school psychologists. The lack of opportunities in practice could be contributing to high levels of burnout and attrition in the field at a time when there is a shortage and need for school psychologists. This study focused on leadership in professional practice rather than state and national level leadership; however collaborative efforts could be critical in an effort to create organizational change and provide the most equitable service delivery for students. 


\section{References}

Alwin, D. F. (Ed.). (1977). Survey design and analysis. Beverly Hills, CA: Sage Publications.

Annan, J., \& Ryba, K. (2013). Networks of professional supervision. School Psychology Quarterly, 28(2), 170-182.

Armistead, L. D., Castillo, J. M., Curtis, M. J., Chappel, A., \& Cunningham, J. (2013). School psychologists' continuing professional development preferences and practices. Psychology in the Schools, 50, 415-432.

Armistead, L. D., \& Smallwood, D. (2010). Making a Career of School Psychology. A Practical Guide to Building Professional Competencies in School Psychology, 245. https://doiorg.libproxy.chapman.edu/10.1007/978-1-4419-6257-7_15

Augustyniak, K. (2014). Identifying and cultivating leadership potential in school psychology: A conceptual framework. Psychology in the Schools, 51(1), 15-31. doi:10.1002/pits.21731

Augustyniak, K., Kilanowski, L., \& Privitera, G. J. (2016). Perceptions of leadership practices of school psychologists: Views of multiple stakeholders. School Psychology Forum, 10(4), 371-385. Retrieved from http://www.nasponline.org/publications/periodicals/spf/volume-10/volume-10-issue-4(winter-2016)/perceptions-of-leadership-practices-of-school-psychologists-views-ofmultiple-stakeholders

Bass, B. M., \& Avolio, B. J. (2004). Multifactor Leadership Questionnaire (3rd ed.). Menlo Park, CA: Mind Garden.

Bass, B. M., \& Steidlmeier, P. (1999). Ethics, character, and authentic transformational leadership behavior. The Leadership Quarterly, 10(2), 181-217. 
Benson, A. J., \& Hughes, J. (1985). Perceptions of role definition processes in school psychology: A national survey. School Psychology Review, 14(1), 64-74.

Boccio, D. E., Weisz, G., \& Lefkowitz, R. (2016) School Psychologists' Management of Administrative Pressure to Practice Unethically. Journal of Applied School Psychology, 32:(4), 313-328, DOI: 10.1080/15377903.2016.1207737

Boccio, D., Weisz, G., \& Lefkowitz, R. (2016). Administrative pressure to practice unethically and burnout within the profession of school psychology. Psychology in the Schools, 53(6), 659-672. doi:10.1002/pits.21931

Boccio, D. E. (2015). Preventing and resisting administrative pressure to practice unethically [Ethics advisory bulletin]. Bethesda, MD: National Association of School Psychologists.

Booker, R. (2013). Leadership of education psychological services: Fit for purpose? Educational Psychology in Practice 29(2), 197-208.

Brown, M.B., Swigart, M. L., Bolen, L., M., Hall, C. W., \& Webster, R. T. (1998). Doctoral and nondoctoral practicing school psychologists: Are there differences? Psychology in the schools 35(4), 347-354.

doi:10.1002/(SICI)1520-6807(199810)35:4<347::AID-PITS5>3.0.CO;2-9

Burke, J.P., Hayworth, C.E., \& Brantley, J.C. (1983). School-psychological providers: A national survey of state departments of education. Psychology in the Schools 20. doi:10.1002/1520-6807(198304)20:2<191::AID-PITS2310200210>3.0.CO;2-E

Burns, M. K. (2013). Contextualizing school psychology practice: Introducing featured research commentaries. School Psychology Review, 42(3), 334-342. Bethesda, MD: The National Association of School Psychologists.

Burns, M.K., Preast, J.L., Kilpatrick, K.D., Taylor, C.N., Young, H., Aguilar, L., Allen, A., 
Copeland, C., Haider, A., \& Henry, L. (2017). Leadership Theory for School Psychologists: Leading for Systems Change. Communique, 46(2), p1, 30-31. Bethesda, MD: The National Association of School Psychologists.

Cassens, A. (2008). Leadership development for the mental health professional of tomorrow: A proposed model for training graduate students in psychology to become effective and competent leaders. Retrieved from http://search.proquest.com/openview/3f4ade6a31ccb5c35119c5fe7408dc8f/1?pqorigsite $=$ gscholar $\& \mathrm{cbl}=18750 \&$ diss $=\mathrm{y}$

Castillo, J. M., Curtis, M. J., \& Tan, S. Y. (2014). Personnel needs in school psychology: A 10year follow-up study on predicted personnel shortages. Psychology in the Schools, 51, 8 $32-849$.

Castillo, J.M., Wolgemuth, J.R., Barclay, C., Mattison, A., Tan, S., Sabnis, S., Brundage, A., \& Marshall, L. (2016). A qualitative study of facilitators and barriers related to comprehensive and integrated school psychological services. Psychology in the Schools, 53(6), 641-658. doi:10.1002/pits.21932

Castillo, J. M., Arroyo-Plaza, J., Tan, S. Y., Sabnis, S., \& Mattison, A. (2017). Facilitators and barriers to model school psychological services. Psychology in the Schools, 54, 152-168.

Conoley, C. W., Conoley, J. C., \& Reese, R. J. (2009). Changing a field of change. Journal of Educational \& Psychological Consultation, 19(3), 236-247.

Conoley, J.C., \& Gutkin, T. (1995). Why didn't—why doesn't—school psychology realize its promise? Journal of School Psychology, 33(3), 209-217. Retrieved from https://www.sciencedirect.com/science/article/pii/002244059500009B

Cowen, K. C. (2012). Communication matters. Communique, 41(2), 17-18. Bethesda, MD: The 
National Association of School Psychologists.

Cowan, K. C. (2012). Stepping up in the Montgomery public schools. Communique, 41(2), pg. 17-18. Bethesda, MD: The National Association of School Psychologists.

Curtis, M. J., Castillo, J. M., \& Gelley, C. (2012). School psychology 2010-part 1:

Demographics, employment, and the context for professional practices. Communiqué, 40(7), 28-30.

Curtis, M. J., Grier, J. E. C., \& Hunley, S. A. (2004). The changing face of school psychology: Trends in data and projections for the future. School Psychology Review, 33, 49-66.

Curtis, M. J., Hunley, S. A., \& Grier, J. E. (2004). The status of school psychology: Implications of a major personnel shortage. Psychology in the Schools, 41, 431-442.

Curtis, M. J., \& Stollar, S. A. (1996). Applying principles and practices of organizational change to school reform. School Psychology Review, 25(4), 409-417.

Dailor, A. N., \& Jacob, S. (2011). Ethically challenging situations reported by school psychologists: Implications for training. Psychology in the Schools, Vol. 48(6). Wiley Periodicals, Inc. DOI: 10.1002/pits.20574

DeVellis, R. F. (2012). Scale development theory and applications. Thousand Oaks, CA: Sage Publications, Inc.

Desrochers, J. (Ed.). (2012). A framework for the personnel evaluation of school psychologists utilizing the NASP practice model. Communique, 41(3), Handout.

Dwyer, K. P., \& Gorin, S. (1996). A national perspective of school psychology in the context of school reform. School Psychology Review, 25(4), 507-511.

Enz, A., \& McCullum, C. (2018). Securing a (new) seat at the table: Distributed leadership and school psychologists. Communique, 46(6). Bethesda, MD: The National Association of 
School Psychologists. Retrieved from www.nasponline.org

Erchul, W. P., \& Raven, B. H. (1997). Social power in school consultation: A contemporary view of French and Raven's bases of power model. Journal of School Psychology, 35, $137-171$

Ervin, R. A., Schaughency, E., Goodman, S.D., McGlinchey, M. T., \& Matthews, A. (2006). Merging research and practice agendas to address reading and behavior school wide. School Psychology Review, 35(2), 198-223.

Fagan, T. K. (1986). School psychology’s dilemma: Reappraising solutions and directing attention to the future. American Psychologist, 41(8), 851-861.

Fagan, T. K., \& Wise, P. S. (1994). School psychology: Past, present, and future. New York: Longman.

Fagan, T. K. (2002). School psychology: Recent descriptions, continued expansion, and an ongoing paradox. School Psychology Review, 31(1), 5-10.

Fairchild, T.N., \& Seeley, T.J.(1996). Evaluation of school psychological services: A case illustration. Psychology in the Schools 33. Retrieved from doi:10.1002/(SICI)15206807(199601)33:1<46::AID-PITS6>3.0.CO;2-U

Fink, A. \& Kosecoff, J. (1998). How to conduct surveys; A step-by-step guide. Thousand Oaks, CA: Sage Publications, Inc.

Fish, M. C., \& Jain, S. (1988). Using systems theory in school assessment and intervention: A structural model for school psychologists. Professional School Psychology, 3(4), 291-300.

Forman, S.G., Shapiro, E.S., Codding, R.S., Gonzales, J.E., Reddy, L.A., Rosenfield, S.A., Sanetti, L. M. H., \& Stoiber, K. C. (2013). Implementation science and school 
psychology. School Psychology Quarterly, 28(2) 77-100.

Forman, S., Smallwood, D., \& Nagle, R. (2005). Organizational and individual factors in bringing research to practice: What we know, where we need to go. Psychology in the Schools, 42(5), 569-576. doi:10.1002/pits.20092

Fowler, F. J. Jr. (1993). Survey Research Methods, 2nd Edition. Applied Social Research Methods Series (Volume 1). Newbury Park, CA: Sage Publications.

Fowler, F. J. Jr. (1995). Improving Survey Questions Design and Evaluation. Applied Social Research Methods Series Volume 38. Thousand Oaks, CA: Sage Publications.

Franklin, M., \& Duley, S. M. (2002). Best practice in planning school psychology service delivery programs: An update. In A. Thomas, \& J. Grimes (Eds.), Best Practices in School Psychology IV (pp. 145-158). Bethesda, MD: The National Association of School Psychologists.

Fullan, M. (2004). Leading in a culture of change, personal action guide and workbook. San Francisco, CA: Jossey-Bass.

Fullan, M. (Ed.). (2009). The challenge of change: Start school improvement now $\left(2^{\text {nd }}\right.$ ed.).Thousand Oaks, CA: Corwin.

George-Levi, S., Schmidt-Barad, T., Natan, I., \& Margalit, M. (2020). Sense of coherence and burnout among school psychologists: The moderating role of loneliness. Current psychology (New Brunswick, N.J.), 1-8. Advance online publication. https://doi.org/10.1007/s12144-020-00766-5

Greenleaf, R. K., Senge, P. M., Covey, S. R., \& Spears, L. C. (2002). Servant Leadership : A Journey Into the Nature of Legitimate Power and Greatness: Vol. Twenty-fifthanniversary edition. Paulist Press. 
Gilman, R., \& Gabriel S. (2004). Perceptions of school psychological services by education professionals: Results from a multi-state survey pilot study. School Psychology Review, $33(2), 271-286$.

Gilman, R., \& Medway, F. J. (2007). Teachers' perceptions of school psychology: A comparison of regular and special education teacher ratings. School Psychology Quarterly, 22, 145-161. doi:10.1037/10453830.22.2.145

Goldberg, S., Allard, L., Andrus, R., Challman, R., Cornell, E., Gorrie, E., Hildreth, G., Rust, M., Thompson, R., Tomlinson, B., \& Zachry, C. (1943). Report on the functions, training, and employment opportunities of school psychologists. Journal of Consulting Psychology, 7(5), 230-243. https://doi-org.libproxy.chapman.edu/10.1037/h0062789

Gorin, S. (2006). Correspondence to Secretary Arne Duncan, U.S. Department of Education. Retrieved from http://www.nasponline.org/advocacy/nclb/naspcomments.pdf

Grimes, J., Kurns, S., \& Tilly III, W. D. (2006). Sustainability: an enduring commitment to success. School Psychology Review, 35(2), 224-244.

Grimes, J. \& Tilly III, W. D. (1996). Policy and process: Means to lasting educational change. School Psychology Review 25(4), 465-476.

Hall, G. E., \& Hord, S. M. (2011). Implementing change: Patterns, principles, and potholes $\left(3^{\text {rd }}\right.$ ed.). Upper Saddle River, NJ: Pearson Education, Inc.

Harrison, P. L. \& Thomas, A. (Eds.). (2014). Best Practices in School Psychology V (Vol. 1-4). Bethesda, MD: National Association of School Psychologists.

Harvey, V. S., \& Struzziero, J. (2000). Effective supervision in school psychology. Bethesda, MD: National Association of School Psychologists.

Hosp, J. L., \& Reschly, D. J. (2002). Regional differences in school psychology practice. School 
Psychology Review, 31(1), 11-29.

Larson, J. P., \& Choi, H.S. (2010). The effect of university training and educational legislation on the role and function of school psychologists. Journal of Applied School Psychology, 26(2), 97-114. doi:10.1080/15377900903433336

Huebner, E. S. (1992). Burnout among school psychologists: An exploratory investigation into its nature, extent, and correlates. School Psychology Quarterly, 7(2), 129-136. https://doi.org/10.1037/h0088251

Huebner, E. S. (1993). Professionals under Stress: A Review of Burnout among the Helping Professions with Implications for School Psychologists. Psychology in the Schools, $30(1), 40-49$.

Huebner, E. S. (1993). Burnout among school psychologists in the USA: Further data related to its prevalence and correlates. School Psychology International, 14(2), 99-109. https://doi-org.libproxy.chapman.edu/10.1177/0143034393142001

Huberty, T. J., \& Huebner, E. S. (1988). A national survey of burnout among school psychologists. Psychology in the Schools, 25(1), 54-61.

Hunley, S., Curtis, M. J., \& Batsche, G. (2002). Best Practices in School Psychology IV. In A. Thomas \& J. Grimes (Eds.), Best Practices in Supervision of School Psychological Services (pp. 103-114). Bethesda, MD: NASP Publications.

Hunley, S., Harvey, V., Curtis, M., Portnoy, L., Chesno Grier, E., \& Helffrich, D. (2000). School psychology supervisors: A national study of demographics and professional practices. Communique, 28(8).

Kelly, J. (2017). President's message: The power of one: Creating connections. Communique, 46(1). Bethesda, MD: The National Association of School Psychologists. 
Kelly, S. (2018). The School Psychologist's Role in Leading Multidisciplinary School-Based Threat Assessment Teams. Contemporary School Psychology, 163-173. doi:10.1007/s40688-017-0153-y

Leithwood, K., Jantzi, D., \& Steinbach, R. (1999). Changing leadership for changing times. McGraw-Hill Education (UK).

Leithwood, K., \& Duke, D. (1999). A century's quest to understand school leadership. In J.

Murphy \& K. Seashore-Louis (Eds.), Handbook of research on educational administration (2nd ed.)(pp. 45-73). San Francisco, CA: Jossey-Bass.

Leithwood, K., Day, C., Sammons, P., Harris, A., \& Hopkins, D. (2006). Seven strong claims about successful school leadership. London, UK: Department for Education and Skills.

Leithwood, K., \& Jantzi, D. (2006). Transformational school leadership for large-scale reform: Effects on students, teachers, and their classroom practices. School Effectiveness and School Improvement, 17, 201 - 227. Retrieved from EBSCOhost: http://www.tandfonline.com/toc/nses20/current\#.UoVcmxUo5y0.

Leithwood, K., \& Sun, J. (2012). The Nature and Effects of Transformational School Leadership:

A Meta-Analytic Review of Unpublished Research. Educational Administration Quarterly, 48(3), 387-423.

Leiter, M. P., \& Maslach, C. (2017). Burnout and engagement: Contributions to a new vision. Burnout Research, 5(C), 55-57. doi: 10.1016/j.burn.2017.04.003

Mägi, K., \& Kikas, E. (2009). School Psychologists’ Role in School. School Psychology International, 30(4), 331-346. doi:10.1177/0143034309106943

Maher, C. (1980). Evaluation of special service delivery systems: an organizational domain 
referenced approach. Psychology in the Schools, 17(1), 60-69.

Malone, C., McCullum, C., \& Bhatt, H. (2016). Carving Pathways to Leadership: An introduction to the NASP Leadership Development Committee. Communique, 44(5). Bethesda, MD: The National Association of School Psychologists.

Maslach, C., Jackson, S. E. (1986). Maslach Burnout Inventory (2nd Ed.). Palo Alto, CA: Consulting Psychologists Press.

Maslach, C., Jackson, S. E., \& Leiter, M. P. (1996). Maslach Burnout Inventory Manual (3rd ed.). Palo Alto, CA: Consulting Psychologists Press. Now published by Mind Garden.

McNamara, K. M., Walcott, C. M., \& Hyson, D. (2019). Results From the NASP 2015 Membership Survey, Part Two: Professional Practices in School Psychology [Research report]. Bethesda, MD: National Association of School Psychologists.

Meacham, M. L. \& Peckham, P. D. (1978). School psychologists at three-quarters century: Congruence between training, practice, preferred role and competence. Journal of School Psychology, 16, 195-206. Doi: 10.1016/0022-4405(78)90001-8

Mertens, D. M. (2015). Research and evaluation in education and psychology. Thousand Oaks, CA: Sage Publishing, Inc.

Meyers, A. B., Meyers, J., Graybill, E. C., Proctor, S. L., \& Huddleston, L. (2012). Ecological approaches to organizational consultation and systems change in educational settings. Journal of Educational and Psychological Consultation, 22, 106-124.

Meyers, J., Roach, A. T., \& Meyers, B. (2009). Engaging in the debate: A critique of Blueprint III. Journal of Educational and Psychological Consultation,19(3), 197-223. doi:10.1080/10474410903117239

Monahan, K.L. (2018). Administrative supervision: Underdefined (and dangerous?) territory. 
Communique, 47(4), 1,23-25.

National Association of School Psychologists. (2010). NASP professional standards. Retrieved from http://www.nasponline.org/standards/2010standards.aspx

NASP (2012). A Framework for the personnel evaluation of school psychologists utilizing the NASP practice model. Communique, 41(3), 1-7.

National Association of School Psychologists. (2016). Addressing shortages in school psychology: Resource guide. Bethesda, MD: Author.

National Association of School Psychologists. (2017). Shortages in school psychology: Challenges to meeting the growing needs of U.S. students and schools [Research summary]. Bethesda, MD: Author.

National Association of School Psychologists. (2010). Principles for professional ethics. Retrieved from http://www.nasponline.org/standards/2010standards.aspx

National Association of School Psychologists. (2007, July). National Association of School Psychologists: Vision, mission, and goals. Retrieved from http://www.nasponline.org/about_nasp/strategicplan.pdf

National Center for Research Methods. (n.d.). Exploring online research methods. http://www.restore.ac.uk/orm/futures/futurescontents.htm

Patten, M. L. (2014). Questionnaire research: A practical guide. Glendale, CA: Pyrczak Publishing

Presser, S. (2004). Methods for testing and evaluating survey questionnaires. Hoboken, NJ : Wiley-Interscience.

Rea, L. M. \& Parker, R. A. (2005). Designing and conducting survey research: A comprehensive guide. San Francisco, CA: Jossey-Bass. 
Reschly, D. J. (1995). Psychological practice in schools: System change in the heartland.

(Electronic database) Greensboro, NC: ERIC Clearinghouse on Counseling and Student Services.

Riley, R. W. (1996). Improving America's schools. School Psychology Review, 25(4), 477-484.

Rossen, E. (2017, July). The Nationally Certified School Psychologist (NCSP) credential:

Number granted in the past year by institution and state and total active. Bethesda, MD: National Association of School Psychologists. Retrieved from http://www.nasponline.org/research-and-policy/nasp-research-center/school-psychologyworkforce

Rossi, P. H., Wright, J. D., \& Anderson, A. B. (1983). Handbook of survey research. San Diego, CA: Academic Press, Inc.

Schilling, E. J., Randolph, M., \& Boan-Lenzo, C. (2018). Job burnout in school psychology: How big is the problem? Contemporary School Psychology, 22(3), 324-331. https://doi.org/10.1007/s40688-017- 0138-x.

Schrage, J. A. (1996). Systems change leading to better integration of services for students with special needs. School Psychology Review, 25(4), 489-495.

Shapiro, E. S. (2006). Are we solving the big problems? School Psychology Review 35(2), 260-265.

Sheridan, S., \& Gutkin, TB. (n.d.). The ecology of school psychology: Examining and changing our paradigm for the 21st century. The ecology of school psychology: Examining and changing our paradigm for the 21st century.

Shriberg, D. (2007). The school psychologist as leader and change agent in a high-stakes era. Journal of Applied School Psychology 23(2), 151-166, DOI: 10.1300/J370v23n02_09 
Shriberg, D. (2008). Defining leadership in school psychology: NASP member and leader perspectives. [PowerPoint slides]. Retrieved from http://www.nasponline.org/conventions/handouts2008/papers/LeadershipQualitativePrese ntationHandoutNASP2008.doc

Shriberg, D., Satchwell, M., McArdle, L., \& James, J.M. (2010). An Exploration of School Psychologists’ Beliefs About Effective Leadership Practice in School Psychology. School Psychology Forum: Research in Practice, 4(4), 8-21. Retrieved from http://www.academia.edu/download/32807835/school_psych_forum_leadership_article.p df

Shriberg, A., Shriberg, D., \& Kumari, R. (2005). Practicing leadership: Principles and Applications (3rd Ed.). New York: Wiley.

Simon, D. J., \& Swerdlik, M. E. (2017). Teaching Supervision Skills to Prepare and Support School Psychologists. Communique 45(7). Retrieved from https://www.nasponline.org/publications/periodicals/communique/issues/volume-45issue

-7/teaching-supervision-skills-to-prepare-and-support-school-psychologists

Skalski, A. K. (2009). Resolve to be an advocate for school psychology. Communiqué, 38(3), 29-30.

Smith, A. R. (2012). Leaders and Change. Communiqué, 41(4). Retrieved from https://www.nasponline.org/publications/periodicals/communique/issues/volume-41issue-4/leaders-and-change

Smith, L. (2008). Schools that change: Evidence-based improvement and effective change leadership. Thousand Oaks, CA: Corwin Press. 
Special Committee on School Psychologists (1948). Training and employment opportunities of school psychologists. Journal of Consulting Psychology, 7(5), 230-243.

Strickland, J. (2017). Building a better survey experience: Tips for optimizing the survey process to collect useful survey data. Psychological Science Agenda, Dec. 2017. https://www.apa.org/science/about/psa/2017/12/survey-experience

Telzrow, C. (1989). Award for excellence for school psychological services programs series. Professional School Psychology 4(1), 59.

Telzrow, C., Burns, M., \& Ysseldyke, J. (2006). Blueprint III: Images of school psychology’s future. Communique, 35(2), 20-21. Bethesda, MD: The National Association of School Psychologists.

Thomas, A., \& Grimes, J. (Eds.). (2002). Best practices in planning school psychology service delivery programs: An update. Best Practices in School Psychology IV (Vol. 1), (pp 145-158). Bethesda, MD: National Association of School Psychologists.

Thomas, A., \& Grimes, J. (Eds.). (2002). Appendix II: Standards for the provision of school psychological services. Best Practices in School Psychology IV (Vol. 2). Bethesda, MD: National Association of School Psychologists.

Thomas, A., \& Grimes, J. (Eds.). (2008). Best practices in school psychology, V. Bethesda, MD: National Association of School Psychologists.

Thomas, S. J. (2004). Using web and paper questionnaires for data-based decision making: From design to interpretation of the results. Thousand Oaks, CA: Corwin Press.

Urdan, T. C. (2017). Statistics in Plain English. New York, New York: Taylor \& Francis. Wenger, R. D., \& Pryzwansky, W. B. (1987). Implementation status of the APA guidelines for 
delivery of services by school psychologists. Professional Psychology: Research and Practice, 18(5), 461-467. Retrieved from http://psycnet.apa.org/fulltext/1988-21560001.html

Wise, P. S. (1985). School psychologists' rankings of stressful events. Journal of School Psychology, 23, 31-41.

Worrell, T. G., Skaggs, G. E., \& Brown, M. B. (2006). School psychologists' job satisfaction: A 22-year perspective in the USA. School Psychology International, 27(2), 131-145.

Ysseldyke, J., Burns, M., Dawson, P., Kelley, B., Morrison, D., Ortiz, S., Rosenfield, S., \& Telzrow, K. (2006). School psychology: A blueprint for training and practice III. Bethesda, MD: National Association of School Psychologists. 
Appendix A

\section{Members of the Research Team}

Student Researcher: Jodi Ruble LaChance, Ed.S., NCSP

Office: (909) 699-5992

Lead Researcher: Randy Busse, Ph.D.

Kris DePedro, Ph.D

Professor Emeritus: John Brady, Ph.D.

\section{Key Information}

You are being asked to take part in a research study. Research studies include only people who choose to take part. A member of the research team will explain the study to you and will answer any questions you might have. You should take your time in deciding whether or not you want to participate.

If you agree to participate in this study, the project will involve:

School Psychologist members of professional networks and the California Association of School Psychologists.

- $\quad$ Procedures will include an online survey that should take approximately 15-20 minutes to complete.

- There are no known risks associated with this study that exceed what would typically be encountered in daily life.

- You will not be paid for your participation.

- $\quad$ You will be provided a copy of this consent form.

\section{Invitation}

My name is Jodi Ruble Lachance and I am a doctorate student at Chapman University in the Ph.D. in Education program with an emphasis in School Psychology. I am conducting a study for my dissertation research to identify the state of school psychology leadership in schools, training and education in leadership, and whether leadership is attainable in the school setting. You are invited to take part in this research study. The information in this form is meant to help you decide whether or not to participate. If you have any questions, please ask.

\section{Why are you being asked to be in this research study?}

As a credentialed school psychologist and member of professional school psychology networks including the California Association of School Psychologists (CASP) your responses to the attached survey will provide critical information in understanding the needs of school psychologists providing leadership in practice.

\section{What is the reason for doing this research study?}

The National Association of School Psychologists (NASP) calls on school psychologists to be leaders, advocate for their role, and to be 'change agents'. Research on school psychology leadership roles in practice is limited. This research is designed to (1) better understand current leadership roles, (2) identify whether school psychologist practitioners are supported as leaders, 
(3) to discover whether organizational supports necessary for comprehensive service delivery are in place, and (4) to determine what is needed to support school psychology leadership in practice.

\section{What will be done during this research study?}

You will be asked to complete an online survey using an internet-based questionnaire that should take approximately 15-20 minutes to complete.

\section{How will my data be used?}

Any personal information that could identify you will be removed before the data are shared.

\section{What are the possible risks of being in this research study?}

The risk of loss of confidentiality is applicable in all studies.

Loss of confidentiality is always a risk, however, the online Qualtrics survey will be anonymous. Neither CASP, professional school psychology networks, nor the researchers have knowledge of who responds to the survey. At no point do the researchers have access to contact information. The survey will be anonymous and completed online via Qualtrics.

\section{What are the possible benefits to other people?}

The data collected for this study will provide valuable information regarding the current status of school psychology leadership in practice using the NASP Model for Comprehensive Services Part I, whether school psychologists as leaders are supported through organizational principles outlined in the NASP Model for Comprehensive Services Part II, and to discover what changes are needed, if any to support school psychology leaders in practice moving forward.

\section{What are the alternatives to being in this research study?}

Instead of being in this research study, you can choose not to participate.

\section{What will participating in this research study cost you?}

There is no cost to you to be in this research study.

\section{What are the possible benefits to you?}

You are not expected to get any direct benefit from being in this study. You will not be compensated for your participation in this research study. 


\section{What should you do if you have a problem during this research study?}

Your welfare is the major concern of every member of the research team. If you have a problem as a direct result of being in this study, you should immediately contact one of the people listed at the beginning of this consent form.

\section{How will information about you be protected?}

Reasonable steps will be taken to protect your privacy and the confidentiality of your study data. The data will be stored electronically through a secure server and will only be seen by the research team.

The only people who will have access to your research records are the members of the research team, the Institutional Review Board (IRB), and any other person, agency, or sponsor as required by law. Information from this study may be published in scientific journals or presented at scientific meetings but the data will be reported as group or summarized data and your identity will be kept strictly confidential.

Please note that all Chapman University employees are required to report any known or suspected abuse of children or minors to appropriate authorities.

\section{What are your rights as a research subject?}

You may ask any questions about this research and have those questions answered before agreeing to participate in the study or during the study.

For study related questions, please contact the investigator(s) listed at the beginning of this form: Jodi LaChance at lacha103@mail.chapman.edu.

For questions concerning your rights or complaints about the research, contact the Institutional Review Board (IRB) at (714) 628-2833 or irb@ chapman.edu.

Q1 The National Association of School Psychologists (NASP) Model for Comprehensive and Integrated School Psychological Services consists of two parts outlining the responsibilities of individual school psychologists (Part I), as well as the responsibilities of school systems to support comprehensive school psychological services (Part II). School psychologists are leaders in that they promote positive outcomes, work effectively in teams, have knowledge and expertise, and empower others through shared goals and actions. The following questions pertain to Part I of the Model. 
Q2 In which of the following domains from the NASP Model of Comprehensive and Integrated Services do you practice in your current role as a school psychologist? (Please check all that apply)

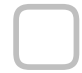

Data-Based Decision Making and Accountability (Permeate all aspects of service delivery) (1)

Consultation and Collaboration (Permeate all aspects of service delivery)

Interventions and Instructional Support to Develop Academic Skills (Student level services) (3)

Interventions and Mental Health Services to Develop Social and Life Skills (Student level services) (4)

School-Wide Practices to Promote Learning (Systems-Level Services) (5)

Preventative and Responsive Services (Systems-Level Services) (6)

Family-School Collaboration (Systems-Level Services) (7)

Diversity in Development and Learning (Foundations in Service Delivery)

Research and Program Evaluation (Foundations in Service Delivery) (9)

Legal Ethical and Professional Practice (Foundations in Service Delivery) (10)

Q3 My training and expertise in all areas of school psychology are utilized in my current position.

Strongly agree (1) 
Somewhat agree (2)

Neither agree nor disagree (3)

Somewhat disagree (4)

Strongly disagree (5)

Q4 What best describes your current role in planning and implementing preventative and responsive services? (Please check all that apply):

\begin{tabular}{c|cc} 
& $\begin{array}{c}\text { Leadership } \\
\text { Role/Facilitator (1) }\end{array}$ & Team Member (2) (3) \\
\hline Universal Screening & \\
(1) & \\
School-Wide \\
Service Delivery \\
(2) \\
School-Wide \\
Positive Behavior \\
(3) \\
Multi-Tiered
\end{tabular}

Q5 What best describes your interest in planning and implementing preventative and responsive services, if you were given time (Please check all that apply):

I would like to I would like to be a No Interest (3)

Lead/Facilitate (1) Team Member (2) 


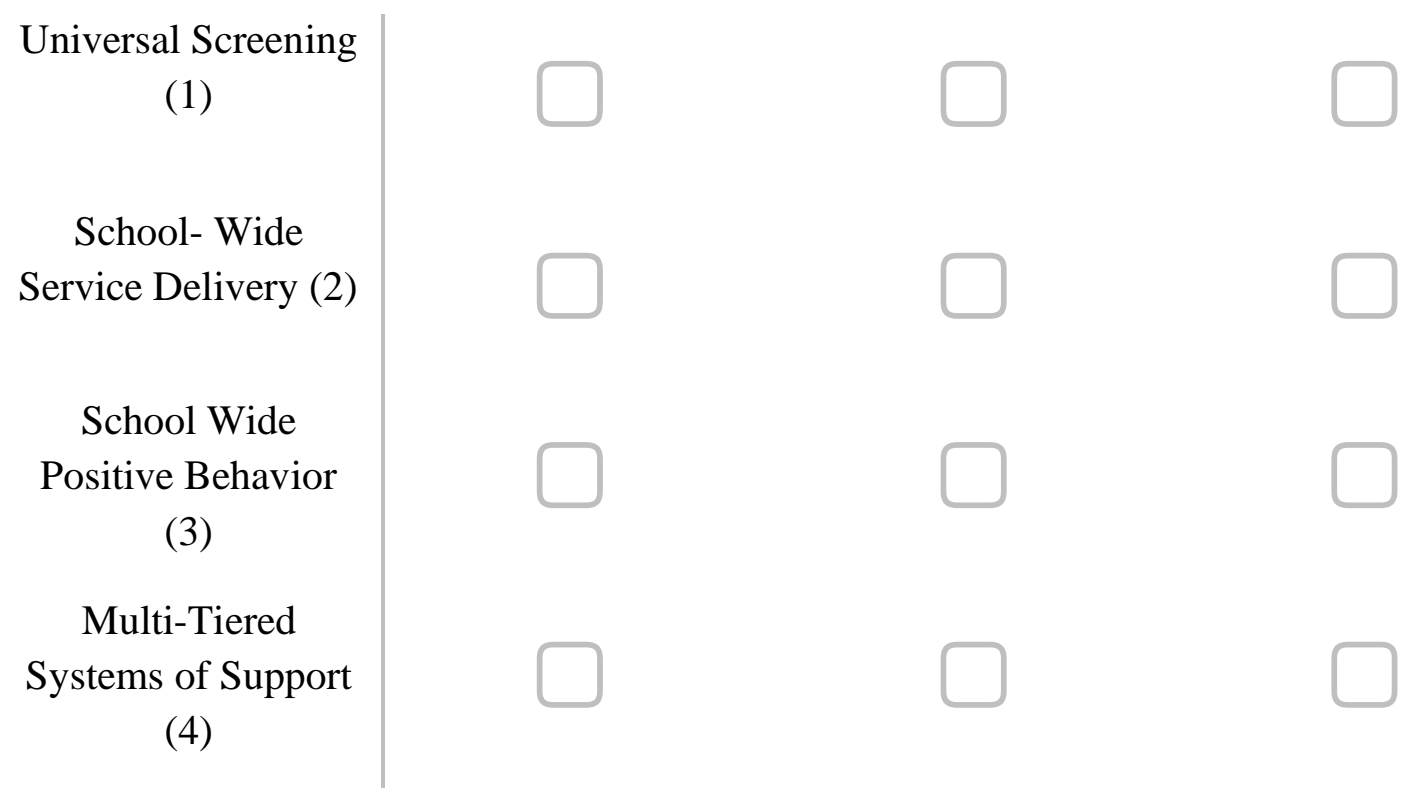

Q6 What best describes your current role in designing, implementing, and evaluating schoolwide promotion of learning?

\begin{tabular}{c|cc} 
& $\begin{array}{c}\text { Leadership } \\
\text { Role/Facilitator (1) }\end{array}$ & Team Member (2) (3) \\
\hline Crisis Preparation, \\
Response, and \\
Recovery (1)
\end{tabular}




School-Wide Data
Collection and
Analysis (6)
Program Evaluation
$(7)$
Other (8)

Q7 What best describes your interest in designing, implementing, and evaluating school wide promotion of learning, if you were given time? (Please check all that apply):

\begin{tabular}{|c|c|c|c|}
\hline & $\begin{array}{c}\text { I would like to } \\
\text { Lead/Facilitate (1) }\end{array}$ & $\begin{array}{l}\text { I would like to be a } \\
\text { Team Member (2) }\end{array}$ & No Interest (3) \\
\hline $\begin{array}{c}\text { Crisis Preparation, } \\
\text { Response, and } \\
\text { Recovery (1) }\end{array}$ & & & \\
\hline $\begin{array}{c}\text { Mental Health Services } \\
\text { (2) }\end{array}$ & & & \\
\hline $\begin{array}{c}\text { School Improvement } \\
\text { Activities (3) }\end{array}$ & & & \\
\hline $\begin{array}{c}\text { Development of } \\
\text { District Policies and } \\
\text { Procedures (4) }\end{array}$ & & & \\
\hline $\begin{array}{c}\text { Safe and Violence Free } \\
\text { Schools (5) }\end{array}$ & & & \\
\hline $\begin{array}{l}\text { School-Wide Data } \\
\text { Collection and } \\
\text { Analysis (6) }\end{array}$ & & & \\
\hline
\end{tabular}




\section{Program Evaluation (7)}

Professional

Development/Training

Staff (8)

Other (9)
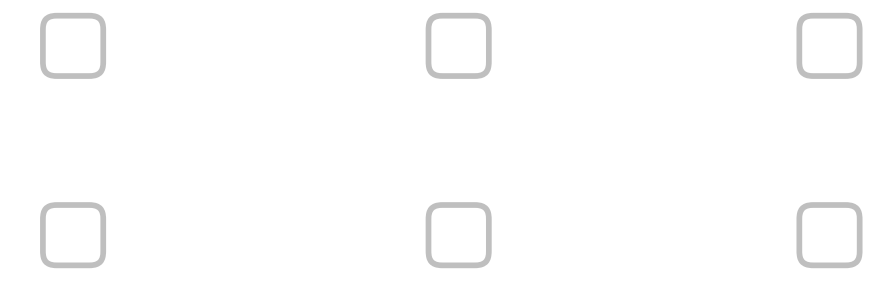

Q8 Formal leadership roles such as supervision and mentoring provide school psychologists opportunities for growth and promotion as well as expanded opportunities for leadership. The following questions inquire about formal leadership roles in school psychology.

Q9 School psychology leadership in schools is important for maintaining the integrity of the profession.

Strongly agree (1)

Somewhat agree (2)

Neither agree nor disagree (3)

Somewhat disagree (4)

Strongly disagree (5)

Q10 In my current role, I hold a formal leadership role in the following areas: (Please check all that apply)

Mentor First Year School Psychologists (1)

Supervise Interns (2) 
Lead School Psychologist (3)

Supervisor of School Psychologists (4)

Other (5)

None (6)

Q11 Which of the following formal leadership roles do you see yourself in the future? (Please check all that apply)

$\square$ Mentor First Year School Psychologists (1)

$\square$ Supervise Interns (2)

$\square$ Lead School Psychologist (3)

Supervisor of School Psychologists (4)

$\square$ Other (5)

None (6)

Q12 My graduate training prepared me to lead in the following areas: (Please check all that apply)

$\square$ School Wide Practices to Promote Learning (systems level services ) (1)

$\square$ Providing Professional Development/Training Staff. (2)

Program Evaluation (3) 
Mentor First Year School Psychologists (4)

Supervise Interns (5)

Lead School Psychologist (6)

Supervisor of School Psychologists (7)

School Wide Data Collection and Analysis (8)

Other (9)

None (10)

Q13 NASP Standards state that school systems should provide credentialed school psychologists with adequate professional support. The following section asks questions about school psychological service delivery and supports in your school system based on the NASP Model for Comprehensive Services part II: Organizational Principles.

Q14 Which of the following best describes the organization of school psychological services in your district?

Building Based: school psychologist is based at one or more buildings reporting to the principal (s) (1)

Within the Special Education department (2)

Within the Student Services Department (3)

Separate School Psychology Department (4)

Other (5) 
Q15 School psychological services in my district are planned and delivered on the basis of a systematic assessment of the educational and psychological needs of the students and families in the local community. (NASP Model Part II, 1.1 )

Strongly agree (1)

Somewhat agree (2)

Neither agree nor disagree (3)

Somewhat disagree (4)

Strongly disagree (5)

Q16 School psychological services in my district are available to all students (general and special education) on an equal basis and are not determined by a specific funding source or based on eligibility. (NASP Model Part II, 1.2 )

Strongly agree (1)

Somewhat agree (2)

Neither agree nor disagree (3)

Somewhat disagree (4)

Strongly disagree (5)

Q17 School psychological services in my district are integrated with other school and community services. School psychological and mental health services are provided through a "seamless" system of care. (NASP Model Part II, 1.3 )

Strongly agree (1)

Somewhat agree (2)

Neither agree nor disagree (3) 
Somewhat disagree (4)

Strongly disagree (5)

Q18 School psychologists in my school district provide a range of services, to include direct and indirect services to meet the academic and mental health needs of students. (NASP Model Part II, 1.6 )

Strongly agree (1)

Somewhat agree (2)

Neither agree nor disagree (3)

Somewhat disagree (4)

Strongly disagree (5)

\section{End of Block: Leadership}

\section{SUPPORTS}

Q19 The following section asks questions about physical, personnel, and fiscal supports in your district based on the NASP Model for Comprehensive Services part II: Organizational Principles.

Q20 My school district supports recruitment and retention of qualified school psychologists by advocating for appropriate ratios of school psychologists to students (The current recommended ratio is 1:750). (NASP Model Part II, 3.2)

Strongly agree (1)

Somewhat agree (2)

Neither agree nor disagree (3)

Somewhat disagree (4) 
Strongly disagree (5)

Q21 There is a sense of equity in the distribution of caseloads and duties between school psychologists in my district.

Strongly agree (1)

Somewhat agree (2)

Neither agree nor disagree (3)

Somewhat disagree (4)

Strongly disagree (5)

Q22 My district provides school psychologists with the following: (Check all that apply) (NASP Model Part II, 3.3 \& 3.4)

Clerical services (scheduling, proof-reading, preparing materials, etc.) (1)

Access to private telephone and office (2)

Advanced technological resources in communication systems and data management systems. (3)

Intervention materials (4)

A variety of current and appropriate assessments sensitive to the individual needs of students you evaluate (test kits and protocols) (5)

Office supplies (paper, stapler, ink, pens, highlighters) (6)

Current scoring software (7)

Access to professional literature (8) 
Professional Interpreter and Translation services (9)

Video conferencing (10)

Locking file cabinet (11)

Desk (12)

Bookshelf (13)

Report Writing software (14)

Accessible Printer/Fax/Scanner (15)

Quiet place to assess students with a table and chairs (16)

Personnel support for documentation of professional development activities. (17)

Laptop Computer and/or IPAD (18)

Access to virtual evaluation platforms (assessments, rating scales) (19)

Social Emotional, Behavioral, and/or Academic Tier 2 and Tier 3 evidence-based curriculum materials (20)

Q23 My district provides adequate resources to fulfill my job duties/role.

Strongly agree (1)

Somewhat agree (2)

Neither agree nor disagree (3)

Somewhat disagree (4) 
Strongly disagree (5)

\section{End of Block: SUPPORTS}

\section{COLLABORATION, CLIMATE, COMMUNICATION}

Q24 School psychologists have a broad role in which collaboration and consultation are a large part (a domain that permeates all aspects of service delivery). School psychologists are charged with a mission to create connections, collaborate, and build relationships and partnerships. School psychologists working in a hierarchical education system may face challenges when it comes to advocating, consulting, and collaborating. The following section asks questions about organizational climate, collaboration, and communication in your district based on the NASP Model for Comprehensive Services part II: Organizational Principles.

Q25 My school district promotes cooperative and collaborative relationships and conflicts are resolved in a constructive and professional manner. (NASP Model Part II, 2.1 )

Strongly agree (1)

Somewhat agree (2)

Neither agree nor disagree (3)

Somewhat disagree (4)

Strongly disagree (5)

Q26 My school district provides an organizational climate in which school psychologists may advocate in a professional manner for the most appropriate services for students and families, without the fear of reprisal from supervisors or administrators. (NASP Model Part II, 2.2 )

Strongly agree (1) 
Somewhat agree (2)

Neither agree nor disagree (3)

Somewhat disagree (4)

Strongly disagree (5)

Q27 My school district promotes a work environment that maximizes job satisfaction and measures of work climate are included in organizational self-evaluation. (NASP Model Part II, 2.3)

Strongly agree (1)

Somewhat agree (2)

Neither agree nor disagree (3)

Somewhat disagree (4)

Strongly disagree (5)

Q28 In my current position, I feel comfortable advocating for my role as a school psychologist.

Strongly agree (1)

Somewhat agree (2)

Neither agree nor disagree (3)

Somewhat disagree (4)

Strongly disagree (5)

Q29 My school district promotes and advocates for balance between my professional and personal life. (NASP Model Part II, 2.4) 
Strongly agree (1)

Somewhat agree (2)

Neither agree nor disagree (3)

Somewhat disagree (4)

Strongly disagree (5)

Q30 My school district provides opportunities for school psychologists to communicate with each other about issues of mutual professional interest on a regular basis. For example, organized monthly school psychologist meetings. (NASP Model Part II, 4.1 )

Strongly agree (1)

Somewhat agree (2)

Neither agree nor disagree (3)

Somewhat disagree (4)

Strongly disagree (5)

Q31 My district supports collaborative problem-solving approaches with other departments and outside agencies in the planning and delivery of school psychological services. (NASP Model Part II, 4.2 )

Strongly agree (1)

Somewhat agree (2)

Neither agree nor disagree (3) 


\section{Somewhat disagree (4)}

Strongly disagree (5)

Q32 My school district ensures that I have access to technology and the training necessary to perform my job adequately and to maintain appropriate and confidential communication with students, families, and service providers within and outside the system. (NASP Model Part II, 4.3)

Strongly agree (1)

Somewhat agree (2)

Neither agree nor disagree (3)

Somewhat disagree (4)

Strongly disagree (5)

\section{End of Block: COLLABORATION, CLIMATE, COMMUNICATION}

\section{Program Administration, Supervision, and Evaluation}

Q33 The ability of school psychologists to provide comprehensive services and the increase in demand for services necessitates supervisors who are competent in collaboration, consultation, and systems change. The following section is regarding your experience with school psychology program administration, supervision, and evaluation in your current role based on the NASP Model for Comprehensive Services part II: Organizational Principles.

Q34 I am supervised by: (If your supervisor is an administrator that was a school psychologist please check both)

\section{School Psychologist (1)}

Principal (2)

Director of Special Education (3) 
Student Services Director (4)

Superintendent (5)

Educational Coordinator (6)

Other (7)

Q35 If your supervisor is a school psychologist, do they have a valid state school psychologist credential and a minimum of 3 years of experience as a practicing school psychologist? (NASP Model Part II, 5.1)

Yes (1)

No (2)

N/A (3)

Q36 What is the highest level of education your supervisor completed?

Masters (1)

Educational Specialist (2)

Doctorate (3)

Don't know (4)

Q37 My supervisor has an understanding of and commitment to which of the following: (Please check all that apply) 


\section{Ethics (1)}

Best practices in service delivery (2)

Professional standards (3)

Models of service provision (4)

Continuing professional development (5)

Sources of funding (6)

Legal and regulatory issues to effectively solve problems (7)

Q38 Supervision methods of school psychologists in my district match the developmental level of the school psychologist. For example, experienced school psychologists may meet as a group or utilize peer mentoring whereas first year school psychologists might meet weekly. (NASP Model Part II, 5.2)

\section{Strongly agree (1)}

Somewhat agree (2)

Neither agree nor disagree (3)

Somewhat disagree (4)

Strongly disagree (5)

Q39 My school district allows time for school psychologists to participate in supervision and mentoring. When a supervising school psychologist is not available, the school system ensures that school psychologists are given opportunities and provided funding to seek peer support and supervision through regional, state, or national school psychologist organizations. (NASP Model Part II, 5.3) 
Strongly agree (1)

Somewhat agree (2)

Neither agree nor disagree (3)

Somewhat disagree (4)

Strongly disagree (5)

Q40 My school district has a coordinated plan for the accountability and evaluation of school psychological services. (NASP Model Part II, 5.4)

Strongly agree (1)

Somewhat agree (2)

Neither agree nor disagree (3)

Somewhat disagree (4)

Strongly disagree (5)

Q41 My supervisor provides professional leadership through participation in school psychology professional organizations and is active in local, state, and federal public policy development. (NASP Model Part II, 5.6)

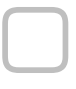

Strongly agree (1)

Somewhat agree (2)

Neither agree nor disagree (3)

Somewhat disagree (4) 
End of Block: Program Administration, Supervision, and Evaluation

\section{PROFESSIONAL DEVELOPMENT AND RECOGNITION SYSTEM}

Q42 The following section is regarding your experience with professional development and recognition systems in your district based on the NASP Model for Comprehensive Services part II: Organizational Principles.

Q43 My school district provides support (e.g., funding, time, supervision) to ensure that school psychologists have access to continuing professional development at a level necessary to remain current regarding professional practices. (NASP Model Part II, 6.1)

Strongly agree (1)

Somewhat agree (2)

Neither agree nor disagree (3)

Somewhat disagree (4)

Strongly disagree (5)

Q44 In the past year, how often did you participate in professional development specific to school psychology?

\section{1-2 times (1)}

3-5 times (2)

More than 5 times (3)

Never (4) 
Q45 How many times in the past 3 years have you attended the following?

National Association of School Psychologists (NASP) Convention (1)

State Association Workshops/Convention (2)

American Psychology Association (APA) Convention (3)

Q46 My performance evaluation is linked to my personal professional development activities and improvement.

Strongly agree (1)

Somewhat agree (2)

Neither agree nor disagree (3)

Somewhat disagree (4)

Strongly disagree (5)

Q47 My school district provides the following levels of recognition to reflect my professional growth (check all that apply): 
Stipend (1)

Opportunity to use new skills (2)

Training others (3)

Promotion in role (4)

Move on the pay scale (5)

Salary (6)

Other (7)

None (8)

Q48 My employer provides the following leadership opportunities for paid promotion and/or advancement (please check all that apply):

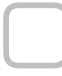

Lead School Psychologist (1)

Supervisor of an Intern (2)

School Psychologist Supervisor (3)

District Level School Psychologist Consultant (4)

Other (5)

None (6)

Q49 My district provides a stipend for the following: (Check all that apply) 
Nationally Certified School Psychologist credential (NCSP) (1)

Doctorate (2)

Licensed Educational Psychologist (LEP) (3)

State and/or National School Psychology association memberships (4)

Support for professional development opportunities (conferences, workshops, travel) (5)

Other (6)

None (7)

Q50 What barriers, if any, exist in providing leadership as a school psychologist?

Q51 Which of the following might best support school psychology leadership in practice? (Please check all that apply)

Continuing training opportunities specific to leadership (NASP workshops, Webinars, University workshop, etc.)

A consortium model for professional collaboration (district, university, community professionals working together)

A Leadership Institute (Short 2-3 day training opportunity)

Graduate training specific to leadership (supervision, systems services, etc.)

Specific School Psychology Leadership Credential

Leadership Model/Framework 
Other

End of Block: PROFESSIONAL DEVELOPMENT AND RECOGNITION SYSTEMS

DEMOGRAPHIC INFORMATION

Q52 Identification

Female (1)

Male (2)

Other (3)

Q53 Which of the following best describes your racial or ethnic background?

Asian American (1)

Black/African American (2)

White/Caucasian (3)

Hispanic/Latino (4)

Native American (5)

Pacific Islander (6)

Other (7)

Q54 What is your age?

Q55 Geographic area where you work:

Urban (1) 
$\square$ Suburban (2)

$\square$ Rural (3)

$\square$ County Program (4)

Q56 Current School Assignment(s): (Please check all that apply)

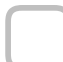

Birth-PreK (1)

$\square$ Preschool (2)

$\square$ Elementary (3)

$\square$ Middle School (4)

$\square$ High School (5)

$\square$ Adult Program (18-21) (6)

$\square$ Other (7)

Q57 Highest level of education completed:

Masters (1)

Educational Specialist (2)

Doctorate (3)

Q58 Credentials (check all that apply)

State Credentialed School Psychologist (1) 


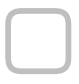

$$
\text { Nationally Certified School Psychologist (NCSP) }
$$

Licensed Educational Psychologist (LEP)

Administrator Credential (4)

Special Education Director Credential (5)

BCBA (6)

Other (7)

Q84 What state do you work in as a school psychologist?

Q59 I am a member of the following organizations: (Check all that apply)

$$
\text { National Association of School Psychologists (1) }
$$

State Association of School Psychologists (2)

Q60 How many years have you been a school psychologist?
$0-5(1)$
6-10 (2)
$11-15(3)$
$16-20(4)$
$21-30(5)$
$31+(6)$ 
Q61 Income:

(1)

$21,000-35,000$ (2)

$51,000-75,000$ (3)

$76,000-100,000$

$>100,000(5)$ 